\title{
Neurochemistry immune systems interaction in depression
}

Citation for published version (APA):

Myint, A. M. (2007). Neurochemistry immune systems interaction in depression. [Doctoral Thesis, Maastricht University]. Datawyse / Universitaire Pers Maastricht. https://doi.org/10.26481/dis.20070118am

Document status and date:

Published: 01/01/2007

DOI:

10.26481/dis.20070118am

Document Version:

Publisher's PDF, also known as Version of record

\section{Please check the document version of this publication:}

- A submitted manuscript is the version of the article upon submission and before peer-review. There can be important differences between the submitted version and the official published version of record.

People interested in the research are advised to contact the author for the final version of the publication, or visit the DOI to the publisher's website.

- The final author version and the galley proof are versions of the publication after peer review.

- The final published version features the final layout of the paper including the volume, issue and page numbers.

Link to publication

\footnotetext{
General rights rights.

- You may freely distribute the URL identifying the publication in the public portal. please follow below link for the End User Agreement:

www.umlib.nl/taverne-license

Take down policy

If you believe that this document breaches copyright please contact us at:

repository@maastrichtuniversity.nl

providing details and we will investigate your claim.
}

Copyright and moral rights for the publications made accessible in the public portal are retained by the authors and/or other copyright owners and it is a condition of accessing publications that users recognise and abide by the legal requirements associated with these

- Users may download and print one copy of any publication from the public portal for the purpose of private study or research.

- You may not further distribute the material or use it for any profit-making activity or commercial gain

If the publication is distributed under the terms of Article $25 \mathrm{fa}$ of the Dutch Copyright Act, indicated by the "Taverne" license above, 
Neurochemistry immune systems interaction in depression 
The publication of this thesis is financially supported by DiaMed Eurogen.

\begin{abstract}
About the cover:
Mona Lisa is Leonardo's supreme evocation of balance ... by Michael J. Gelb in da Vinci Decoded.

Mona Lisa's smile lies on the cup of good and evil, compassion and cruelty, seduction and innocence, the fleeting and the eternal. She is the Western equivalent of the Chinese symbol of yin and yang . . by Michael $J$ Gelb in How to think like Leonardo da Vinci.
\end{abstract}

The combination of Mona Lisa's smile and the symbol yin and yang on the cover of this thesis reflects the balances and challenges mentioned in the basic hypothesis of this work.

Copyright (C) 2007 Aye Mu Myint

ISBN: 978-90-5278-596-7

Universitaire Pers Maastricht 


\title{
Neurochemistry immune systems interaction in depression
}

\author{
DISSERTATION \\ to obtain the degree of Doctor at \\ the Maastricht University, \\ on the authority of the Rector Magnificus, \\ Prof. dr. G.P.M.F. Mols \\ in accordance with the decision of the Board of Deans \\ to be defended in public on \\ Thursday $18^{\text {th }}$ January 2007 at 16:00 hour
}

By

Aye Mu Myint

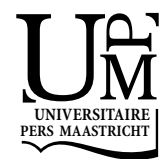




\section{Supervisors}

Prof. dr. H.W.M. Steinbusch

Prof. dr. B.E. Leonard

\section{Co-supervisor}

Prof. dr. S. Scharpé (Antwerp, Belgium)

\section{Assessment Committee}

Prof. dr. J. van Os (Chairman)

Prof. dr. V. Arolt (Muenster, Germany)

Prof. dr. W. Buurman

Prof. dr. N. Mueller (Munich, Germany)

Prof. dr. W. Riedel 
This thesis is dedicated to those who are suffering... 



\section{Abbreviations}

$\begin{array}{ll}\text { 3HAA } & \text { 3-hydroxy anthranallic acid } \\ \text { 3OHK } & \text { 3-hydroxykynurenine } \\ \text { 5HIAA } & \text { 5-hydroxyindoleacetic acid } \\ \text { 5-HT } & \text { serotonin } \\ \text { ACTH } & \text { adrenocorticotrophic hormone } \\ \text { AIDS } & \text { acquired immune deficiency syndrome } \\ \text { AVP } & \text { argentine vasopressin } \\ \text { BDNF } & \text { brain derived neurotrophic factor } \\ \text { BPRS } & \text { brief psychiatric rating scale } \\ \text { CAA } & \text { competing amino acids } \\ \text { COX } & \text { cyclooxygenase } \\ \text { CRF } & \text { corticotrophin releasing factor } \\ \text { DG } & \text { dentate gyrus } \\ \text { DRN } & \text { dorsal raphe nucleus } \\ \text { DSM } & \text { statistical diagnostic manual } \\ \text { DST } & \text { dexamethasone suppression test } \\ \text { ECG } & \text { electrocardiogram } \\ \text { ECT } & \text { electroconvulsive therapy } \\ \text { EEG } & \text { electroencephalogram } \\ \text { EIA } & \text { enzyme-immuno assay } \\ \text { ELISA } & \text { enzyme-linked immunosorbant assay } \\ \text { GABA } & \text { gamma amino butyric acid } \\ \text { GFAP } & \text { green fibrillary acid protein } \\ \text { GR } & \text { glucocorticoid receptor } \\ \text { HDRS } & \text { Hamilton depression rating scale } \\ \text { HIV } & \text { human immunodeficicncy virus } \\ \text { HPA } & \text { hypothalamo-pituitary-adrenal } \\ \text { HPT } & \text { hypothalamo-pituitary-thyroid } \\ \text { IDO } & \text { indoleamine 2,3-dioxygenase } \\ \text { IFN } & \text { interferon } \\ \text { IL } & \text { interleukin } \\ \text { IRS } & \text { inflammatory response system } \\ \text { KA } & \text { kynurenic acid } \\ \text { KYN } & \text { kynurenine } \\ \text { LPS } & \text { lipopolysaccharide } \\ \text { MAO } & \text { monoamine oxidase } \\ \text { MAOI } & \text { monoamine oxidase inhibitor } \\ \text { MDD } & \text { major depressive disorder } \\ \text { MHPG } & \text { 3-methoxy-4-hydroxyphenyl-glycol } \\ \text { MR } & \text { mineralocorticoid receptor } \\ \text { NKC } & \text { natural killer cell } \\ & \end{array}$


NAD nicotinamide adenine dinucleotide

NMDA N-methyl-D-aspartate

NO nitric oxide

OBX olfactory bulbectomised

PG prostaglandin

QA quinolinic acid

SNRI serotonin noradrenaline reuptake inhibitor

SSRI selective serotonin reuptake inhibitor

TBS tris buffered saline

TCA tricyclic antidepressant

TDO tryptophan 2,3-dioxygenase

TGF transforming growth factor

Th T helper

TNF tumour necrosis factor

TSH thyroid stimulating hormone

TRH throtrophin releasing hormone

TRP tryptophan

TSH thyroid stimulating hormone

WHO World Health Organisation 


\section{Contents}

Abbreviations

7

Chapter 1.1 General introduction

Chapter 1.2 Cytokines-Serotonin system interaction through IDO: A neurodegeneration hypothesis of depression

Chapter 2 Th1, Th2, and Th3 cytokine alterations in major depression

Chapter 3 Role of paroxetine in Interferon- $\alpha$-induced immune and behavioural changes in male Wister rats

Chapter 4 Effect of peripheral Interferon- $\alpha$ injection on astrocyte and microglial changes in hippocampus of male Wister rats

Chapter 5 Effect of COX2 inhibitor celecoxib on behaviour and immune changes in Olfactory-bulbectomised rat model of depression

Chapter 6 Kynurenine pathway in Major Depression: Evidence of impaired neuroprotection

Chapter 7 Changes in the immune system in depression and dementia: causal or co-incidental effects?

Chapter 8 General discussion and future perspective

Summary

Acknowledgement

Curriculum vitae

List of Publication 


\section{Chapter 1.1}

General Introduction 


\section{Burden of Depression}

The term "depression" originated from the French word "depressare", which is related to "deprimere", meaning "to press down" (1). However, the concept of depression was known to ancient Greeks as melancholia which was defined by the symptoms "repulsion to eat, despondency, insomnia, irritability and restlessness" $(2,3)$. Only in the $20^{\text {th }}$ century has depression received a precise definition. Thus according to the Diagnostic and Statistical Manual of Disease (DSM) $4^{\text {th }}$ Edition, a major depressive episode occurs when patients exhibit 5 or more of the following symptoms that persist for at least 2 weeks: depressed mood, diminished interest or pleasure in all activities, significant weight loss or weight gain, insomnia or hypersomnia, psychomotor retardation or agitation, fatigue, feeling of worthlessness or guilt, diminished ability to concentrate and recurrent thoughts of suicide or death (4).

Depression is one of the commonest psychiatric disorders accounting, in Europe, for approximately $13 \%$ life-time incidence with $4 \%$ being diagnosed with major depression in the previous 12 months (5). Depression has a major detrimental impact on the quality of life of the patient irrespective of the geographical, educational, socioeconomic and racial boundaries. According to the 1990 Global Burden of Disease of the World Health Organisation (WHO) (6), depression has a greater negative impact on the quality of life of the patient than cardiovascular disease and has been projected to be the second most important cause of disability, as disability adjusted years, by 2030 (7). This finding has been replicated in several national studies (8-10). In addition, mood disorders and anxiety disorders rank more highly than a number of common physical disorders in terms of the number of days lost from work (11). Disability in key occupational, domestic and social roles is strongly related to both the severity and persistence of the disorder (12).

The pattern of occurrence, increasing severity and the frequency of resistance to treatment are some of the reasons for the high burden of depression $(13,14)$. Depression is frequently a recurrent condition and whereas the outcome of acute treatment is generally good, a small proportion of patients show poor treatment response with up to $30 \%$ showing only a partial response. It has been estimated that about $30 \%$ of patients relapse in the first year of treatment while about $80 \%$ of those with major depression have at least one further episode (15). These facts emphasise the importance of timely and adequate treatment in preventing the disorder from becoming a chronic condition. Unfortunately antidepressants are frequently limited in their efficacy and have unacceptable side effects combined with a slow onset of action with frequent interactions with concurrent medication. This leads to poor patient compliance that has been estimated to be about $56 \%$ following the first 3 months of antidepressant treatment (16), the placebo response being as high as $30 \%$. Thus there is a need to develop more effective and better tolerated antidepressants. Diagnostic and prognostic markers of depression would undoubtedly assist not only in the accurate and early diagnosis of the disorder but also help to predict the possible outcome of antidepressant treatment. 


\title{
How do antidepressants work: a synopsis of the monoamine hypothesis of depression
}

\author{
Monoamine Hypothesis
}

There are many theories and hypotheses regarding the pathophysiology of depression. However, for most of the last 50 years, the biological approach to depression has been dominated by the monoamine hypothesis (17). This hypothesis proposes that depression is caused by a functional deficit in monoamines, particularly noradrenalin and serotonin, at key sites in the brain. The hypothesis was also developed to explain the antidepressant effects of the tricyclic antidepressants (TCAs) and monoamine oxidase inhibitors (MAOIs) $(18,19)$.

However, the hypothesis could neither explain why up to 2-3 weeks of continued medication was needed to alleviate depressive symptoms, even though monoamine changes often occur within 1-2 days nor why other drugs such as cocaine and amphetamine that enhanced serotonergic or noradrenergic transmission are not effective in treating depression (20). Furthermore, the hypothesis could not explain why antidepressants are effective in other disorders, such as social phobia (21), why other drugs such as tianeptine are active even though they are thought to enhance serotonin reuptake, an effect opposite to the SSRI antidepressants (22-24). Neither can the hypothesis explain why the densities of some serotonin $(5-\mathrm{HT})$ receptors are increased by long-term electroconvulsive therapy, one of the most effective treatments of depression (25). More recently it has been proposed that there is a structural deficit in some serotonin receptors that are functionally involved in the regulation of mood (26). Nevertheless, despite these serious limitations, the monoamine hypothesis stimulated the development of safer antidepressants like the selective serotonin reuptake inhibitors (SSRIs), such as, citalopram, fluoxetine, fluvoxamine, paroxetine and setraline, the selective noradrenaline reuptake inhibitors and the dual action antidepressants, venlafaxine and milnacipran, that modify both central noradrenergic and serotonergic systems (27).

\section{Role of current antidepressants}

Pharmacotherapy has been the main treatment strategy for depression over the past 40 years. Up to 1980, tricyclic antidepressants (TCAs) represented the major pharmacological treatment for depression. The TCAs differ from each other in their potency to inhibit presynaptic noradrenaline or serotonin uptake and in their propensity for causing variety of untoward effects (28). Thus they induce anticholinergic, antihistaminergic and cardiotoxic side effects related to their antagonistic action mainly on muscarinic M1, histamine $\mathrm{H} 1$ and adrenergic- $\alpha 1$ receptors and cardiac $\mathrm{Na}^{+}$and $\mathrm{Ca}^{+}$channels (29-32).

The first generation of MAO-A inhibitors also induced severe side effects such as hypertensive crises because of the irreversible inhibition of MAO-A that catabolises the monoamines. Therefore, the selective and reversible second generation of MAO-A inhibitors such as moclobemide was developed (33), drugs that were less likely to permit the passage of dietary monoamine through the wall of the gastrointestinal tract.

Nowadays, the SSRIs are most widely used in clinical practice. Zimelidine was the first specific SSRI but was withdrawn from the market due to its serious intestinal side effects. This was replaced by fluoxetine and fluvoxamine (28). All the SSRIs (fluoxet- 
ine, setraline, paroxetine, fluvoxamine, and citalopram) selectively block the reuptake of serotonin centrally and thereby resulting in an increase of serotonin in the synaptic cleft (34-36). Though SSRIs take approximately 2 weeks to increase the serotonin neurotransmission $(37,38)$, these are well tolerated and safe.

Recently, serotonin and noradrenaline reuptake inhibitor venlafaxine and milnacipran were introduced (28). Venlafaxine has a predominantly inhibitory effect on the serotonin transporter at low doses but inhibits the uptake of both serotonin and noradrenaline at high doses. Conversely milnacipran blocks the noradrenalin transporter at low doses but inhibits the uptake of both monoamines at high doses (39).

More recently, several selective 5-HT1A receptor agonists have been available but the antidepressant efficacy is limited $(40,41)$. The 5-HT2 receptor antagonist nefazodone also shows low antidepressant efficacy (42).

The tetracyclic antidepressants, mianserin and mirtazepine differ from the different types of reuptake inhibitor antidepressants in that they primarily act by enhancing the release of noradrenaline by blocking the presynaptic alpha-2 adrenoceptors on the presynaptic nerve terminals. Mirtazepine, an analogue of mianserin, has an additional property in that it also enhances the release of serotonin. While these antidepressants lack many of the untoward side effects of the reuptake inhibitors they are potent $\mathrm{H} 1$ antagonists, thereby causing sedation, and are also more likely to cause weight gain.

Despite all these different types of antidepressants that are now available, the efficacy in treating depression has not noticeably improved since the introduction of imipramine in 1958. In addition, the rate of relapse and the frequency of recurrence are still far too high. Clearly there is a need for more effective antidepressants.

\section{Recent hypotheses of depression}

\section{Hypothalamic-Pituitary-Adrenal (HPA) Axis}

The association between abnormality of HPA axis and depression has long been known (43). There were well documented abnormalities of HPA axis function in depressed patients, such as, enhance 24-hour urinary free cortisol and raised serum cortisol levels (44-47), impaired dexamethasone suppression $(48,49)$, and blunting of adrenocorticotrophic hormone $(\mathrm{ACTH})$ release in response to corticotrophin-releasing factor (CRF) challenge $(50,51)$. During the last decade, more evidence has been produced to link chronic stress or stressful life events such as loss of parents (52) and child physical or sexual abuse (53) with the onset of depression and its severity (54-56). It has been suggested that such events might cause long-lasting alterations in corticotrophin releasing factor (CRF) containing neurones, thereby increasing an individual's vulnerability to stressors later in life (57).

The neuroendocrine response to any stressor is mediated through the HPA axis. This cascade begins in the central nervous system with increase release of CRF from the hypothalamus into the portal vasculature (58), to act on anterior pituitary CRF receptors. The anterior pituitary gland responds by stimulating the release of adrenocorticotrophic hormone (ACTH), which stimulates the synthesis of cortisol from the adrenal cortex. In addition, arginine vasopressin (AVP) has recently been established as a co-secretagogue to CRF, which is co-expressed with CRF in situations of stress (59). It acts on anterior 
pituitary AVP receptors and produces a major increase in ACTH release by synergistic interaction with CRF at the second messenger level.

Two hypotheses have been proposed as pathophysiological explanations for the HPA overactivity observed in depression. The first involves increased brain CRF driving the HPA axis into "overdrive" (60); it is suggested that CRF may provide a link between the monoamine and neuroendocrine theories of depression since CRF appears to regulate tyrosine hydroxylase, the rate limiting enzyme in the synthesis of noradrenaline (61). The second hypothesis suggests impaired negative feedback at both the pituitary corticotroph and central glucocorticoid receptor levels (62) and it is proposed that a primary alteration in glucocorticoid receptor (GR) or mineralocorticoid receptor (MR) number or function may contribute to the pathophysiology of depression (63). However, a study by Dinan and co-workers (64) suggests there is a switch from CRF to AVP regulation of HPA axis during depression, implying that a CRF antagonist would be unlikely to correct the HPA disturbance observed in depression whereas a blockade of AVP receptor might offer a more appropriate pharmacological approach (58).

\section{Other neuroendocrine axis and non-amine neurotransmitters}

It is well documented that hypothyroidism can lead to major depression and could be reversed by thyroxine treatment (65). There is some evidence of a dysfunction of the hypothalamic-pituitary-thyroid (HPT) axis in major depression. In some patients with major depression, slightly elevated thyroxine (T4) levels (66), a blunted response of thyroid stimulating hormone (TSH) to thyrotropin-releasing hormone $(\mathrm{TRH})(66,67)$, and loss of normal nocturnal surge in TSH levels (68) are reported. Decrease in T4, and free T4, levels after antidepressant treatment is also reported (69).

There are other non-amine neurotransmitters that are hypothesised to be involved in pathophysiology of major depression. Recently, an antagonist of substance P, a cotransmitter with serotonin (neurotransmitter) involved in the transmission of pain, has been reported to have antidepressant qualities in placebo-controlled trial in patients with moderate to severe depression (70). The involvement of gamma-amino-butyric acid (GABA) and glutamatergic neurotransmission in pathophysiology of depression is also proposed $(71,72)$.

A neurotrophic factor, brain derived neurotrophic factor (BDNF) is also proposed to be involved in pathophysiology of depression. An experimental study demonstrated that centrally administered BDNF attenuated the depressive behaviour (73). In addition, chronic antidepressant treatment has been shown to increase BDNF expression, particularly in the hippocampus $(74,75)$.

\section{Neurogenesis and neuroplasticity hypotheses}

The neurogenesis hypothesis (76) proposes that (the adult) neurogenesis is impaired in depression and is responsible for the hippocampal structural changes (77), which is reversible in the remission stage of the disease (78). It has been shown in some studies that treatment with antidepressants $(79,80)$, electroconvulsive therapy $(\mathrm{ECT})(81,82)$, and increased physical activity (83), can stimulate the proliferation of hippocampal progenitor cells, which contribute to the first stage of adult neurogenesis. Enhanced activity of the serotonergic system has also been reported to improve adult hippocampal 
neurogenesis (84). However, in addition to the hippocampus, other regions in the brain also show changes in depression. The alterations in prefrontal neurons and glial cell numbers (85), and substantially reduced glial cell density in the amygdale that are moderately improved by mood stabilizers (86), are also reported to occur in major depression. Moreover, in major depression, there are changes in other neurotrophic factors such as BDNF that can influence the neuronal plasticity.

Based on above factors, severe and chronic disturbance of cellular plasticity, including reduced neurogenesis, forms the basis of the neurogenesis and cellular plasticity hypothesis of major depression (87). However, whether these changes are the cause or consequence of depression is presently unclear. In addition, the mechanism whereby adult neurogenesis and plasticity could be involved in major depression and how this hypothesis can be applied diagnostically is unclear.

\section{Macrophage theory of depression and role of inflammatory changes}

The macrophage theory of depression (88) is the first theory that brings the role of immune system and inflammatory changes into pathophysiology of depression. In this hypothesis, interleukin (IL) $1 \beta$, which is secreted from the macrophages, directly stimulates the CRF secretion in the hypothalamus and induces hyperactivity of the HPA axis. This theory therefore links the immune system with the neuroendocrine and neurotransmitter changes in major depression.

It is well documented that acute infections, in both animals and man, are usually accompanied by a cluster of non-specific symptoms which include fever, hypersomnia, hyperalgesia, anorexia, anhedonia, memory defects and depressed behaviour (89). Since the release of pro-inflammatory cytokines such as IL1 $\beta$, IL6 and tumour necrosis factor (TNF) $\alpha$ are an integral part of the host response to infection, these cytokines are considered to play a pivotal role in neurotransmitter and neuroendocrine changes. The stimulation of HPA axis by IL1 thereby increases the secretion of ACTH from the anterior pituitary and glucocorticoids from adrenals (90). There is also evidence that IL1 can increase the turnover of serotonin in vivo in some regions of the rat brain (91) as shown by an increase in the steady-state concentration of the main metabolite, 5hydroxyindoleaccetic acid (5HIAA). Moreover, IL1 also induces an increase in the functional activity of central noradrenergic system. Thus in the several mesolimbic regions of the rat brain, IL1 increases the concentration of the main metabolite of noradrenaline, 3-methoxy-4-hydroxyphenyl-glycol (MHPG) (92).

Experimentally it has been shown that the systemic injection of lipopolysaccharide (LPS), obtained from the bacterial cell wall and a strong inducer of the synthesis and release of pro-inflammatory cytokines, also produces depression like "sickness behaviour" that is largely attenuated by the prior administration of IL1 antagonist IL10 (93). In human studies it has been shown that the interferon (IFN), the cytokine used to treat certain cancers and viral infections, can induce depression. In short term applications of high doses of IFN $\alpha$ given intravenously, 20 to 60 percent of patients developed organic mental disorders after short latency period of several days but symptoms generally subside promptly after cessation of treatment (94-101). Compared to the side effects occurring in high-dose therapy, neuropsychiatric effects during low-dose therapy are reported to be less severe and occur after a longer latency in 4 to 16 percent of patients (102). 
It is well established that major depression is associated with dysregulation of immune mediators. These changes include the rise in IL1 $\beta$, IL6, IL12, soluble IL6R, IL2, soluble IL2R, IL1Ra, IL10 and IFN $\gamma$ (103-110). There is also evidence from in vitro studies that when human monocytes are incubated with different classes of antidepressants together with LPS that stimulates the release of pro-inflammatory cytokines, the release of IL1, IL6 and TNF $\alpha$ are markedly inhibited (111). The enhanced lymphocyte proliferation and stimulated synthesis of IL1 and IL2 from spleen cells that occurs in the rats subjected to chronic mild stress is also reversed following chronic treatment with imipramine (112). Other studies show that antidepressants can induce increases in anti-inflammatory cytokine IL10 and a decrease in $\operatorname{IFN} \gamma(113,114)$.

However, there is some controversy regarding the anti-inflammatory effect of different types of antidepressants. Changes produced in rats following an acute challenge with LPS, such as a reduction in the body weight and food consumption, and a reduction in intake of saccharine flavoured water, have been shown to be reversed by the chronic treatment with a tricyclic antidepressant but not with venlafaxine or a SSRI (115). These findings are supported by another in vivo study in which desipramine has been shown to impair the secretion of both IL1 and TNF $\alpha$ following a challenge with LPS, while no effect has been observed with venlafaxine or paroxetine (116). However, in olfactory bulbectomised (OBX) rat model of depression, it has been shown that the elevated acute phase protein response is attenuated by both tricyclic antidepressants and SSRIs (117). Moreover, SSRIs have been shown to decrease the release of IL6 and acute phase proteins in patients with major depression (118).

As IL1 could indirectly increase the synthesis of inflammatory mediator prostaglandin (PG) E2 (119), the increased PGE2 concentration in the saliva, blood and cerebrospinal fluid of depressed patients has also been documented (120-123). Based on these findings the inhibitory activity of antidepressants on cyclo-oxygenase (COX) which is involved in synthesis of inflammatory mediator, PGE2, has been proposed as a mechanism of antidepressant action in reducing the inflammatory changes (124). The role of omega-3 fatty acid against PGE2 and omega- 6 fatty acid is also proposed in macrophage theory of depression (88) and animal studies have provided a possible mechanism for the role omega-3 fatty acid in depression (125-127). These studies support the possible beneficial effects of COX2-inhibitors (128) and omega-3 fatty acid (129-132) as putative antidepressants. Moreover, during the last decade, the enhancing effect of pro-inflammatory cytokines on the enzyme indoleamine 2,3-dioxygenase (IDO) that in turn enhances the tryptophan catabolism which might results in low serotonin synthesis also becomes of interest (133-137).

Thus the involvement of the pro-inflammatory cytokines in pathophysiology of depression is well confirmed. Several mechanisms are proposed through which bloodborne cytokines to reach target receptors in the brain. The active transport mechanism, transport across circumventricular organs, transport by binding to the receptors in the blood vessels that course through the brain and retrograde transport of cytokines through the vagus nerve have been proposed (138). The role of IL1 and TNF in neuronal injury is also documented. These pro-inflammatory cytokines have both protective and degenerative effects on the neurons and glia depending on their concentrations and duration of exposure (139).

These observations raise a question whether depression is a neurodegenerative disease induced by chronic inflammation. In addition, how those immune changes and 
monoamine changes are linked to each other in an integrated mechanism in the pathophysiology of depression also becomes an important problem of research. Moreover, the specificity of the immune changes in depression is unclear as is the possible role of coping mechanisms. These are some of the questions that need to be addressed. This thesis will seek to address some of the questions raised by the neurodegeneration hypothesis of depression.

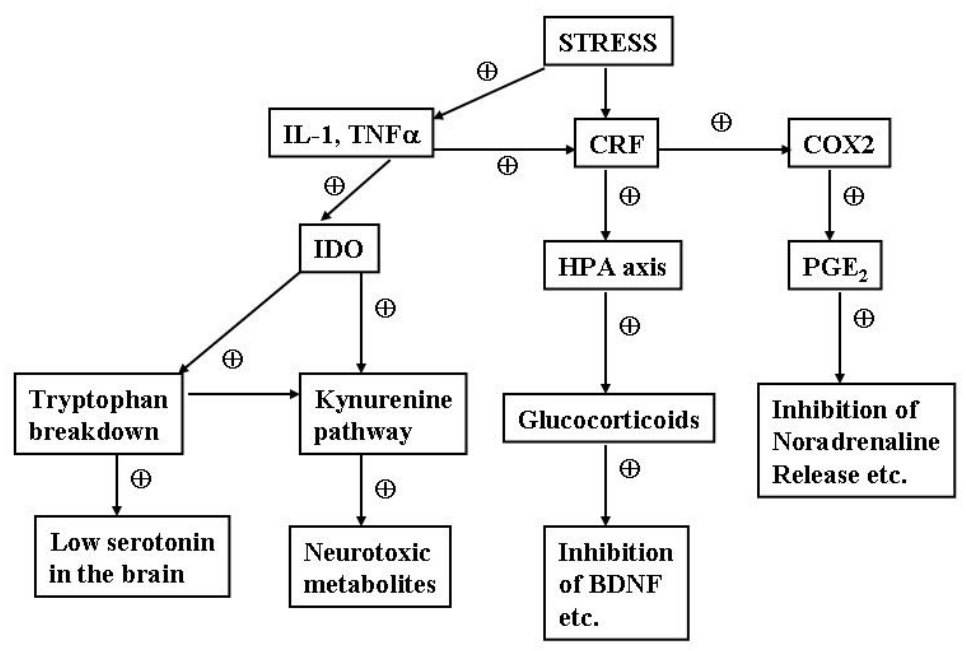

Figure 1. Stress induced immune activation and its link to neuroendocrine and neurotransmitter changes

\section{References}

1. Santos J, Chen L-S., de Erausquin GA. Phenomenology of depression: towards a neuroscientific perspective. In: Gilliam F, Kanner, AM., Sheline, YI., editor. DEPRESSION AND BRAIN DYSFUNCTION. London and New York: Taylor \& Francis; 2006. p. 1-49.

2. Sartorius N. Concepts of depression: sporadic revolutions of continuous evolution. Hum Psychopharmacol 2001;16(S1):S3-S6.

3. Berrios G, Porter, R. eds. A History of Clinical Psychiatry: The Origin and History of Psychiatric Diseases. Continuum International. London, Athlone; 1995.

4. APA. Diagnostic and statistical manual of mental disorders. 4th Ed ed. Washington DC: American Psychiatric Press; 1994.

5. ESEMeD/MHEDEA2000. Prevalence of mental disorders in Europe: results fromthe European Study of the Epidemiology of Mental Disorders (ESEMeD) Project. Acta Psychiatr. Scand. 2004;109 (Suppl. 1):21-27.

6. Murray CJ, Lopez AD. Global mortality, disability, and the contribution of risk factors: Global Burden of Disease Study. Lancet 1997;349(9063):1436-42.

7. Mathers C, Loncar, D. Updated projections of global mortality and burden of disease, 2002-2030: data sources, methods and results. Geneva: WHO; 2005. 
8. Mathers CD, Vos ET, Stevenson CE, Begg SJ. The Australian Burden of Disease Study: measuring the loss of health from diseases, injuries and risk factors. Med J Aust 2000;172(12):592-6.

9. Melse JM, Essink-Bot ML, Kramers PG, Hoeymans N. A national burden of disease calculation: Dutch disability-adjusted life-years. Dutch Burden of Disease Group. Am J Public Health 2000;90(8):1241-7.

10. Ustun TB, Ayuso-Mateos JL, Chatterji S, Mathers C, Murray CJ. Global burden of depressive disorders in the year 2000. Br J Psychiatry 2004;184:386-92.

11. ESEMeD/MHEDEA2000. Disability and quality of life impact of mental disorders in Europe: results from the European Study of the Epidemiology of Mental Disorders (ESEMeD) project. Acta Psychiatr. Scand. 2004;109 (Suppl.1):38-46.

12. Brugha TS, Evans, S. Quality of life, social support and physical health. In: Singleton N, Lewis, G., editor. Better or Worse: A longitudinal Study of the Mental Health of Adults Living in Private Housholds in Great Britain. London: Department of Health; 2003. p. 146-156.

13. Greden JF. The burden of recurrent depression: causes, consequences, and future prospects. J Clin Psychiatry 2001;62 Suppl 22:5-9.

14. Greden JF. The burden of disease for treatment-resistant depression. J Clin Psychiatry 2001;62 Suppl $16: 26-31$.

15. Paykel ES, Scott J, Cornwall PL, Abbott R, Crane C, Pope M, et al. Duration of relapse prevention after cognitive therapy in residual depression: follow-up of controlled trial. Psychol Med 2005;35(1):59-68.

16. Greden JF. Unmet need: what justifies the search for a new antidepressant? J Clin Psychiatry 2002;63 Suppl 2:3-7.

17. Van Praag HM. Anxiety/aggression-driven depression. A paradigm of functionalization and verticalization of psychiatric diagnosis. Prog Neuropsychopharmacol Biol Psychiatry 2001;25(4):893924.

18. Bunney WE, Jr., Davis JM. Norepinephrine in depressive reactions. A review. Arch Gen Psychiatry 1965;13(6):483-94.

19. Schildkraut JJ, Gordon EK, Durell J. Catecholamine metabolism in affective disorders. I. Normetanephrine and VMA excretion in depressed patients treated with imipramine. J Psychiatr Res 1965;3(4):213-28.

20. Hindmarch I. Expanding the horizons of depression: beyond the monoamine hypothesis. Hum Psychopharmacol 2001;16(3):203-218.

21. Sheehan DV, Raj BA, Trehan RR, Knapp EL. Serotonin in panic disorder and social phobia. Int Clin Psychopharmacol 1993;8 Suppl 2:63-77.

22. Loo H, Saiz-Ruiz J, Costa e Silva J, Ansseau M, Herrington R, Vaz-Serra A, et al. Efficacy and safety of tianeptine in the treatment of depressive disorders in comparison with fluoxetine. $\mathrm{J}$ Affect Disord 1999;56(2-3):109-18.

23. Pineyro G, Blier P. Autoregulation of serotonin neurons: role in antidepressant drug action. Pharmacol Rev 1999;51(3):533-91.

24. Wilde MI, Benfield P. Tianeptine. A review of its pharmacodynamic and pharmacokinetic properties, and therapeutic efficacy in depression and coexisting anxiety and depression. Drugs 1995;49(3):411-39.

25. Butler MO, Morinobu S, Duman RS. Chronic electroconvulsive seizures increase the expression of serotonin2 receptor mRNA in rat frontal cortex. J Neurochem 1993;61(4):1270-6.

26. Charney DS, Menkes DB, Heninger GR. Receptor sensitivity and the mechanism of action of antidepressant treatment. Implications for the etiology and therapy of depression. Arch Gen Psychiatry 1981;38(10):1160-80.

27. Hindmarch I. Beyond the monoamine hypothesis: mechanisms, molecules and methods. Eur Psychiatry 2002;17 Suppl 3:294-9.

28. Pacher P, Kohegyi E, Kecskemeti V, Furst S. Current trends in the development of new antidepressants. Curr Med Chem 2001;8(2):89-100.

29. Healy DG, Harkin A, Cryan JF, Kelly JP, Leonard BE. Metyrapone displays antidepressant-like properties in preclinical paradigms. Psychopharmacology (Berl) 1999;145(3):303-8.

30. Pacher P, Ungvari Z, Kecskemeti V, Koller A. Serotonin reuptake inhibitor, fluoxetine, dilates isolated skeletal muscle arterioles. Possible role of altered Ca2+ sensitivity. Br J Pharmacol 1999;127(3):740-6.

31. Baldessarini RJ, Tondo L, Faedda GL, Suppes TR, Floris G, Rudas N. Effects of the rate of discontinuing lithium maintenance treatment in bipolar disorders. J Clin Psychiatry 1996;57(10):441-8.

32. Glassman AH, Carino JS, Roose SP. Adverse effects of tricyclic antidepressants: focus on the elderly. Adv Biochem Psychopharmacol 1984;39:391-8.

33. Caccia S. Metabolism of the newer antidepressants. An overview of the pharmacological and pharmacokinetic implications. Clin Pharmacokinet 1998;34(4):281-302.

34. Wong PT, Feng H, Teo WL. Interaction of the dopaminergic and serotonergic systems in the rat striatum: effects of selective antagonists and uptake inhibitors. Neurosci Res 1995;23(1):115-9. 
35. Wong DT, Bymaster FP, Engleman EA. Prozac (fluoxetine, Lilly 110140), the first selective serotonin uptake inhibitor and an antidepressant drug: twenty years since its first publication. Life Sci 1995;57(5):411-41.

36. Wong DT, Bymaster FP. Development of antidepressant drugs. Fluoxetine (Prozac) and other selective serotonin uptake inhibitors. Adv Exp Med Biol 1995;363:77-95.

37. Goodnick PJ, Goldstein BJ. Selective serotonin reuptake inhibitors in affective disorders-II. Efficacy and quality of life. J Psychopharmacol 1998;12(3 Suppl B):S21-54.

38. Goodnick PJ, Goldstein BJ. Selective serotonin reuptake inhibitors in affective disorders-I. Basic pharmacology. J Psychopharmacol 1998;12(3 Suppl B):S5-20.

39. Briley M, Prost JF, Moret C. Preclinical pharmacology of milnacipran. Int Clin Psychopharmacol 1996;11 Suppl 4:9-14.

40. Dimitriou EC, Dimitriou CE. Buspirone augmentation of antidepressant therapy. J Clin Psychopharmacol 1998;18(6):465-9.

41. Landen M, Bjorling G, Agren H, Fahlen T. A randomized, double-blind, placebo-controlled trial of buspirone in combination with an SSRI in patients with treatment-refractory depression. J Clin Psychiatry 1998;59(12):664-8.

42. Davis R, Whittington R, Bryson HM. Nefazodone. A review of its pharmacology and clinical efficacy in the management of major depression. Drugs 1997;53(4):608-36.

43. Board F, Persky H, Hamburg DA. Psychological stress and endocrine functions; blood levels of adrenocortical and thyroid hormones in acutely disturbed patients. Psychosom Med 1956;18(4):324-33.

44. Linkowski P, Van Cauter E, Leclercq R, Desmedt D, Brasseur M, Golstein J, et al. ACTH, cortisol and growth hormone 24-hour profiles in major depressive illness. Acta Psychiatr Belg 1985;85(5):615-23.

45. Linkowski P, Mendlewicz J, Leclercq R, Brasseur M, Hubain P, Golstein J, et al. The 24-hour profile of adrenocorticotropin and cortisol in major depressive illness. J Clin Endocrinol Metab 1985;61(3):429-38.

46. Carpenter WT, Jr., Bunney WE, Jr. Adrenal cortical activity in depressive illness. Am J Psychiatry 1971;128(1):31-40.

47. Gibbons JL, Mc HP. Plasma cortisol in depressive illness. J Psychiatr Res 1962;1:162-71.

48. Nuller JL, Ostroumova MN. Resistance to inhibiting effect of dexamethasone in patients with endogenous depression. Acta Psychiatr Scand 1980;61(2):169-77.

49. Holsboer F, Wiedemann K, Gerken A, Boll E. The plasma dexamethasone variable in depression: testretest studies and early biophase kinetics. Psychiatry Res 1986;17(2):97-103.

50. Gold PW, Calabrese JR, Kling MA, Avgerinos P, Khan I, Gallucci WT, et al. Abnormal ACTH and cortisol responses to ovine corticotropin releasing factor in patients with primary affective disorder. Prog Neuropsychopharmacol Biol Psychiatry 1986;10(1):57-65.

51. Holsboer F, Gerken A, von Bardeleben U, Grimm W, Beyer H, Muller OA, et al. Human corticotropinreleasing hormone in depression-correlation with thyrotropin secretion following thyrotropin-releasing hormone. Biol Psychiatry 1986;21(7):601-11.

52. Kendler KS, Neale MC, Kessler RC, Heath AC, Eaves LJ. Childhood parental loss and adult psychopathology in women. A twin study perspective. Arch Gen Psychiatry 1992;49(2):109-16.

53. McCauley J, Kern DE, Kolodner K, Dill L, Schroeder AF, DeChant HK, et al. Clinical characteristics of women with a history of childhood abuse: unhealed wounds. Jama 1997;277(17):1362-8.

54. Hammen C, Davila J, Brown G, Ellicott A, Gitlin M. Psychiatric history and stress: predictors of severity of unipolar depression. J Abnorm Psychol 1992;101(1):45-52.

55. Post RM. Transduction of psychosocial stress into the neurobiology of recurrent affective disorder. Am J Psychiatry 1992;149(8):999-1010.

56. Brown GW, Bifulco A, Harris TO. Life events, vulnerability and onset of depression: some refinements. Br J Psychiatry 1987;150:30-42.

57. Arborelius L, Owens MJ, Plotsky PM, Nemeroff CB. The role of corticotropin-releasing factor in depression and anxiety disorders. J Endocrinol 1999;160(1):1-12.

58. Dinan T. Novel approaches to the treatment of depression by modulating the hypothalamic - pituitaryadrenal axis. Hum Psychopharmacol 2001;16(1):89-93.

59. Scott LV, Dinan TG. Vasopressin and the regulation of hypothalamic-pituitary-adrenal axis function: implications for the pathophysiology of depression. Life Sci 1998;62(22):1985-98.

60. Nemeroff CB. The corticotropin-releasing factor (CRF) hypothesis of depression: new findings and new directions. Mol Psychiatry 1996;1(4):336-42.

61. Redmond M, Leonard, BE. An evaluation of the role of the noradrenergic system in the neurobiology of deprssion: a review. Hum Psychopharmacol Clin Exp 1997;12:407-430.

62. Young EA, Haskett RF, Murphy-Weinberg V, Watson SJ, Akil H. Loss of glucocorticoid fast feedback in depression. Arch Gen Psychiatry 1991;48(8):693-9. 
63. Plotsky PM, Owens MJ, Nemeroff CB. Psychoneuroendocrinology of depression. Hypothalamicpituitary-adrenal axis. Psychiatr Clin North Am 1998;21(2):293-307.

64. Dinan TG, Lavelle E, Scott LV, Newell-Price J, Medbak S, Grossman AB. Desmopressin normalizes the blunted adrenocorticotropin response to corticotropin-releasing hormone in melancholic depression: evidence of enhanced vasopressinergic responsivity. J Clin Endocrinol Metab 1999;84(6):2238-40.

65. Gold MS, Pottash AL, Extein I. Hypothyroidism and depression. Evidence from complete thyroid function evaluation. Jama 1981;245(19):1919-22.

66. Wahby VS, Ibrahim GA, Giller EL, Martin RP, Saddik FW, Singh SP, et al. Relationship of age to TSH response to TRH in depressed men. Acta Psychiatr Scand 1988;78(3):283-8.

67. Hein MD, Jackson IM. Review: thyroid function in psychiatric illness. Gen Hosp Psychiatry 1990;12(4):232-44.

68. Bartalena L, Placidi GF, Martino E, Falcone M, Pellegrini L, Dell'Osso L, et al. Nocturnal serum thyrotropin (TSH) surge and the TSH response to TSH-releasing hormone: dissociated behavior in untreated depressives. J Clin Endocrinol Metab 1990;71(3):650-5.

69. Gendall KA, Joyce PR, Mulder RT, Luty SE. Thyroid indices and response to fluoxetine and nortriptyline in major depression. J Psychopharmacol 2003;17(4):431-7.

70. Kramer MS, Matzura-Wolfe D, Polis A, Getson A, Amaraneni PG, Solbach MP, et al. A placebocontrolled crossover study of rizatriptan in the treatment of multiple migraine attacks. Rizatriptan Multiple Attack Study Group. Neurology 1998;51(3):773-81.

71. Sanacora G, Gueorguieva R, Epperson CN, Wu YT, Appel M, Rothman DL, et al. Subtype-specific alterations of gamma-aminobutyric acid and glutamate in patients with major depression. Arch Gen Psychiatry 2004;61(7):705-13.

72. Ongur D, Drevets WC, Price JL. Glial reduction in the subgenual prefrontal cortex in mood disorders. Proc Natl Acad Sci U S A 1998;95(22):13290-5.

73. Siuciak JA, Boylan C, Fritsche M, Altar CA, Lindsay RM. BDNF increases monoaminergic activity in rat brain following intracerebroventricular or intraparenchymal administration. Brain Res 1996;710(12):11-20.

74. Nibuya M, Nestler EJ, Duman RS. Chronic antidepressant administration increases the expression of cAMP response element binding protein (CREB) in rat hippocampus. J Neurosci 1996;16(7):2365-72.

75. Nibuya M, Morinobu S, Duman RS. Regulation of BDNF and trkB mRNA in rat brain by chronic electroconvulsive seizure and antidepressant drug treatments. J Neurosci 1995;15(11):7539-47.

76. Jacobs BL. Adult brain neurogenesis and depression. Brain Behav Immun 2002;16(5):602-9.

77. Sheline YI. 3D MRI studies of neuroanatomic changes in unipolar major depression: the role of stress and medical comorbidity. Biol Psychiatry 2000;48(8):791-800.

78. Fuchs E, Czeh B, Kole MH, Michaelis T, Lucassen PJ. Alterations of neuroplasticity in depression: the hippocampus and beyond. Eur Neuropsychopharmacol 2004;14 Suppl 5:S481-90.

79. Czeh B, Michaelis T, Watanabe T, Frahm J, de Biurrun G, van Kampen M, et al. Stress-induced changes in cerebral metabolites, hippocampal volume, and cell proliferation are prevented by antidepressant treatment with tianeptine. Proc Natl Acad Sci U S A 2001;98(22):12796-801.

80. Malberg JE, Eisch AJ, Nestler EJ, Duman RS. Chronic antidepressant treatment increases neurogenesis in adult rat hippocampus. J Neurosci 2000;20(24):9104-10.

81. Madsen TM, Treschow A, Bengzon J, Bolwig TG, Lindvall O, Tingstrom A. Increased neurogenesis in a model of electroconvulsive therapy. Biol Psychiatry 2000;47(12):1043-9.

82. Scott BW, Wojtowicz JM, Burnham WM. Neurogenesis in the dentate gyrus of the rat following electroconvulsive shock seizures. Exp Neurol 2000;165(2):231-6.

83. van Praag H, Christie BR, Sejnowski TJ, Gage FH. Running enhances neurogenesis, learning, and longterm potentiation in mice. Proc Natl Acad Sci U S A 1999;96(23):13427-31.

84. Gould E. Serotonin and hippocampal neurogenesis. Neuropsychopharmacology 1999;21(2 Suppl):46S$51 \mathrm{~S}$.

85. Rajkowska G. Postmortem studies in mood disorders indicate altered numbers of neurons and glial cells. Biol Psychiatry 2000;48(8):766-77.

86. Bowley MP, Drevets WC, Ongur D, Price JL. Low glial numbers in the amygdala in major depressive disorder. Biol Psychiatry 2002;52(5):404-12.

87. Kempermann G, Kronenberg G. Depressed new neurons - adult hippocampal neurogenesis and a cellular plasticity hypothesis of major depression. Biol Psychiatry 2003;54(5):499-503.

88. Smith RS. The macrophage theory of depression. Med Hypotheses 1991;35(4):298-306.

89. Hart BL. Biological basis of the behavior of sick animals. Neurosci Biobehav Rev 1988;12(2):123-37.

90. Tsagarakis S, Gillies G, Rees LH, Besser M, Grossman A. Interleukin-1 directly stimulates the release of corticotrophin releasing factor from rat hypothalamus. Neuroendocrinology 1989;49(1):98-101. 
91. Gemma C, De Luigi A, De Simoni MG. Permissive role of glucocorticoids on interleukin-1 activation of the hypothalamic serotonergic system. Brain Res 1994;651(1-2):169-73.

92. Dunn AJ. Systemic interleukin-1 administration stimulates hypothalamic norepinephrine metabolism parallelling the increased plasma corticosterone. Life Sci 1988;43(5):429-35.

93. Bluthe RM, Castanon N, Pousset F, Bristow A, Ball C, Lestage J, et al. Central injection of IL10 antagonizes the behavioural effects of lipopolysaccharide in rats. Psychoneuroendocrinology 1999;24(3):301-11.

94. Meyers CA, Obbens EA, Scheibel RS, Moser RP. Neurotoxicity of intraventricularly administered alpha-interferon for leptomeningeal disease. Cancer 1991;68(1):88-92.

95. Iivanainen M, Laaksonen R, Niemi ML, Farkkila M, Bergstrom L, Mattson K, et al. Memory and psychomotor impairment following high-dose interferon treatment in amyotrophic lateral sclerosis. Acta Neurol Scand 1985;72(5):475-80.

96. Farkkila M, Iivanainen M, Roine R, Bergstrom L, Laaksonen R, Niemi ML, et al. Neurotoxic and other side effects of high-dose interferon in amyotrophic lateral sclerosis. Acta Neurol Scand 1984;70(1):42-6.

97. Poutiainen E, Hokkanen L, Niemi ML, Farkkila M. Reversible cognitive decline during high-dose alphainterferon treatment. Pharmacol Biochem Behav 1994;47(4):901-5.

98. Mattson K, Niiranen A, Iivanainen M, Farkkila M, Bergstrom L, Holsti LR, et al. Neurotoxicity of interferon. Cancer Treat Rep 1983;67(10):958-61.

99. Rohatiner AZ, Prior PF, Burton AC, Smith AT, Balkwill FR, Lister TA. Central nervous system toxicity of interferon. Br J Cancer 1983;47(3):419-22.

100. Niiranen A, Laaksonen R, Iivanainen M, Mattson K, Farkkila M, Cantell K. Behavioral assessment of patients treated with alpha-interferon. Acta Psychiatr Scand 1988;78(5):622-6.

101. Smedley H, Katrak M, Sikora K, Wheeler T. Neurological effects of recombinant human interferon. $\mathrm{Br}$ Med J (Clin Res Ed) 1983;286(6361):262-4.

102. Schaefer M, Engelbrecht MA, Gut O, Fiebich BL, Bauer J, Schmidt F, et al. Interferon alpha (IFNalpha) and psychiatric syndromes: a review. Prog Neuropsychopharmacol Biol Psychiatry 2002;26(4):731-46.

103. Kim YK, Suh IB, Kim H, Han CS, Lim CS, Choi SH, et al. The plasma levels of interleukin-12 in schizophrenia, major depression, and bipolar mania: effects of psychotropic drugs. Mol Psychiatry 2002;7(10):1107-14.

104. Maes M, Stevens W, DeClerck L, Bridts C, Peeters D, Schotte C, et al. Immune disorders in depression: higher T helper/T suppressor-cytotoxic cell ratio. Acta Psychiatr Scand 1992;86(6):423-31.

105. Maes M, Stevens WJ, Declerck LS, Bridts CH, Peeters D, Schotte C, et al. Significantly increased expression of T-cell activation markers (interleukin-2 and HLA-DR) in depression: further evidence for an inflammatory process during that illness. Prog Neuropsychopharmacol Biol Psychiatry $1993 ; 17(2): 241-55$.

106. Maes M. Cytokines in major depression. Biol Psychiatry 1994;36(7):498-9.

107. Maes M, Meltzer HY, Bosmans E, Bergmans R, Vandoolaeghe E, Ranjan R, et al. Increased plasma concentrations of interleukin-6, soluble interleukin-6, soluble interleukin-2 and transferrin receptor in major depression. J Affect Disord 1995;34(4):301-9.

108. Musselman DL, Miller AH, Porter MR, Manatunga A, Gao F, Penna S, et al. Higher than normal plasma interleukin-6 concentrations in cancer patients with depression: preliminary findings. Am J Psychiatry 2001;158(8):1252-7.

109. Seidel A, Arolt V, Hunstiger M, Rink L, Behnisch A, Kirchner H. Increased CD56+ natural killer cells and related cytokines in major depression. Clin Immunol Immunopathol 1996;78(1):83-5.

110. Kubera M, Kenis G, Bosmans E, Zieba A, Dudek D, Nowak G, et al. Plasma levels of interleukin-6, interleukin-10, and interleukin-1 receptor antagonist in depression: comparison between the acute state and after remission. Pol J Pharmacol 2000;52(3):237-41.

111. Xia Z, DePierre JW, Nassberger L. Tricyclic antidepressants inhibit IL6, IL1 beta and TNF-alpha release in human blood monocytes and IL2 and interferon-gamma in T cells. Immunopharmacology 1996;34(1):27-37.

112. Kubera M, Symbirtsev A, Basta-Kaim A, Borycz J, Roman A, Papp M, et al. Effect of chronic treatment with imipramine on interleukin 1 and interleukin 2 production by splenocytes obtained from rats subjected to a chronic mild stress model of depression. Pol J Pharmacol 1996;48(5):503-6.

113. Kubera M, Kenis G, Bosmans E, Scharpe S, Maes M. Effects of serotonin and serotonergic agonists and antagonists on the production of interferon-gamma and interleukin-10. Neuropsychopharmacology 2000;23(1):89-98.

114. Kubera M, Kenis G, Bosmans E, Jaworska-Feil L, Lason W, Scharpe S, et al. Suppressive effect of TRH and imipramine on human interferon-gamma and interleukin-10 production in vitro. Pol $\mathrm{J}$ Pharmacol 2000;52(6):481-6. 
115. Shen Y, Connor TJ, Nolan Y, Kelly JP, Leonard BE. Differential effect of chronic antidepressant treatments on lipopolysaccharide-induced depressive-like behavioural symptoms in the rat. Life Sci 1999;65(17):1773-86.

116. Connor TJ, Kelliher P, Shen Y, Harkin A, Kelly JP, Leonard BE. Effect of subchronic antidepressant treatments on behavioral, neurochemical, and endocrine changes in the forced-swim test. Pharmacol Biochem Behav 2000;65(4):591-7.

117. Leonard BE, Song C. Changes in the immune system in rodent models of depression. Int J Neuropsychopharmacol 2002;5(4):345-56.

118. Sluzewska A, Rybakowski JK, Laciak M, Mackiewicz A, Sobieska M, Wiktorowicz K. Interleukin-6 serum levels in depressed patients before and after treatment with fluoxetine. Ann N Y Acad Sci 1995;762:474-6.

119. Lopez-Figueroa MO, Day HE, Akil H, Watson SJ. Nitric oxide in the stress axis. Histol Histopathol $1998 ; 13(4): 1243-52$.

120. Nishino S, Ueno R, Ohishi K, Sakai T, Hayaishi O. Salivary prostaglandin concentrations: possible state indicators for major depression. Am J Psychiatry 1989;146(3):365-8.

121. Calabrese JR, Skwerer RG, Barna B, Gulledge AD, Valenzuela R, Butkus A, et al. Depression, immunocompetence, and prostaglandins of the E series. Psychiatry Res 1986;17(1):41-7.

122. Gerner RH, Merrill JE. Cerebrospinal fluid prostaglandin E in depression, mania, and schizophrenia compared to normals. Biol Psychiatry 1983;18(5):565-9.

123. Linnoila M, Whorton AR, Rubinow DR, Cowdry RW, Ninan PT, Waters RN. CSF prostaglandin levels in depressed and schizophrenic patients. Arch Gen Psychiatry 1983;40(4):405-6.

124. Leonard BE. The immune system, depression and the action of antidepressants. Prog Neuropsychopharmacol Biol Psychiatry 2001;25:767-780.

125. DeMar JC, Jr., Ma K, Bell JM, Igarashi M, Greenstein D, Rapoport SI. One generation of n-3 polyunsaturated fatty acid deprivation increases depression and aggression test scores in rats. J Lipid Res 2006;47(1):172-80.

126. Carlezon WA, Jr., Mague SD, Parow AM, Stoll AL, Cohen BM, Renshaw PF. Antidepressant-like effects of uridine and omega-3 fatty acids are potentiated by combined treatment in rats. Biol Psychiatry 2005;57(4):343-50.

127. Watanabe S, Kanada S, Takenaka M, Hamazaki T. Dietary n-3 fatty acids selectively attenuate LPSinduced behavioral depression in mice. Physiol Behav 2004;81(4):605-13.

128. Muller N, Schwarz MJ, Dehning S, Douhe A, Cerovecki A, Goldstein-Muller B, et al. The cyclooxygenase-2 inhibitor celecoxib has therapeutic effects in major depression: results of a doubleblind, randomized, placebo controlled, add-on pilot study to reboxetine. Mol Psychiatry 2006;11(7):6804.

129. Freeman MP, Hibbeln JR, Wisner KL, Brumbach BH, Watchman M, Gelenberg AJ. Randomized doseranging pilot trial of omega-3 fatty acids for postpartum depression. Acta Psychiatr Scand 2006;113(1):31-5.

130. Nemets H, Nemets B, Apter A, Bracha Z, Belmaker RH. Omega-3 treatment of childhood depression: a controlled, double-blind pilot study. Am J Psychiatry 2006;163(6):1098-100.

131. Keck PE, Jr., Mintz J, McElroy SL, Freeman MP, Suppes T, Frye MA, et al. Double-Blind, Randomized, Placebo-Controlled Trials of Ethyl-Eicosapentanoate in the Treatment of Bipolar Depression and Rapid Cycling Bipolar Disorder. Biol Psychiatry 2006.

132. Su KP, Huang SY, Chiu CC, Shen WW. Omega-3 fatty acids in major depressive disorder. A preliminary double-blind, placebo-controlled trial. Eur Neuropsychopharmacol 2003;13(4):267-71.

133. Carlin JM, Borden EC, Sondel PM, Byrne GI. Biologic-response-modifier-induced indoleamine 2,3dioxygenase activity in human peripheral blood mononuclear cell cultures. J Immunol 1987;139(7):2414-8.

134. Carlin JM, Borden EC, Sondel PM, Byrne GI. Interferon-induced indoleamine 2,3-dioxygenase activity in human mononuclear phagocytes. J Leukoc Biol 1989;45(1):29-34.

135. Hu B, Hissong BD, Carlin JM. Interleukin-1 enhances indoleamine 2,3-dioxygenase activity by increasing specific mRNA expression in human mononuclear phagocytes. J Interferon Cytokine Res 1995;15(7):617-24.

136. Taylor MW, Feng GS. Relationship between interferon-gamma, indoleamine 2,3-dioxygenase, and tryptophan catabolism. Faseb J 1991;5(11):2516-22.

137. Yasui H, Takai K, Yoshida R, Hayaishi O. Interferon enhances tryptophan metabolism by inducing pulmonary indoleamine 2,3-dioxygenase: its possible occurrence in cancer patients. Proc Natl Acad Sci U S A 1986;83(17):6622-6. 


\section{CHAPTER 1.1}

138. Maier SF, Watkins LR. Immune-to-central nervous system communication and its role in modulating pain and cognition: Implications for cancer and cancer treatment. Brain Behav Immun 2003;17 Suppl 1:S125-31.

139. Allan SM TP, Rothwell NJ. Interleukin-1 and Neuronal Injury. Nat Rev Immunol 2005;05:629-640. 


\section{Chapter 1.2}

\section{Cytokine-Serotonin interaction through IDO: A neurodegeneration hypothesis of depression}

Med Hypotheses. 2003 Nov-Dec;61(5-6):519-25. 


\section{Summary}

There are different theories and hypotheses related to the aetiology of depression. The interaction between brain 5-HT level and the activity of its autoreceptors plays a role in mood changes and depression. In major depression, activation of the Inflammatory Response System (IRS) and, increased concentrations of proinflammatory cytokines, prostaglandin E2 and negative immuno-regulatory cytokines in peripheral blood have been reported. Recently, pro-inflammatory cytokines have been found to have profound effects on the metabolism of brain serotonin through the enzyme indoleamine 2,3dioxygenase (IDO) that metabolizes the tryptophan, the precursor of 5-HT to neurodegenerative quinolinate and neuroprotective kynurenate. The cytokine-serotonin interaction that leads to the challenge between quinolinate and kynurenate in the brain explains the neurodegeneration hypothesis of depression. 


\section{Introduction}

Stress is originally an engineering term introduced to human physiology by Hans Syle in 1936 as any condition that seriously perturbs the physiological and psychological homeostasis of an organism. None of the living creature is free from stress. If the stressful situation, regardless of the type whether physical or psychological, continues over a period of time, well adjusted under stress state or depression in human beings and sickness behaviour in animals can occur. Depression, a pain of mind is the most terrible suffering of mankind more than all the bodily pain. Scientists had done many research studies on depression and there are theories and hypotheses related to the aetiology of depression.

The depression-prone subjects have a vulnerable serotonergic system (1). In times of stress, more 5-HT is necessary for coping the stress and though up-regulation of 5HT2 receptor occurs as a compensatory mechanism, 5-HT turnover dysfunction occurs and major depression develop after long-term melancholia (2). Since tryptophan is the precursor of 5-HT, tryptophan depletion also has depressogenic effect (3).

The relationship between psychiatric illness and immune system was first observed in 1927 by Wagner-Jauregg, the only psychiatrist who ever awarded Noble prize for his work on malaria inoculation in dementia paralytica (4). During recent years, many studies have been carried out on the relationship between psychological stress, depression and immune system (5-8). In major depression, activation of the Inflammatory Response System (IRS) and, increased concentrations of proinflammatory cytokines, prostaglandin E2 and negative immuno-regulatory cytokines in peripheral blood have been reported (9-12). In animals, different stressors are reported to increase interleukin1 messenger RNA expression in the hypothalamus (13), elevate interleukin-1 activity in cell culture supernatants (14), and enhance biologically active interleukin-1 in the hypothalamus (15), increase stimulated production of interleukin-1 $\beta$ and TNF- $\alpha$ by isolated alveolar macrophages (16), or increase plasma concentrations of interleukin-6 $(17,18)$.

Recently, the link between cytokines and the serotonergic turnover has been explored. It was reported that cytokines such as IL1 $\beta$, IL2 and IFN $\gamma$ reduce the production of 5-HT by stimulating the activity of indoleamine 2,3-dioxygenase (IDO), an enzyme which converts tryptophan, the precursor of 5-HT to kynurenine $(19,20)$. The kynurenine is again metabolized (21) into quinolinic acid (quinolinate) and kynurenic acid (kynurenate), the excitotoxic NMDA receptor agonist (22) and the antagonist of all three ionotropic excitatory aminoacid receptors (23), respectively. Therefore, it is proposed that overexpression of IDO leads to depletion of plasma tryptophan and reduced synthesis of 5-HT in the brain, which finally may induce serotonin-depletion related disorder such as major depression. The involvement of the interaction between cytokine and serotonergic system through IDO and tryptophan degradation pathway beyond IDO in stress and depression still need exploration.

After reviewing the hypotheses, a question is raised why some people could adapt the stress well while the others undergo depression and it brought this hypothesis which emphasizes the balance between neurodegeneration and neuroprotection as a result of tryptophan degradation following the cytokine-serotonin interaction through the enzyme IDO. 


\section{Serotonin and depression}

The monoamine hypothesis of depression proposed that low levels of one or more of the brain monoamine neurotransmitters; serotonin, noradrenaline and dopamine could produce depression. This hypothesis is again refined in a way that depressive illness may arise, specifically, from decreased brain serotonin (5-HT) function (24). The subsequent evidences that the level of 5-HT precursor tryptophan was decreased in depressed patients (25), mood lowering effects occurred after administration of tryptophan-free diet (3), and the administration of tryptophan produced an antidepressant effect (26) supported the hypothesis.

The 5-HT system is also influenced by the terminal autoreceptors. Out of five different subtypes of 5-HT receptors, three of them, namely, 5-HT1B, 5-HT1D and 5HT1A autoreceptors are known to be involved in depression. It is well established that the release of 5-HT into the synapse of serotonergic neurons is also under the control of those autoreceptors, and acute blockade of these receptors could result in enhanced extracellular 5-HT levels and, hence, antidepressant activity. These autoreceptors were thought to be 5-HT1B receptor subtype and the introduction of selective 5-HT1B receptor antagonist confirmed this in both rodent and human brain $(27,28)$. The 5 HT1B and 5-HT1D autoreceptors are found to be present in dorsal raphe nucleus (DRN) and can modulate 5-HT levels within this brain region $(29,30)$.

Regarding the link of 5-HT2A receptor to depression, recent experiments have shown that these receptors may mediate some of the antidepressant effects seen in putative animal models of anxiety and depression (31). In time of stress, more 5-HT is needed to cope with demands and upregulation of 5-HT2 receptors is a compensatory response to maintain 5-HT turnover. Ultimately, however, 5-HT turnover dysfunction occurs and major depression will develop, in the longer term followed by melancholia (2). The newer antidepressants are developed to modify the serotonergic system such as selective serotonin reuptake inhibitors, serotonin and noradrenalin reuptake inhibitors, 5-HT2 receptor antagonists and 5-HT1A receptor partial agonists and are reported to be effective in treatment of depression (32). Taken together, it is clear that the interaction between brain 5-HT level and the activity of its autoreceptors plays a role in mood changes and depression.

\section{Cytokines and depression}

The cytokines are a diverse group of proteins that may be regarded as the hormones of the immune system. The interaction among the pro-inflammatory cytokines (IL1 $\beta$, IL6, IL8, TNF $\alpha$ ) can result in synergistic activities in both cytokine production and cytokine activities. Pro-inflammatory cytokine interactions are also associated with a synergistic induction of neurological and psychiatric manifestations (33). Another category of cytokines known as anti-inflammatory cytokines (IL1Ra, IL4, IL10, TGF $\beta 1$ ) can antagonize the actions of pro-inflammatory cytokines. There are two components of cytokine balance. The first is the balance within a cytokine system like IL1 increases the synthesis and secretion of IL1Ra, the up-regulation of which is proposed to attenuate the deleterious effect of IL1 by blocking the IL1 receptor (34). The second is the balance among different cytokine systems like TGF $\beta 1$ inhibits IL1 and TNF $\alpha$ activities (35).

Most of the cytokines can be synthesized and released within the nervous system (36). Although most cytokines in the brain are secreted by astrocytes and microglia, 
some evidence suggests that under certain conditions, neurons can also produce cytokines (37). Within the brain, IL1 has been found in several brain regions including the hippocampus and specific hypothalamic structures such as the paraventricular nucleus and arcuate nucleus. IL1 immunoreactive nerve fibres have also been described in the human brain, particularly in the hypothalamus (38). Widespread TNF and other cytokine immunoreactivity have been detected in the murine brain (39). Human astroglial cell line stimulated by IL1 has been shown to produce colony stimulating factor, TNF $\alpha$, additional IL1, and IL6 $(40,41)$.

There is a growing body of circumstantial evidences that suggests that major depression is associated with dysregulation of immune mediators such as rise in IL1 $\beta$, IL6, soluble IL6R, IL2, and soluble IL2R $(42,43)$. The increased IL1Ra level was also reported in patients with major depression (44). It was proven that the antidepressants can decrease the IFN $\gamma /$ IL10 ratio which might be partly due to increase in antiinflammatory cytokine, IL10 (45). It has been hypothesized that cytokine hypersecretion may be involved in the pathophysiology of depressive disorders (46). In addition, a proinflammatory cytokine, IL12 is found to be suppressed by antidepressive drugs (12). Moreover, recent animal and human studies have shown that the psychological stressor such as immobilization, open field, speech task and academic exam can elicit an activation of inflammatory response system $(5,8,9,47)$. In integrative term, a balance between pro-inflammatory cytokines and anti-inflammatory cytokines plays a role in appropriate modulation of cellular responses in the brain in psychological stress and depression.

\section{Cytokine-Serotonin interaction in depression}

Recently, pro-inflammatory cytokines have been found to have profound effects on the metabolism of brain serotonin, dopamine and noradrenalin in mice and rats (48). In clinical studies, significant decrease in serum tryptophan concentration has been noted in patients receiving IL2 or IFN $\alpha(49,50)$. There are two major mechanisms involved in cytokine-induced tryptophan depletion. The first mechanism is that cytokine may induce TRP depletion directly by reducing food intake $(33,51)$, since TRP levels are strongly modulated by dietary intake (52). The second mechanism is that cytokines induce TRP depletion by enhancing the activity of indoleamine 2,3-dioxygenase (IDO), the first enzyme in the kynurenine pathway, that degrades and converts TRP to kynurenine $(53,54)$. IDO is the enzyme active not only on L-tryptophan but also on Land L-5-hydroxytryptophan, 5-HT, and melatonin (55) and is widely distributed in the intestinal tissues, lungs, placenta and the brain. It was observed that IFN $\gamma$, TNF $\alpha$, IL1 and IL2 can enhance IDO activity (56-60).

The Kynurenine is again metabolized into kynurenic acid, quinolinic acid and anthranilic acid (Fig-1) by kynurenine aminotransferase, kynurenine 3-monooxygenase (kynurenine 3-hydroxylase) and kynureninase, respectively (61). Both kynurenine 3monooxygenase and kynureninase are also shown to be activated by IFN $\gamma$ and TNF $\alpha$ (62). The anthranilic acid is again metabolized into quinolinic acid, the excitotoxic NMDA receptor agonist (22) whereas kynurenic acid is the antagonist of all three ionotropic excitatory amino acid receptors (23). These products are the results of cytokine-serotonin interaction through IDO enzyme that plays a pivotal role in tryptophan depletion in depression. 


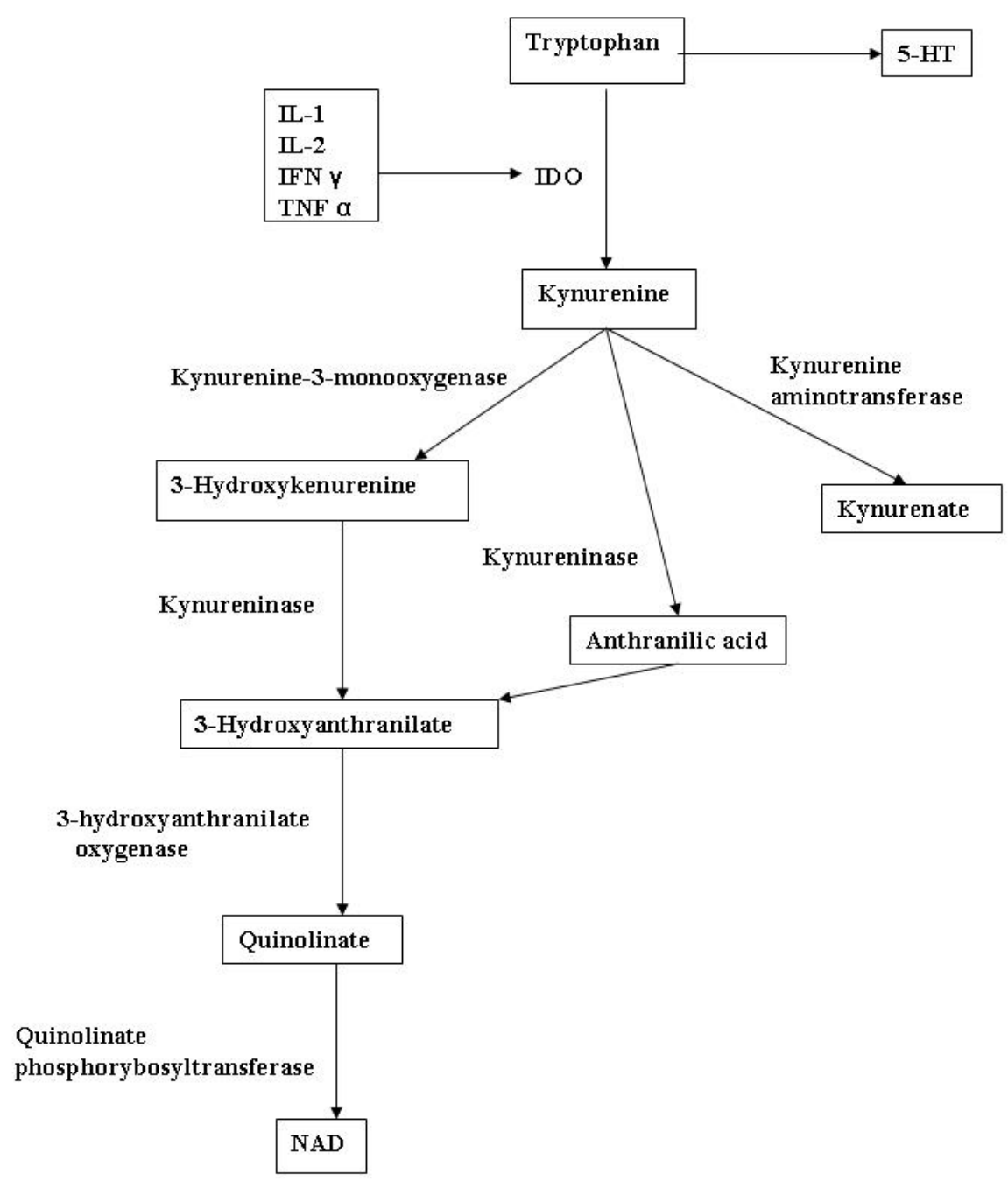

Figure 1—Figure showing the cytokine-serotonin interaction through IDO 


\section{Neurodegeneration hypothesis of depression}

Major depression is a recurrent illness, the interval between episodes tends to shorten while with each new episode there is an increasing risk for the occurrence of another (63). It is reported that the onset, recurrence and remission depend on childhood adversity (64). It is also reported that depression is common in old age and especially among those in nursing home (65), and is common in those with chronic medical illness like coronary heart disease and diabetes (66), Parkinson's disease (67), stroke (68) and cancer (69). Taken all above findings together, the depression is associated with aging, medical illness and chronic stress.

As it is mentioned, the cytokine-serotonin interaction through the enzyme IDO that results in tryptophan depletion into kynurenine pathway plays an important role in pathophysiology of depression. Chronic psychological stress or medical illness can result in rise of pro-inflammatory cytokines and than in tryptophan depletion and lead to depression in the end. A question is raised why some people who had undergone chronic psychological or physical stress could cope with that situation, and it brings the following neurodegeneration hypothesis (Figure-2).

Figure-2 Neurodegeneration hypothesis of depression

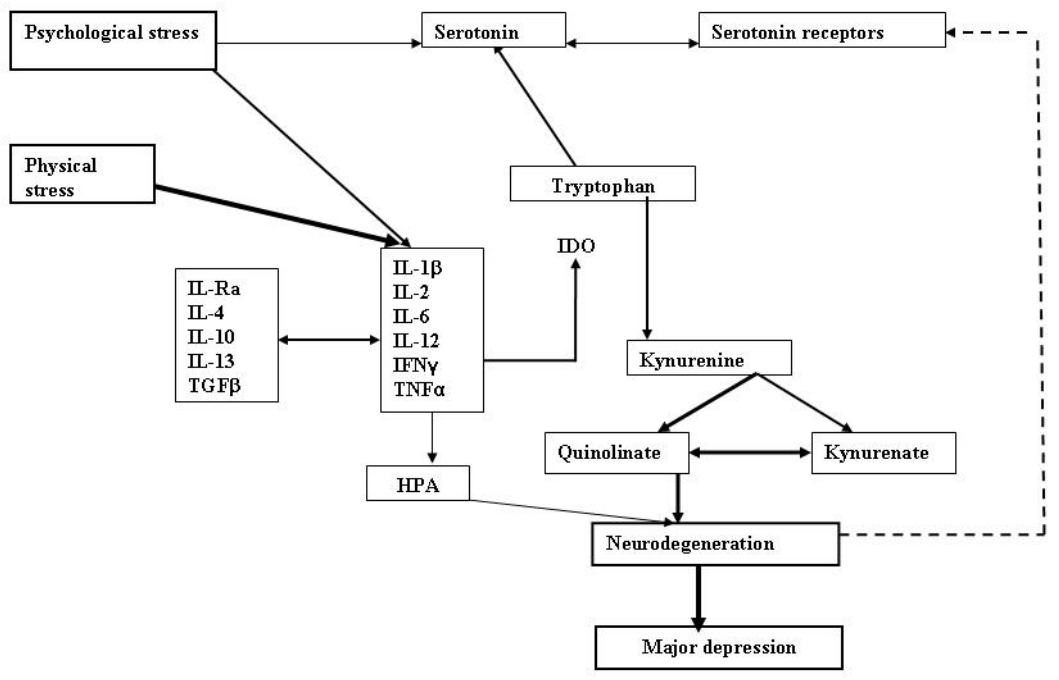

The psychological stress induces tryptophan depletion by increasing in demand and mood changes develop. It was balanced by modification of serotonin synthesis and expression of different serotonin receptors. This is the first point how people cope with psychological stress. When the psychological stress continues over a period of time, the 
increase of pro-inflammatory cytokines occurs. In case of physical stress or medical illness also, the pro-inflammatory cytokines increase. The adverse effects of proinflammatory cytokines will be balanced by increase production of anti-inflammatory cytokines. The sickness behaviour will develop due to pro-inflammatory cytokines and it will relieve due to the second coping strategy, the balance between pro-inflammatory cytokines and anti-inflammatory cytokines. Because of these pro-inflammatory cytokines, IDO enzyme is activated and further tryptophan depletion through kynurenine pathway occurs. As a result of this pathway, neurodegenerative quinolinate and neuroprotective kynurenate are produced in the brain. Here is the third and important coping strategy, the challenge between neurodegeneration and neuroprotection. Normally, neurodegeneration process will be more pronounced to a certain extent and thus aging in terms of brain function occurs with age and degree of exposure to stress. If the balance between pro- and anti-inflammatory cytokines disturbed or stress continues further, the tryptophan degradation through kynurenine pathway becomes more pronounced and the neurodegeneration-neuroprotection challenge becomes extensive. When this challenge shifts to degenerative side, pronounced neurodegeneration of areas of brain involved in neuroendocrinology of stress and memory such as hippocampus occurs. This neurodegeneration may also occur in other areas related to stress coping mechanism. Finally, the neurodegeneration disturbs all the coping strategies in the brain and result in major depression or treatment resistant depression. The neurodegeneration process will be reinforced by the neurotoxic effect of high cortisone level during stress $(70,71)$.

This neurodegeneration hypothesis is supported by the findings of Bremner and group $(72)$ and Sheline and co-workers $(73,74)$ which stated the atrophy of hippocampus in major depression that increases with longer duration of depression. It is also supported by the findings that adult neurogenesis occurs in brain structures that exhibit a high degree of neural plasticity such as hippocampus and olfactory bulb $(75,76)$ and olfactory bulbectomised rats show typical behavioural and biochemical changes in human depression (77).

This hypothesis can explain how people cope with different stress at different stages according to severity and duration of stress and why major depression develops.

\section{Future Research Direction}

It is still necessary to confirm the neurodegeneration in major depression with stronger evidences. The factors influencing the biochemical pathway of tryptophan depletion are also necessary to be explored in more detailed. Moreover, the role of cytokine-serotonin interaction in other related psychiatric disorders is also an area to be explored in the future.

\section{References}

1. Maes M, Meltzer H.Y. The serotonin hypothesis of major depression. In F.E. Bloom \& D.J. Kupfer (eds.) Psychopharmacology: The fourth generation of progress: New York; Raven Press, pp 933-944, 1995.

2. Stokes PE. The potential role of excessive cortisol induced by HPA hyperfunction in the pathogenesis of depression. Eur Neuropsychopharmacol 1995;5 Suppl:77-82.

3. Young SN, Smith SE, Pihl RO, Ervin FR. Tryptophan depletion causes a rapid lowering of mood in normal males. Psychopharmacology (Berl) 1985;87(2):173-177. 
4. Raju TN. The Nobel chronicles. 1927: Julius Wagner-Jauregg (1857-1940). Lancet 1998;352(9141):1714.

5. Maes M. Psychological stress and the inflammatory response system. Clin Sci (Lond) 2001;101(2):193194.

6. Connor TJ, Leonard BE. Depression, stress and immunological activation: the role of cytokines in depressive disorders. Life Sci 1998;62(7):583-606.

7. Song C, Kenis G, van Gastel A, Bosmans E, Lin A, de Jong R, et al. Influence of psychological stress on immune-inflammatory variables in normal humans. Part II. Altered serum concentrations of natural antiinflammatory agents and soluble membrane antigens of monocytes and T lymphocytes. Psychiatry Res 1999;85(3):293-303.

8. Kim YK, Maes, M. The role of cytokine network in psychological stress. Acta Neuropsychiatrica 2002 (in press).

9. Maes M. Major depression and activation of the inflammatory response system. Adv Exp Med Biol 1999;461:25-46.

10. Leonard BE. Changes in the immune system in depression and dementia: causal or co-incidental effects? Int J Dev Neurosci 2001;19(3):305-312.

11. Licinio J, Wong ML. The role of inflammatory mediators in the biology of major depression: central nervous system cytokines modulate the biological substrate of depressive symptoms, regulate stressresponsive systems, and contribute to neurotoxicity and neuroprotection. Mol Psychiatry 1999;4(4):317327.

12. Kim YK, Suh, I.B., Han, C.S., Lim, C.S., Choi, S.H., Licinio, J. The plasma levels of interleukin-12 in schizophrenia, major depression, and bipolar mania: effects of psychotropic drugs. Mol Psychiatry 2002 (in press).

13. Minami M, Kuraishi Y, Yamaguchi T, Nakai S, Hirai Y, Satoh M. Immobilization stress induces interleukin-1 beta mRNA in the rat hypothalamus. Neurosci Lett 1991;123(2):254-256.

14. Khlusov IA, Dygai AM, Gol'dberg ED. [The adrenergic regulation of interleukin production by bone marrow cells during immobilization stress]. Biull Eksp Biol Med 1993;116(12):570-572.

15. Shintani F, Nakaki T, Kanba S, Kato R, Asai M. Role of interleukin-1 in stress responses. A putative neurotransmitter. Mol Neurobiol 1995;10(1):47-71.

16. Persoons JH, Schornagel K, Breve J, Berkenbosch F, Kraal G. Acute stress affects cytokines and nitric oxide production by alveolar macrophages differently. Am J Respir Crit Care Med 1995;152(2):619-624.

17. Zhou D, Kusnecov AW, Shurin MR, DePaoli M, Rabin BS. Exposure to physical and psychological stressors elevates plasma interleukin 6: relationship to the activation of hypothalamic-pituitary-adrenal axis. Endocrinology 1993;133(6):2523-2530.

18. Shizuya K, Komori T, Fujiwara R, Miyahara S, Ohmori M, Nomura J. The influence of restraint stress on the expression of mRNAs for IL6 and the IL6 receptor in the hypothalamus and midbrain of the rat. Life Sci 1997;61(10):PL 135-140.

19. Guillemin GJ, Kerr SJ, Pemberton LA, Smith DG, Smythe GA, Armati PJ, et al. IFN-betalb induces kynurenine pathway metabolism in human macrophages: potential implications for multiple sclerosis treatment. J Interferon Cytokine Res 2001;21(12):1097-1101.

20. Sakash JB, Byrne GI, Lichtman A, Libby P. Cytokines induce indoleamine 2,3-dioxygenase expression in human atheroma-asociated cells: implications for persistent Chlamydophila pneumoniae infection. Infect Immun 2002;70(7):3959-3961.

21. Dang Y, Dale WE, Brown OR. Comparative effects of oxygen on indoleamine 2,3-dioxygenase and tryptophan 2,3-dioxygenase of the kynurenine pathway. Free Radic Biol Med 2000;28(4):615-624.

22. Schwarcz R, Whetsell WO, Jr., Mangano RM. Quinolinic acid: an endogenous metabolite that produces axon-sparing lesions in rat brain. Science 1983;219(4582):316-318.

23. Perkins MN, Stone TW. An iontophoretic investigation of the actions of convulsant kynurenines and their interaction with the endogenous excitant quinolinic acid. Brain Res 1982;247(1):184-187.

24. Coppen A. The biochemistry of affective disorders. Br J Psychiatry 1967;113(504):1237-1264.

25. Anderson IM, Parry-Billings M, Newsholme EA, Poortmans JR, Cowen PJ. Decreased plasma tryptophan concentration in major depression: relationship to melancholia and weight loss. J Affect Disord 1990;20(3):185-191.

26. Shopsin B. Enhancement of the antidepressant response to L-tryptophan by a liver pyrrolase inhibitor: a rational treatment approach. Neuropsychobiology 1978;4(3):188-192.

27. Selkirk JV, Scott C, Ho M, Burton MJ, Watson J, Gaster LM, et al. SB-224289—a novel selective (human) 5-HT1B receptor antagonist with negative intrinsic activity. Br J Pharmacol 1998;125(1):202208. 
28. Middlemiss DN, Gothert M, Schlicker E, Scott CM, Selkirk JV, Watson J, et al. SB-236057, a selective 5-HT1B receptor inverse agonist, blocks the 5-HT human terminal autoreceptor. Eur J Pharmacol 1999;375(1-3):359-365.

29. Stamford JA, Davidson C, McLaughlin DP, Hopwood SE. Control of dorsal raphe 5-HT function by multiple 5-HT(1) autoreceptors: parallel purposes or pointless plurality? Trends Neurosci 2000;23(10):459-465.

30. Roberts C, Price GW. Interaction of serotonin autoreceptor antagonists in the rat dorsal raphe nucleus: an in vitro fast cyclic voltammetry study. Neurosci Lett 2001;300(1):45-48.

31. Skrebuhhova T, Allikmets L, Matto V. Effects of anxiogenic drugs in rat forced swimming test. Methods Find Exp Clin Pharmacol 1999;21(3):173-178.

32. Williams JW, Jr., Mulrow CD, Chiquette E, Noel PH, Aguilar C, Cornell J. A systematic review of newer pharmacotherapies for depression in adults: evidence report summary. Ann Intern Med 2000;132(9):743-756.

33. Plata-Salaman CR. Cytokine-induced anorexia. Behavioral, cellular, and molecular mechanisms. Ann N Y Acad Sci 1998;856:160-170.

34. Dinarello CA. Biologic basis for interleukin-1 in disease. Blood 1996;87(6):2095-2147.

35. Plata-Salaman CR, Ilyin SE. Interleukin-1beta (IL1beta)-induced modulation of the hypothalamic IL1beta system, tumor necrosis factor-alpha, and transforming growth factor-beta1 mRNAs in obese $(\mathrm{fa} / \mathrm{fa})$ and lean $(\mathrm{Fa} / \mathrm{Fa})$ Zucker rats: implications to ILlbeta feedback systems and cytokine-cytokine interactions. J Neurosci Res 1997;49(5):541-550.

36. Kronfol Z, Remick DG. Cytokines and the brain: implications for clinical psychiatry. Am J Psychiatry 2000;157(5):683-694.

37. Freidin M, Bennett MV, Kessler JA. Cultured sympathetic neurons synthesize and release the cytokine interleukin 1 beta. Proc Natl Acad Sci U S A 1992;89(21):10440-10443.

38. Breder CD, Dinarello CA, Saper CB. Interleukin-1 immunoreactive innervation of the human hypothalamus. Science 1988;240(4850):321-324.

39. Breder CD, Tsujimoto M, Terano Y, Scott DW, Saper CB. Distribution and characterization of tumor necrosis factor-alpha-like immunoreactivity in the murine central nervous system. J Comp Neurol 1993;337(4):543-567.

40. Bethea JR, Chung IY, Sparacio SM, Gillespie GY, Benveniste EN. Interleukin-1 beta induction of tumor necrosis factor-alpha gene expression in human astroglioma cells. J Neuroimmunol 1992;36(2-3):179191.

41. Tweardy DJ, Mott PL, Glazer EW. Monokine modulation of human astroglial cell production of granulocyte colony-stimulating factor and granulocyte-macrophage colony-stimulating factor. I. Effects of IL1 alpha and IL-beta. J Immunol 1990;144(6):2233-2241.

42. Maes M, Bosmans E, Meltzer HY, Scharpe S, Suy E. Interleukin-1 beta: a putative mediator of HPA axis hyperactivity in major depression? Am J Psychiatry 1993;150(8):1189-1193.

43. Sluzewska A, Rybakowski J, Bosmans E, Sobieska M, Berghmans R, Maes M, et al. Indicators of immune activation in major depression. Psychiatry Res 1996;64(3):161-167.

44. Maes M, Bosmans E, De Jongh R, Kenis G, Vandoolaeghe E, Neels H. Increased serum IL6 and IL1 receptor antagonist concentrations in major depression and treatment resistant depression. Cytokine 1997;9(11):853-858

45. Kubera M, Lin AH, Kenis G, Bosmans E, van Bockstaele D, Maes M. Anti-Inflammatory effects of antidepressants through suppression of the interferon-gamma/interleukin-10 production ratio. J Clin Psychopharmacol 2001;21(2):199-206.

46. Leonard BE. The immune system, depression and the action of antidepressants. Prog Neuropsychopharmacol Biol Psychiatry 2001;25(4):767-780.

47. Leonard BE, Song C. Stress, depression, and the role of cytokines. Adv Exp Med Biol 1999;461:251-265.

48. Dunn AJ, Wang J, Ando T. Effects of cytokines on cerebral neurotransmission. Comparison with the effects of stress. Adv Exp Med Biol 1999;461:117-127.

49. Brown RR, Ozaki Y, Datta SP, Borden EC, Sondel PM, Malone DG. Implications of interferon-induced tryptophan catabolism in cancer, auto-immune diseases and AIDS. Adv Exp Med Biol 1991;294:425435.

50. Brown RR, Lee CM, Kohler PC, Hank JA, Storer BE, Sondel PM. Altered tryptophan and neopterin metabolism in cancer patients treated with recombinant interleukin 2. Cancer Res 1989;49(17):49414944.

51. Reichenberg A, Yirmiya R, Schuld A, Kraus T, Haack M, Morag A, et al. Cytokine-associated emotional and cognitive disturbances in humans. Arch Gen Psychiatry 2001;58(5):445-452.

52. Smith KA, Fairburn CG, Cowen PJ. Relapse of depression after rapid depletion of tryptophan. Lancet 1997;349(9056):915-919. 
53. Heyes MP, Saito K, Markey SP. Human macrophages convert L-tryptophan into the neurotoxin quinolinic acid. Biochem J 1992;283 ( Pt 3):633-635.

54. Mellor AL, Munn DH. Tryptophan catabolism and T-cell tolerance: immunosuppression by starvation? Immunol Today 1999;20(10):469-473.

55. Hirata F, Hayaishi O. Possible participation of superoxide anion in the intestinal tryptophan 2,3dioxygenase reaction. J Biol Chem 1971;246(24):7825-7826.

56. Babcock TA, Carlin JM. Transcriptional activation of indoleamine dioxygenase by interleukin 1 and tumor necrosis factor alpha in interferon-treated epithelial cells. Cytokine 2000;12(6):588-594

57. Currier AR, Ziegler MH, Riley MM, Babcock TA, Telbis VP, Carlin JM. Tumor necrosis factor-alpha and lipopolysaccharide enhance interferon-induced antichlamydial indoleamine dioxygenase activity independently. J Interferon Cytokine Res 2000;20(4):369-376.

58. Daubener W, MacKenzie CR. IFN-gamma activated indoleamine 2,3-dioxygenase activity in human cells is an antiparasitic and an antibacterial effector mechanism. Adv Exp Med Biol 1999;467:517-524.

59. $\mathrm{Hu} \mathrm{B}$, Hissong $\mathrm{BD}$, Carlin JM. Interleukin-1 enhances indoleamine 2,3-dioxygenase activity by increasing specific mRNA expression in human mononuclear phagocytes. J Interferon Cytokine Res 1995;15(7):617-624.

60. Carlin JM, Borden EC, Sondel PM, Byrne GI. Interferon-induced indoleamine 2,3-dioxygenase activity in human mononuclear phagocytes. J Leukoc Biol 1989;45(1):29-34.

61. Bender DA. The kynurenine pathway of tryptophan metabolism. In Quinolinic acid and kynurenines. Edited by T.W, Stones, CRC Press. Boca Raton, FL, pp3-38. 1989.

62. Chiarugi A, Calvani M, Meli E, Traggiai E, Moroni F. Synthesis and release of neurotoxic kynurenine metabolites by human monocyte-derived macrophages. J Neuroimmunol 2001;120(1-2):190-198.

63. Kasper S. The rationale for long-term antidepressant therapy. Int Clin Psychopharmacol 1993;8(4):225235.

64. Gilman S, Kawachi I, Fitzmaurice G, Buka S. Childhood adversity and the onset, recurrence, and remission of major depression. Ann Epidemiol 2002;12(7):506.

65. Datto CJ, Oslin DW, Streim JE, Scheinthal SM, DiFilippo S, Katz IR. Pharmacologic treatment of depression in nursing home residents: a mental health services perspective. J Geriatr Psychiatry Neurol 2002;15(3):141-146.

66. Kinder LS, Kamarck TW, Baum A, Orchard TJ. Depressive symptomatology and coronary heart disease in Type I diabetes mellitus: a study of possible mechanisms. Health Psychol 2002;21(6):542-552.

67. Edwards E, Kitt C, Oliver E, Finkelstein J, Wagster M, McDonald WM. Depression and Parkinson's disease: a new look at an old problem. Depress Anxiety 2002;16(1):39-48.

68. Whyte EM, Mulsant BH. Post stroke depression: epidemiology, pathophysiology, and biological treatment. Biol Psychiatry 2002;52(3):253-264.

69. Stommel M, Given BA, Given CW. Depression and functional status as predictors of death among cancer patients. Cancer 2002;94(10):2719-2727.

70. Watanabe Y, Gould E, McEwen BS. Stress induces atrophy of apical dendrites of hippocampal CA3 pyramidal neurons. Brain Res 1992;588(2):341-345.

71. Luine VN. Steroid hormone influences on spatial memory. Ann N Y Acad Sci 1994;743:201-211.

72. Bremner JD, Narayan M, Anderson ER, Staib LH, Miller HL, Charney DS. Hippocampal volume reduction in major depression. Am J Psychiatry 2000;157(1):115-118.

73. Sheline YI. Hippocampal atrophy in major depression: a result of depression-induced neurotoxicity? Mol Psychiatry 1996;1(4):298-299.

74. Sheline YI, Sanghavi M, Mintun MA, Gado MH. Depression duration but not age predicts hippocampal volume loss in medically healthy women with recurrent major depression. J Neurosci 1999;19(12):50345043 .

75. Altman J. Autoradiographic and histological studies of postnatal neurogenesis. 3. Dating the time of production and onset of differentiation of cerebellar microneurons in rats. $\mathrm{J}$ Comp Neurol 1969;136(3):269-293.

76. Eriksson PS, Perfilieva E, Bjork-Eriksson T, Alborn AM, Nordborg C, Peterson DA, et al. Neurogenesis in the adult human hippocampus. Nat Med 1998;4(11):1313-1317.

77. Kelly JP, Wrynn AS, Leonard BE. The olfactory bulbectomized rat as a model of depression: an update. Pharmacol Ther 1997;74(3):299-316. 


\begin{abstract}
Aim of the thesis
The general aim of this thesis is to find out whether our proposed hypothesis is true as part of the pathophysiological mechanisms of both experimental and clinical major depression. The specific objectives of this thesis are: to investigate the imbalance between pro- and anti- inflammatory cytokines in patients with major depression, to investigate the association between peripheral cytokine changes and central cytokine changes and depressive behaviour in rats and role of SSRI antidepressant, to investigate the association between peripheral cytokine and central inflammatory related morphological changes in rats and role of SSRI antidepressant, to investigate the role of antiinflammatory agent on peripheral and central cytokine changes and behaviour in animal model of depression, and to investigate the kynurenine pathway metabolites changes in major depression.
\end{abstract}

\title{
Outline of the thesis
}

The second part of the first chapter explained how the stress induced immune changes are related to brain amine changes that can induce acute depressive mood and how these immune changes can induce neuroprotection-neurodegeneration imbalance through kynurenine metabolism that can bring long term, chronic or treatment resistant depression. In Chapter 2, we investigated the pro- and anti-inflammatory cytokine imbalance in clinical major depression. In Chapter 3, we discussed on our findings on the relationship between a pro-inflammatory cytokine IFN $\alpha$ induced peripheral and the central proand anti-inflammatory cytokines changes and behavioural changes in the rats and the preventive role of SSRI antidepressant, paroxetine. In Chapter 4, we mentioned about the peripheral IFN $\alpha$ induced brain inflammatory cells, astrocytes and microglia changes in the hippocampus of the rats and the preventive role of SSRI antidepressant fluoxetine. In Chapter 5, the results of the study on role of anti-inflammatory COX2 inhibitor celecoxib on immune and behavioural changes in OBX rat model of depression. The Chapter 6 is related to the findings that prove our hypothesis regarding the neuroprotection-neurodegeneration imbalance through kynurenine pathway in major depression.

In Chapter 7 we reviewed the inflammatory related changes in major depression and their relationship with inflammatory related changes in dementia. And the general discussion and future perspectives based on our findings were mentioned in the last chapter. 


\section{Chapter 2}

\section{Th1, Th2, and Th3 cytokine alterations in major depression}

Aye Mu Myint, Brian E Leonard, Harry WM Steinbusch, Yong Ku Kim

$J$ Affect Disord. 2005;88(2):167-73. 


\begin{abstract}
Background: Many studies have shown that the balance between Th1 cytokines and Th2 cytokines plays a role in modulation of cellular responses in the brain during psychological stress and psychiatric disorders. The Th3 cytokine, transforming growth factor beta-1 (TGF $\beta 1$ ), has been shown to regulate the balance between Th1 and Th2 cytokines. However, the role of TGF $\beta 1$ in the psychoimmunology of depression has never been explored.

Methods: A total of 40 depressed patients and 80 normal controls were recruited. The plasma levels of IFN $\gamma$, IL4, and TGF $\beta 1$ were studied at the time of admission and 8 weeks after antidepressant treatment.

Results: The proportion of patients who showed immunoreactivity to IFN $\gamma$ and IL4 in the plasma, and the plasma IFN $\gamma$ /IL4 ratio, were significantly higher in depressed patients than in controls. The IFN $\gamma / \mathrm{TGF} \beta 1$ ratio was also higher in depressed patients, and TGF $\beta 1$ levels showed a significant negative correlation with the HDRS depression scale. After treatment, TGF $\beta 1$ level increased significantly, and the IFN $\gamma /$ IL4 4 ratio decreased significantly, in the patient group. However, Th1 changes in male and female showed different trend such as Th1 arm was decreased after the treatment in all male whereas it was increased in premenopausal age women.

Limitations: Replication and extension using a larger sample size are required.

Conclusions: The Th1 and Th2 cytokine imbalance was observed in subpopulation of depressed patients. TGF $\beta 1$ seemed to play a role in the pathophysiology of depression in this population. Moreover, antidepressant treatment was found to affect the Th1/Th2 balance through the action of TGF $\beta 1$.
\end{abstract}




\section{Introduction}

The relationship between endogenous psychoses and $\mathrm{T}$ and $\mathrm{B}$ lymphocytes was first observed by a group of Russian clinicians in 1980 (1). Since then, many studies have focused on lymphocyte activities and psychiatric disorders (2-5), the change in cytokines in psychiatric disorders (6-10) and the presence of cytokines in the brain (11). Based on the macrophage theory of depression (12), circumstantial evidence was provided that major depression is associated with dysregulation of immune mediators, such as the rise in IL1 $\beta$, IL6, IL12, soluble IL6R, IL2, soluble IL2R, IL1Ra and IFN $\gamma$ (13-19). These changes have been considered in terms of the imbalance between individual pro- and anti-inflammatory cytokines and the Th1 and Th2 imbalance in major depression. It was observed that antidepressants can decrease the IFN $\gamma /$ IL10 ratio, partly due to an increase in the anti-inflammatory cytokine, IL10 (20). IFN $\gamma$ is produced mainly by T-helper type 1 (Th1) cells and NK cells (21), and IL10 is produced mainly by Th2 cells (22). Taken together, many studies suggest that an imbalance between Th1 cytokines and Th2 cytokines or pro-inflammatory and anti-inflammatory cytokines plays a role in the appropriate modulation of cellular response in the brain during psychological stress and psychiatric disorders (23-26).

Recently, it was proposed that there are populations of regulatory $\mathrm{T}$ cells, some designated Th3, that exert their action primarily by secreting transforming growth factor beta-1 (TGF $\beta 1$ ). In the past, role of this cytokine in immune tolerance was largely discussed in oral tolerance (27). The action of this cytokine was shown to suppress production of Th1 cytokines, such as interferon- $\gamma$ (IFN $\gamma$ ), tumour necrosis factor- $\alpha$ $(\mathrm{TNF} \alpha)$, IL2, and IL2R and was found in the eyes, placenta, testis, central nervous system and adrenal cortex $(28,29)$. Even though the major role of TGF $\beta 1$ was discussed in terms of oral tolerance, since it was also found in central nervous system and adrenal cortex, another possible role for this cytokine in maintaining the Th1 and Th2 balance in depression. However, the role of TGF $\beta 1$ in relation to the psychoimmunology of depression has never been explored.

In this study, we explored the role of 3 cytokines, IFN $\gamma$, IL4, and TGF $\beta 1$, which represent the cytokines of the Th1, Th2, and Th3 types, in major depression. Cytokine levels were measured at the time of admission and 8 weeks after effective antidepressant treatment. Our results suggested that the Th3 cytokine, TGF $\beta 1$ certainly have a role in psychoimmunology of depression.

\section{Subjects and Methods}

\section{Subjects}

Among psychiatric patients admitted to the Psychiatry Department, Korea University Medical Centre, from August 1999 to September 2002, 40 patients with major depression who met the Diagnostic and Statistical Manual (DSM-IV) criteria (30) based on clinical interviews using a Structured Clinical Interview for DSM-IV (31) were recruited. All patients were either medication-naïve (first-onset) or medication-free for at least 4 months. This study was approved by the institutional ethical committee of Korea University. 
The psychopathological status of the patients was assessed by a trained physician (Y-K Kim) using the Brief Psychiatric Rating Scale (BPRS) (32) and the Hamilton Depression Rating Scale (HDRS) (33) on admission and 8 weeks later.

Twenty-two of 40 patients completed the 8-week study. Among them, 8 were treated with paroxetine (mean, $33.7 \mathrm{mg}$; range, 20-40 mg), 6 with fluoxetine (mean, $36.6 \mathrm{mg}$; range, 20-60 mg), 5 with nefazodone (mean, $390 \mathrm{mg}$; range, 200-600 mg), and 3 with venlafaxine (mean, $175 \mathrm{mg}$; range, 150-225 mg). Six patients were also given an antipsychotic medication (risperidone or olanzapine) for controlling psychotic symptoms.

Patients who had history of any concomitant psychiatric illness, such as substance or alcohol abuse, or history of infection or known autoimmune disease were excluded. Patients were found to have a normal blood and urine tests, be free from venereal diseases and have normal electrocardiogram (ECG) and electroencephalogram (EEG). The laboratory tests were rechecked after 8 weeks.

Eighty healthy age and sex matched controls (1 patient: 2 controls) were recruited among healthy individuals who visited the same hospital for regular health screening during the same period. Those with any history of psychiatric illness, diagnosed autoimmune disease, or substance or alcohol abuse were excluded. All subjects were free from any physical illness within the 2 weeks before the study. They showed normal laboratory findings in blood chemistry, renal, thyroid and liver function, VDRL tests, chest X-ray, ECG, and EEG.

\section{Methods}

Fasting venous blood $(10 \mathrm{ml})$ was withdrawn with a lithium heparin vacuum tube between 8:00-9:00 A.M. Plasma was separated immediately and stored at $-70^{\circ} \mathrm{C}$. For the depressed patients, blood was sampled again at 8 weeks later.

Human cytokines IL4, IFN $\gamma$, and TGF $\beta 1$ were assayed using DuoSet ELISA Development System (R\&D Systems, UK). All assays were carried out in duplicate by the same operator using the recommended buffers, diluents, and substrates. The IFN- $\gamma$ ELISA was established with a detection range from $2 \mathrm{pg} / \mathrm{ml}$ to $500 \mathrm{pg} / \mathrm{ml}$, and the intraand inter-assay coefficients of variation were $6.7 \%$ and $9.2 \%$, respectively. The IL4 ELISA was established with a detection range from $3.0 \mathrm{pg} / \mathrm{ml}$ to $1000 \mathrm{pg} / \mathrm{ml}$, and the intra- and inter-assay coefficients of variation were $5.6 \%$ and $7.08 \%$, respectively. The TGF $\beta 1$ ELISA was established with a detection range from $50 \mathrm{pg} / \mathrm{ml}$ to $2500 \mathrm{pg} / \mathrm{ml}$. This assay was performed on plasma samples activated with acidic solution since TGF $\beta 1$ is secreted mainly in latent forms (34). The intra- and inter-assay coefficients of variation were $5.3 \%$ and $9.8 \%$, respectively. The cytokine assays were carried out in Cellular Neuroscience Division, Psychiatry and Neuropsychology Department, Faculty of Medicine, University of Maastricht.

\section{Statistical analysis}

The comparisons of demographic data, percent of subjects with cytokine immunoreactivity in plasma, and TGF $\beta 1$ values between normal control and patient group were done using Student's t-test and Chi-square test. The IFN $\gamma$, IL4 values and Th1/Th2 and Th1/Th3 ratios between the patients and control and between the patient groups before and after treatment were compared by non-parametric statistics. Pearson's product 
moment correlation coefficients were calculated to examine the relationships between the cytokine levels and clinical variables. The null hypothesis was rejected at $\mathrm{P}<0.05$.

\section{Results}

\section{Demographic data}

Table 1. Demographic data of the study subjects

\begin{tabular}{|c|c|c|}
\hline & Major depression $(n=40)$ & Normal controls $(n=80)$ \\
\hline Sex (male/female) & $13 / 27$ & $26 / 54$ \\
\hline Age (years) & $\begin{array}{c}40.7 \pm 15.5 \\
(17-65)\end{array}$ & $\begin{array}{c}40.3 \pm 13.1 \\
(17-64)\end{array}$ \\
\hline $\operatorname{BMI}\left(\mathrm{kg} / \mathrm{m}^{2}\right)$ & $21.4 \pm 2.5$ & $22.0 \pm 2.7$ \\
\hline Age of onset (years) & $\begin{array}{c}38.9 \pm 17.0 \\
(17-54)\end{array}$ & \\
\hline Duration of total illness (months) & $\begin{array}{c}22.1 \pm 33.6 \\
(1-144)\end{array}$ & \\
\hline Duration of current episode (months) & $\begin{array}{c}1.9 \pm 1.2 \\
(1-4)\end{array}$ & \\
\hline Numbers of previous admission (n) & $\begin{array}{c}0.5 \pm 1.0 \\
(0-4)\end{array}$ & \\
\hline Numbers of episodes (n) & $1.5 \pm 1.1(1-7)$ & \\
\hline Family history (yes/no) & $5 / 35$ & \\
\hline \multicolumn{3}{|l|}{ Medication status on admission: } \\
\hline Medication-naïve & 19 & \\
\hline Medication-free & 21 & \\
\hline \multicolumn{3}{|l|}{ Subtypes: } \\
\hline melancholic & 25 & \\
\hline Atypical & 9 & \\
\hline psychotic & 6 & \\
\hline \multicolumn{3}{|l|}{ Psychopathology scores\#: } \\
\hline BPRS at admission & $16.1 \pm 7.8$ & \\
\hline BPRS at 8 weeks & $4.3 \pm 4.1$ & \\
\hline HDRS at admission & $23.7 \pm 7.6$ & \\
\hline HDRS at 8 weeks & $5.6 \pm 4.2$ & \\
\hline
\end{tabular}

\# The psychopathological scores were based on the Brief Psychiatric Rating Scale (BPRS) and the Hamilton Depression Rating Scale (HDRS). 
Table 1 lists the demographic data of the 122 study subjects. There were no significant differences in the male:female ratio between MDD and normal control groups $(\chi 2=0.03$; $\mathrm{df}=1 ; \mathrm{P}=0.5$ ), and there were no significant differences in body mass index (BMI) between the groups $(\mathrm{t}=0.7 ; \mathrm{df}=120 ; \mathrm{P}=0.40)$. There was also no significant difference in age between the MDD and normal control groups.

\section{Plasma IFN, IL4, and TGFß1 levels in MDD patients and normal controls}

In this part of the study, only pre-treatment cytokine levels were considered, so all 40 enrolled patients were included. IFN $\gamma$ was detectable in 18 MDD patients $(45 \%)$ and 4 normal controls $(5 \%)(\mathrm{p}<0.01)$ while IL4 was detectable in 38 MDD patients $(95 \%)$ and 42 normal controls $(52.5 \%)(\mathrm{p}<0.05)$. A total of 20 MDD patients $(50 \%)$ and 36 normal controls (45\%) showed only IL4 to be detectable but IFN $\gamma$, not. TGF $\beta 1$ was detected in all patients and control subjects. For the purpose of analysis, only the patients and controls with detectable cytokine levels were included. IFN $\gamma$ and IL4 levels of MDD showed no difference from the controls but TGF $\beta 1$ showed a slight decrease (Table 2). However, IFN $\gamma /$ IL4 (Th1/Th2) and IFN $\gamma /$ TGF $\beta 1$ (Th1/Th3) ratios were significantly higher $(\mathrm{p}<0.001)$ in depressed patients. TGF $\beta 1$ was negatively correlated with HDRS score $(\mathrm{r}=-0.41, \mathrm{p}=0.006)$. There were no significant correlations between IL4, IFN $\gamma$, and TGF $\beta 1$ levels and any other clinical variable including age, duration of illness, age of onset, number of admissions, number of episodes, or psychopathology score (data not shown). There were no significant differences in the cytokine levels between male and female.

Table 2. Plasma IFN- $\gamma$, IL4, and TGF $\beta 1$ levels in the study subjects who showed plasma immunoreactivity to all Th1, Th2 and Th3 cytokines.

\begin{tabular}{lccc}
\hline & $\begin{array}{c}\text { Major depression } \\
(\mathrm{n}=18)\end{array}$ & $\begin{array}{c}\text { Normal controls } \\
(\mathrm{n}=3)\end{array}$ & Statistics \\
\hline IFN- $\gamma$ & $41.28 \pm 20.2 \mathrm{pg} / \mathrm{ml}$ & $82.1 \pm 124.39 \mathrm{pg} / \mathrm{ml}$ & $\mathrm{Z}=0.51 ; \mathrm{p}=0.65$ \\
IL4 & $10.92 \pm 1.04 \mathrm{pg} / \mathrm{ml}$ & $21.67 \pm 20.73 \mathrm{pg} / \mathrm{ml}$ & $\mathrm{Z}=0 ; \mathrm{p}=1$ \\
$\mathrm{TGF} \beta 1$ & $13.21 \pm 7.6 \mathrm{ng} / \mathrm{ml}$ & $22.1 \pm 7.6 \mathrm{ng} / \mathrm{ml}$ & $\mathrm{Z}=-1.66 ; \mathrm{p}=0.09$ \\
IFN- $\gamma /$ IL4 & $1.7 \pm 2.3$ & $0.2 \pm 1.1$ & $\mathrm{Z}=-3.944 ; \mathrm{p}<0.0001$ \\
IFN- $\gamma /$ TGF $\beta 1$ & $1.6 \pm 2.3$ & $0.1 \pm 1.0$ & $\mathrm{Z}=-5.51 ; \mathrm{p}<0.0001$ \\
\hline
\end{tabular}

n.s $=$ not significant

Changes in IFN- $\gamma, I L 4$, and TGF $\beta 1$ before and after treatment

Twenty-two MDD patients completed the 8-week trial and were included in a second analysis. The changes in the cytokine levels between pre-treatment and post-treatment were analyzed by Wilcoxin Signed Rank test. There were no significant changes in IFN $\gamma$ though the absolute values have increased. However, TGF $\beta 1$ and IL4 values were 
significantly higher after treatment (Table 3). The IFN $\gamma /$ IL4 (Th1/Th2) ratio decreased significantly $(\mathrm{p}<0.05)$, but the IFN $\gamma /$ TGF $\beta 1$ (Th1/Th3) ratio did not change. When the role of gender was considered, all male patients with detectable pretreatment IFN $\gamma$ values showed reduction in IFN $\gamma$ after treatment though $66.67 \%$ of female (age ranged 21 years to 34 years) showed increase in IFN $\gamma$ and $33.33 \%$ of female (age ranged 55 to57 years) showed decrease after treatment $(\mathrm{p}<0.05)$. When absolute values were considered, there was a trend showing that female patients had higher IFN $\gamma$ values after treatment $(\mathrm{z}=-1.87, \mathrm{p}=0.06)$. However, there was no difference in IL4 and TGF $\beta 1$ changes since all showed decrease in IL4 and an increase in TGF $\beta 1$ after treatment. There were no significant correlations between the changes of the cytokines levels and the changes of the HDRS or BPRS total scores (data not shown).

Table 3. Changes of plasma IFN- $\gamma$, IL4, and TGF $\beta 1$ levels before and after 8 weeks of treatmentin patients who showed plasma immunoreactivity to all Th1, Th2 and Th3 cytokines.

\begin{tabular}{lccc}
\hline & $\begin{array}{c}\text { Before treatment } \\
(\mathrm{n}=10)\end{array}$ & $\begin{array}{c}\text { After treatment } \\
(\mathrm{n}=10)\end{array}$ & Statistics \\
\hline IFN- $\gamma$ & $19.8 \pm 26.7 \mathrm{pg} / \mathrm{ml}$ & $14.2 \pm 24.6 \mathrm{pg} / \mathrm{ml}$ & $\mathrm{Z}=-0.889 ;$ n.s. \\
IL4 & $11.2 \pm 7.2 \mathrm{pg} / \mathrm{ml}$ & $9.2 \pm 2.1 \mathrm{pg} / \mathrm{ml}$ & $\mathrm{Z}=-2.306 ; \mathrm{p}<0.05$ \\
TGF $\beta 1$ & $17.7 \pm 10.3 \mathrm{ng} / \mathrm{ml}$ & $25.8 \pm 7.4 \mathrm{ng} / \mathrm{ml}$ & $\mathrm{Z}=-2.549 ; \mathrm{p}<0.01$ \\
IFN- $\gamma /$ IL4 & $2.1 \pm 1.7$ & $1.2 \pm 1.5$ & $\mathrm{Z}=-1.511 ; \mathrm{p}<0.05$ \\
IFN- $\gamma$ TGF $\beta 1$ & $1.3 \pm 1.6$ & $0.8 \pm 1.4$ & $\mathrm{Z}=-0.357 ;$ n.s. \\
\hline
\end{tabular}

n.s $=$ not significant

\section{Discussion}

Our data demonstrated that among the depressed patients nearly $50 \%$ showed high proinflammatory cytokine activity. Moreover, the results showed depressed patients had higher plasma cytokine levels of both Th1 and Th2 subsets but plasma Th3 cytokine showed a trend to be lower compared to normal controls. The Th1/Th2 and Th1/Th3 ratios were also significantly higher in patients than normal controls. In addition, the plasma Th3 cytokine, TGF $\beta 1$ level was negatively correlated with the HDRS symptom score. In depressed patients, after the 8 weeks treatment, Th1 and Th2 cytokines were reduced, though the difference in Th1 was not statistically significant. The Th1/Th2 ratio was significantly decreased. The plasma TGF $\beta 1$ was significantly increased after 8 weeks treatment with antidepressant medication. The results indicate that $\mathrm{Th} 1$, Th2, and Th3 are all involved in the depressed state of a subgroup of depressed patients and are all corrected by antidepressant treatment.

The role of high Th1 and Th2 cytokines in depression has been well documented (14-19, 35). It has also been found that antidepressants can decrease the Th1/Th2 or proinflammatory/anti-inflammatory cytokine ratio $(20,36,37)$ and it has been hypothesized that cytokine hypersecretion may be involved in the pathophysiology of depressive disorders (38). The neurodegenerative hypothesis of depression has been proposed as a 
result of the imbalance between pro-inflammatory and anti-inflammatory cytokines that leads to production of a high concentration of the neurodegenerative metabolite, quinolinic acid, in the brain 39). The impaired balance between Th1 and Th2 cytokines is believed to play a role in appropriate modulation of cellular responses in the brain during psychological stress and depression (25). Our findings that the Th1 and Th2 cytokine levels and the Th1/Th2 ratio in patients were higher than in normal controls are in agreement with the previous findings.

In the present study, a significant change in the Th1 cytokine, IFN- $\gamma$ was not detected. This could be due to the difference in methodology used and the gender difference. In the previous studies, stimulated whole blood was used to analyze cytokine concentrations whereas plasma samples were used in the present study. Regarding the gender issue, almost all previous studies were carried out in male patients. In our study also, all male patients showed reduction in IFN- $\gamma$ after treatment. However, those female patients of reproductive age showed increase in IFN- $\gamma$ levels after treatment. The gender difference in inflammatory response in different illness conditions $(40,41)$ had been reported. Moreover, it was reported in an epidemiological study that age and gender significantly affected on plasma cytokine levels in depressed and schizophrenic patients (42). Nevertheless, we found a significant decreased in Th1/Th2 ratios following antidepressant treatment. Therefore, our finding also is in agreement with the hypothesis that the balance in the Th1 and Th2 cytokines could be important in the pathophysiology of depression.

In plasma samples, the Th3 cytokine, TGF $\beta 1$, showed lower value in depressed patients before treatment and the Th1/Th3 ratio was significantly higher in the depressed patients. Moreover, plasma Th3 levels were significantly and inversely correlated with the HDRS depression scale of the patients and were increased after treatment. It has been documented that increased TGF $\beta 1$ production correlates with the resolution of inflammatory responses, particularly in organ specific autoimmune diseases (29). TGF $\beta 1$ was proposed to play an important role in maintaining tolerance in immunologically privileged sites including the central nervous system. These findings explain the significant increase in the Th3 cytokine after antidepressant therapy in our patients, the change being associated with the decrease in the Th1/Th2 ratio. It has been reported that TGF $\beta 1$ promotes Th2 differentiation, which leads to increased IL4 production and decreased IFN $\gamma$ synthesis (43). In the present study, although both Th1 and Th2 cytokine levels reduced after treatment, the Th1/Th2 values also reduced. This could indicate a shift in the cytokine balance towards the Th2 side. Thus, not only the balance between Th1 and Th2 cytokines, but also the increase in the Th3 cytokine plays a significant role in the pathophysiology of depression and antidepressants were shown to change the Th1/Th2 balance at least in a subgroup of patients.

This study has some limitations. Since we collected the plasma samples only in the beginning and at the end of 8 week therapy, some significant changes in cytokine levels could have been missed. Moreover, if we had also measured the cytokine levels in basal and stimulated whole blood culture supernatants, we might have obtained a more comprehensive view regarding the changes. Future studies will attempt to assess these possibilities.

In conclusion, the result of this study showed the importance of the Th3 cytokine, TGF $\beta 1$, in the psychoimmunology of depressed patients. The antidepressants seem to 
react through the regulatory effect of TGF $\beta 1$ on the Th1 and Th2 balance, with a shift towards the latter.

\section{Acknowledgement}

The authors wish to acknowledge the financial support by Korea University Grant. This study was supported by a grant of the Korean Health 21 R\&D Project, Ministry of Health \& Welfare, Republic of Korea (A040042).

\section{References}

1. Dvorakova M, Zvolsky P, Herzog P. Endogenous psychoses and T and B lymphocytes. Folia Haematol Int Mag Klin Morphol Blutforsch 1980;107(2):221-8.

2. Schleifer SJ, Keller SE, Siris SG, Davis KL, Stein M. Depression and immunity. Lymphocyte function in ambulatory depressed patients, hospitalized schizophrenic patients, and patients hospitalized for herniorrhaphy. Arch Gen Psychiatry 1985;42(2):129-33.

3. Oskolkova SN. [Immunologic characteristics of patients with reactive depressions]. Zh Nevropatol Psikhiatr Im S S Korsakova 1985;85(4):557-60.

4. Maes M, Bosmans E, Suy E, Minner B, Raus J. Immune cell parameters in severely depressed patients: negative findings. J Affect Disord 1989;17(2):121-8.

5. Muller N, Ackenheil M, Eckstein R, Hofschuster E, Mempel W. Reduced suppressor cell function in psychiatric patients. Ann N Y Acad Sci 1987;496:686-90.

6. Darko DF, Gillin JC, Risch SG, Golshan S, Bulloch K, Baird SM. Peripheral white blood cells and HPA axis neurohormones in major depression. Int J Neurosci 1989;45(1-2):153-9.

7. Darko DF, Gillin JC, Risch SC, Bulloch K, Golshan S, Tasevska Z, et al. Mitogen-stimulated lymphocyte proliferation and pituitary hormones in major depression. Biol Psychiatry 1989;26(2):145-55.

8. Villemain F, Chatenoud L, Guillibert E, Pelicier Y, Bach JF. Decreased production of interleukin-2 in schizophrenia. Ann N Y Acad Sci 1987;496:669-75.

9. Kim YK, Kim L, Lee MS. Relationships between interleukins, neurotransmitters and psychopathology in drug-free male schizophrenics. Schizophr Res 2000;44(3):165-75.

10. Kim YK, Myint AM, Lee BH, Han CS, Lee SW, Leonard BE, et al. T-helper types 1, 2, and 3 cytokine interactions in symptomatic manic patients. Psychiatry Res 2004;129(3):267-72.

11. Breder CD, Dinarello CA, Saper CB. Interleukin-1 immunoreactive innervation of the human hypothalamus. Science 1988;240(4850):321-4.

12. Smith RS. The macrophage theory of depression. Med Hypotheses 1991;35(4):298-306.

13. Kim YK, Suh IB, Kim H, Han CS, Lim CS, Choi SH, et al. The plasma levels of interleukin-12 in schizophrenia, major depression, and bipolar mania: effects of psychotropic drugs. Mol Psychiatry 2002;7(10):1107-14.

14. Maes M, Stevens W, DeClerck L, Bridts C, Peeters D, Schotte C, et al. Immune disorders in depression: higher T helper/T suppressor-cytotoxic cell ratio. Acta Psychiatr Scand 1992;86(6):423-31.

15. Maes M, Stevens WJ, Declerck LS, Bridts CH, Peeters D, Schotte C, et al. Significantly increased expression of T-cell activation markers (interleukin-2 and HLA-DR) in depression: further evidence for an inflammatory process during that illness. Prog Neuropsychopharmacol Biol Psychiatry 1993;17(2):241-55.

16. Maes M. Cytokines in major depression. Biol Psychiatry 1994;36(7):498-9.

17. Maes M, Meltzer HY, Bosmans E, Bergmans R, Vandoolaeghe E, Ranjan R, et al. Increased plasma concentrations of interleukin-6, soluble interleukin-6, soluble interleukin-2 and transferrin receptor in major depression. J Affect Disord 1995;34(4):301-9.

18. Musselman DL, Miller AH, Porter MR, Manatunga A, Gao F, Penna S, et al. Higher than normal plasma interleukin-6 concentrations in cancer patients with depression: preliminary findings. Am J Psychiatry 2001;158(8):1252-7.

19. Seidel A, Arolt V, Hunstiger M, Rink L, Behnisch A, Kirchner H. Increased CD56+ natural killer cells and related cytokines in major depression. Clin Immunol Immunopathol 1996;78(1):83-5.

20. Kubera M, Lin AH, Kenis G, Bosmans E, van Bockstaele D, Maes M. Anti-Inflammatory effects of antidepressants through suppression of the interferon-gamma/interleukin-10 production ratio. J Clin Psychopharmacol 2001;21(2):199-206. 
21. Richtsmeier WJ, Johns ME, Cantrell RW, Sorge K. Interferon sensitivity of fibroblast cell cultures derived from patients with neoplasms of the head and neck. Otolaryngol Head Neck Surg 1985;93(4):492-9.

22. Fiorentino DF, Zlotnik A, Mosmann TR, Howard M, O'Garra A. IL10 inhibits cytokine production by activated macrophages. J Immunol 1991;147(11):3815-22.

23. Anisman H, Merali Z. Cytokines, stress and depressive illness: brain-immune interactions. Ann Med 2003;35(1):2-11.

24. Dubas-Slemp H, Marmurowska-Michalowska H, Szuster-Ciesielska A, Kaminska T, Kandefer-Szerszen M. [The role of cytokines in depression]. Psychiatr Pol 2003;37(5):787-98.

25. Kim YK, Maes, M. The role of cytokine network in psychological stress. Acta Neuropsychiatrica 2003;15:148-155.

26. Guereno MT, Diez RA. [Cytokines and psychiatry]. Vertex 2002;13(48):111-9.

27. Weiner HL. Oral tolerance: immune mechanisms and the generation of Th3-type TGF-beta-secreting regulatory cells. Microbes Infect 2001;3(11):947-54.

28. Schmitt E, Hoehn P, Huels C, Goedert S, Palm N, Rude E, et al. T helper type 1 development of naive $\mathrm{CD} 4+\mathrm{T}$ cells requires the coordinate action of interleukin-12 and interferon-gamma and is inhibited by transforming growth factor-beta. Eur J Immunol 1994;24(4):793-8.

29. Prud'homme GJ, Piccirillo CA. The inhibitory effects of transforming growth factor-beta-1 (TGF-beta1) in autoimmune diseases. J Autoimmun 2000;14(1):23-42.

30. APA. Diagnostic and statistical manual of mental disorders, 4 rd Ed, Washington, DC: American Psychiatric Press. 1994.

31. First M, Spitzer RL, Gibbon M, William JB. Structured clinical Interview for DSM-IV Axis I DisorderPatient Edition(SCID-I/P, version 2.0), Biometrics Research Department, New York State Psychiatric Institute, New York. 1998.

32. Overall JE, Gorham DR. The brief psychiatric rating scale. Psychol Rep 1962;10:799-812.

33. Hamilton M. A rating scale for depression. J Neurol Neurosurg Psychiatry 1960;23:56-62.

34. Miyazono K, Yuki K, Takaku F, Wernstedt C, Kanzaki T, Olofsson A, et al. Latent forms of TGF-beta: structure and biology. Ann N Y Acad Sci 1990;593:51-8.

35. Maes M, Bosmans E, Meltzer HY, Scharpe S, Suy E. Interleukin-1 beta: a putative mediator of HPA axis hyperactivity in major depression? Am J Psychiatry 1993;150(8):1189-93.

36. Maes M. The immunoregulatory effects of antidepressants. Hum Psychopharmacol 2001;16(1):95-103.

37. Kubera M, Maes M, Holan V, Basta-Kaim A, Roman A, Shani J. Prolonged desipramine treatment increases the production of interleukin-10, an anti-inflammatory cytokine, in C57BL/6 mice subjected to the chronic mild stress model of depression. J Affect Disord 2001;63(1-3):171-8.

38. Leonard BE. The immune system, depression and the action of antidepressants. Prog Neuropsychopharmacol Biol Psychiatry 2001;25(4):767-80.

39. Myint AM, Kim YK. Cytokine-serotonin interaction through IDO: a neurodegeneration hypothesis of depression. Med Hypotheses 2003;61(5-6):519-25.

40. Wang J, Grunler J, Lewitt MS. Gender-specific pattern of insulin-like growth factor-binding protein-3 protease activity in mouse thyroid. Endocrinology 2004;145(3):1137-43.

41. Wichmann MW, Muller C, Meyer G, Adam M, Angele MK, Eisenmenger SJ, et al. Different immune responses to abdominal surgery in men and women. Langenbecks Arch Surg 2003;387(11-12):397-401.

42. Haack M, Hinze-Selch D, Fenzel T, Kraus T, Kuhn M, Schuld A, et al. Plasma levels of cytokines and soluble cytokine receptors in psychiatric patients upon hospital admission: effects of confounding factors and diagnosis. J Psychiatr Res 1999;33(5):407-18.

43. Barral-Netto M, Barral A, Brownell CE, Skeiky YA, Ellingsworth LR, Twardzik DR, et al. Transforming growth factor-beta in leishmanial infection: a parasite escape mechanism. Science 1992;257(5069):545-8. 


\section{Chapter 3}

\section{Role of paroxetine in interferon- $\alpha$ - induced immune and behavioural changes in male Wister rats}

Aye Mu Myint, Siobhain O’Mahony, Marta Kubera, Yong Ku Kim, Christina Kenny, Agneiszka Kaim-Basta, Harry WM Steinbusch, and Brian E Leonard J. Psychopharm. 2006. In press. 


\begin{abstract}
Background: Treatment with pro-inflammatory cytokine, IFN $\alpha$ was documented to result in neuropsychiatric complications including depression and treatment with antidepressant, paroxetine could improve the depressive symptoms. Therefore, the effects of IFN $\alpha$ on behaviour and cytokine changes in the whole blood culture and in the prefrontal cortex, hypothalamus and hippocampus areas of the brain in Wistar rats were investigated with emphasis on the role of paroxetine in the prevention of depressive behaviour induced by pro-inflammatory cytokines.

Method: The group of rats treated with IFN $\alpha$ (s.c. $50,000 \mathrm{IU} / \mathrm{kg}$ for 3 days $/$ week for 5 weeks) was compared with 3 other groups; (1) saline control (s.c normal saline 0.2 $\mathrm{ml} / \mathrm{kg} /$ day for 7 weeks) group, (2) paroxetine control group (Paroxetine suspension orally $10 \mathrm{mg} / \mathrm{kg} /$ day for 7 weeks) and (3) group treated with paroxetine for 2 weeks followed by IFN $\alpha$ for 5 weeks.

Result: In open-filed, the IFN $\alpha$ treated rats showed anxiety behaviour compared to the rats from the other groups. There was no significant difference in home cage emergence test, Morris water maze and object recognition test. There is no significant difference in plasma corticosterone between groups. The pro-inflammatory cytokines (TNF $\alpha$, IL1 $\beta$ and IFN $\gamma$ ), were significantly higher whereas the anti-inflammatory cytokine, IL10 was lower in the stimulated whole blood culture of IFN $\alpha$ treated rats. In the brain, both proinflammatory cytokine IL1 $\beta$ and anti-inflammatory cytokine IL10 were higher in hypothalamus of the IFN $\alpha$ treated rats; by contrast the concentration of IL10 was lowest in hippocampus region of this group compared to the other groups. The paroxetine pretreated rats did not show these cytokine changes following IFN $\alpha$ treatment.
\end{abstract}

Conclusion: Thus it appears that paroxetine pre-treatment prevents the proinflammatory changes in blood and brain following IFN $\alpha$ treatment in turn prevents the anxiety behaviour. 


\section{Introduction}

Interferon- $\alpha$ (IFN $\alpha)$ is used for the treatment of chronic viral diseases such as chronic hepatitis $\mathrm{B}$ and $\mathrm{C}$ and for the treatment of different malignancies (1). The duration of treatment varies from months, in the case of hepatitis, to years, in certain types of malignancies and the therapy may induce different side effects. Following chronic treatments, there are more severe side effects involving the immune system and the brain $(2,3)$. In short term applications of high doses of IFN $\alpha$ given intravenously or intracerebroventricularly, 20 to 60 percent of patients developed organic mental disorders after short latency of several days but symptoms generally subside promptly after cessation of treatment (4-11). However, it was reported that moderate deficits in cognitive function occassionally persisted even after cessation of therapy (12). Compared to the side effects occurring in high-dose therapy, neuropsychiatric effects during low-dose therapy are reported to be less severe and occur after a longer latency in 4 to 16 percent of patients (13).

It is widely accepted that major depression is accompanied by disturbances in the serotonin (5-HT) metabolism (14-16). IFN $\alpha$ up-regulates the transcription of the central 5-HT transporter, which increases the reuptake of 5-HT and thereby reduces the extracellular 5-HT concentration (17). It was also reported that IFN $\alpha$ increases the binding at low affinity 5-HT1A receptor sites that might induce the psychiatric symptoms of depression and anxiety (18). In addition, the IFN $\alpha$ induced protein (15-kDa protein), stimulates IFN $\gamma$ synthesis (19) and thus activates the enzyme indolamine 2-3, dioxygenase (IDO) which catabolises tryptophan to kynurenine (20), which is again catabolised into neurodegenerative quinolinic acid and neuroprotective kynurenic acid and the chronic imbalance in those two metabolites could lead to depression (21). It is also proposed that IFN $\alpha$ may induce depression through activation of the HPA system and an increased synthesis of IL1 $\beta$ (22). Tryptophan depletion and a reduction in serotonin synthesis following the cytokine induced induction of IDO also contribute to pathology of depression (23).

Antidepressants have been shown to correct the imbalances between pro- and antiinflammatory cytokines or T-helper 1 (Th1) and T-helper 2 (Th2) cytokines in both animal and human studies $(24,25)$. In addition, the T-helper 3 (Th3) cytokine, transforming growth factor (TGF) $\beta 1$, regulates the balance between the pro- and antiinflammatory cytokines in depressed patients after treatment with antidepressants (25). There is evidence that paroxetine is an effective SSRI antidepressant in the treatment $(26,27)$ and prevention $(28,29)$ of IFN $\alpha$-induced depressive illness. However, the role of paroxetine in correcting the changes in behaviour and dysfunctional brain and blood immune system changes in rats has not been previously reported. It is hypothesized that paroxetine may prevent the changes in behavioural untoward effects caused by chronic parenteral administration of IFN $\alpha$ by decreasing the proinflammatory changes and thereby limiting the adverse effects on the serotonin system. 


\section{Materials and Methods}

\section{Animals}

Male Wistar rats from Charles River Laboratory weighing 250-300gm were housed individually in standard Makrolon cage and kept under 12-hour reversed light-dirk cycle with food (standard diet, Charles River) and water ad libitum. The study was approved by the institutional ethical committee for animal experimentation, University of Maastricht, The Netherlands.

\section{Treatment}

The rats were assigned to 4 different treatment groups of 10 rats each as followed (Table 1).

Table. 1. Table showing the different treatment groups of animals

\begin{tabular}{ll}
\hline Group & Treatment (N=10/group) \\
\hline Control & Saline (s.c) $0.2 \mathrm{ml} / \mathrm{kg}$ everyday for 47 days \\
IFN $\alpha$ & $\begin{array}{l}\text { Saline (s.c) } 0.2 \mathrm{ml} / \mathrm{kg} \text { everyday for } 14 \text { days followed by IFN } \alpha \text { s.c (Interon A, Schering } \\
\text { Plough) } 50,000 \mathrm{IU} / \mathrm{kg} \text { for } 3 \text { days } / \text { week for } 5 \text { weeks }\end{array}$ \\
$\mathrm{P}+\mathrm{IFN \alpha}$ & $\begin{array}{l}\text { Paroxetine suspension (Seroxat, GlaxoSmithKline) orally } 10 \mathrm{mg} / \mathrm{kg} \text { for } 14 \text { days } \\
\text { followed by IFN } \alpha \text { s.c (Interon A,Schering Plough) } 50,000 \mathrm{IU} / \mathrm{kg} \text { for } 3 \text { days } / \text { week for } 5 \\
\text { weeks }\end{array}$ \\
& Paroxetine suspension (Seroxat, GlaxoSmithKline) orally $10 \mathrm{mg} / \mathrm{kg}$ for 47 days \\
\hline
\end{tabular}

All injections or medications were given between 13:00 to 14:00 hours daily to avoid the effects of handling for administration of medication on behavioural experiment. The dose of IFN $\alpha$ was selected on the basis of previous experiments in the published literature (30-33). The route and frequency of injection of IFN $\alpha$ reflected the clinical situation. The dose of paroxetine used based on the previous studies by other investigators $(34,35)$.

\section{Behavioural procedures}

The following behavioural studies were undertaken commencing 7 days after Interon-A treatment (i.e. 21 days after the start of the experiment). Randomisation was carried out to avoid the confounding effect of time of the day and immediate effect of an injection or medication. The body weight was measured once a week.

Exposure to the open field arena for $5 \mathrm{~min}$. The apparatus consisted of a square Plexiglas base $(100 \mathrm{~cm} \times 100 \mathrm{~cm})$ with a black floor and $40 \mathrm{~cm}$ high transparent Plexiglas walls (36). The arena was arbitrarily divided into 4 corners, 4 walls and centre. A camera was placed $250 \mathrm{~cm}$ above the centre of the open field. After the rat was placed in the centre of the arena, the distance moved and the velocity of movement of the rat 
were tracked automatically with a computerised system (Ethovision, Noldus, The Netherlands). Testing was carried out in 5 min session per day for four days.

Object recognition test. The object recognition test was performed as described elsewhere (37). The apparatus consisted of a circular arena, $83 \mathrm{~cm}$ in diameter. Half of the $40 \mathrm{~cm}$ high wall was made of grey polyvinyl chloride, the other half of transparent polyvinyl chloride. The light intensity was equal in the different parts of the apparatus. Two objects are placed in a symmetrical position about $10 \mathrm{~cm}$ away from the grey wall. Four different sets of objects used were: 1) a cone consisting of a grey polyvinyl chloride base (maximal diameter $18 \mathrm{~cm}$ ) with a collar on top made of brass (total height 16 $\mathrm{cm}), 2$ ) a standard 11 transparent glass bottle (diameter $10 \mathrm{~cm}$, height $22 \mathrm{~cm}$ ) filled with sand, 3) a metal cube $(10.0 \times 5.0 \times 7.5 \mathrm{~cm})$ with two holes (diameter $1.9 \mathrm{~cm})$, and 4$)$ an aluminium cube with a tapering top $(13.0 \times 8.0 \times 8.0 \mathrm{~cm})$. The objects were heavy enough to prevent from being displaced by the rats.

In the first week, the animals were handled daily and were adapted to the procedure for the first two days; the rats were allowed to explore the apparatus in the absence of any objects twice for 3 min each day. In the following 2 weeks the rats were adapted to the testing procedure until they showed a stable discrimination performance, i.e., the rats could recognise the old object at a 1-h interval after the exposure to the objects but could not recognise after 24 hours.

A testing session comprised two trials. The duration of each trial was $3 \mathrm{~min}$. During the first trial (T1) the apparatus contains two identical objects (samples). A rat was always placed in the centre of the transparent front segment of the apparatus facing the wall. After the first exploration period the rat was put back in its home cage. Subsequently, after a 1-hour interval, the rat was put back in the apparatus for the second trial (T2), but in this occasion with two dissimilar objects, a familiar one (the sample) and a new one. The times spent exploring each object during T1 and T2 was recorded manually by means of a personal computer. A third trial (T3) was undertaken 24 hours later with two dissimilar (one old and one new) objects. To avoid interference there is always one day without testing between $\mathrm{T} 3$ of first testing and T1 of next testing.

Behaviour in Morris water maze: Morris water maze test was performed using a black water tank (diameter 1,53m) (38). The escape platform (diameter $11 \mathrm{~cm}$ ) was submerged $(1,5 \mathrm{~cm})$ below the surface of the water. The water temperature was $22^{\circ} \mathrm{C}$. The water was not made opaque, because the escape platform was black and hence virtually invisible in the black tank. The water tank was divided into four quadrants designated (training, right adjacent, left adjacent and opposite) relative to the position of the escape platform. Abundant spatial cues were provided by the furniture in the room. A video camera, mounted in the centre above the circular pool, enabled all the movements in terms of distance, velocity and location of a rat to be tracked automatically (Ethovision, Noldus equipment) and the results stored on a personal computer.

At the beginning of the experiment, the rat was placed in the tank from four different randomly chosen start positions, and trained to find the invisible platform at a fixed position in the water tank. A trial lasted until the rat has located the platform or until $60 \mathrm{~s}$ had elapsed. If a rat could not find the platform within $60 \mathrm{~s}$, it was placed on the platform for $3 \mathrm{~s}$ and then removed from the water tank. On the first day, the rats were subjected to four trials. On the 3 subsequent days the rats were given 8 trials per day. The time between each trial was 10 mins. A probe trial lasting $60 \mathrm{~s}$, during which the platform was removed from the water tank, was given after the last trial. In the probe 
trial the rats were placed in the tank facing the wall of the tank from the position opposite to the quadrant in which the platform was removed (38).

Home Cage Emergence Test. The home cage emergence test was applied once a week throughout the experimental period. In this test, the cage which contains the rat that housed in it was placed in the middle of the open field (39). The cage top was left open so that the rat could emerge via an easily accessible grid. The latency (in seconds) to emerge from the home cage (i.e., the time taken until a rat was on the grid outside its cage with all four legs) was scored.

\section{Biochemical analyses}

Sample collection. One week after cessation of behavioural experiment and drug treatments, the rats were euthanized with thiopentone $(150 \mathrm{mg} / \mathrm{kg}$ i.p). The blood was collected from the aorta in heparinised tubes within 3 to 5 minutes after the rats had been anaesthetised with thiopentone. The procedure was taken out between 09:00 to 10:00 hours in the morning. One $\mathrm{ml}$ of whole blood was taken for the whole blood stimulation culture and the remainder was centrifuged and plasma was collected and stored at $-70^{\circ} \mathrm{C}$ for corticosterone analysis.

Immediately after blood collection, the rats were decapitated and three brain areas (hippocampus, hypothalamus and pre-frontal cortex) were dissected on a frosted glass plate and put in sterile chilled PBS ( $\mathrm{pH} 7.4-7.6)$ containing protease inhibitor cocktail (Roche) and stored at $-70^{\circ} \mathrm{C}$ for analysis of cytokines at a later date.

Serum corticosterone analysis. Plasma corticosterone was analysed using EIA kit for rat and mouse corticosterone from IDS. The detection limit was $18 \mathrm{ng} / \mathrm{ml}$ and the intraassay coefficient of variation was $3.1 \%$.

Blood culture and cytokine analysis. The pro-inflammatory IL1 $\beta$, TNF $\alpha$, IFN $\gamma$ and antiinflammatory IL10 and TGF $\beta 1$ cytokines were analysed in both supernatants from stimulated and unstimulated cultures. The whole blood was collected at room temperature to prepare cultures. Whole blood was cultured in 24-well Costar plate and for each rat, 2 stimulated culture wells and 2 unstimulated culture wells were prepared. In each well $250 \mu \mathrm{l}$ of whole blood was incubated at $37^{\circ} \mathrm{C}$ for 48 hours with $750 \mu$ l of RPMI 1640 medium containing $50 \mu \mathrm{g} / \mathrm{ml}$ LPS (Sigma) and $10 \mu \mathrm{g} / \mathrm{ml}$ Concanavalin A (Sigma) for the stimulated cultures (40). The RPMI 1640 without mitogens was used for unstimulated culture. The supernatants were collected after 48-hour incubation and kept at $-70^{\circ} \mathrm{C}$ for the analysis of cytokines at a later date. The blood cytokines were analysed in duplicate using ELISA developed with DuoSet ELISA from R\&D System, UK for rat IL1 $\beta$, TNF $\alpha$, IFN $\gamma$ and IL10 and TGF $\beta 1$ according to the instructions of the manufacturer. The detection limits were $39.06 \mathrm{pg} / \mathrm{ml}$ for IFN $\gamma$ and $62.5 \mathrm{pg} / \mathrm{ml}$ for the other cytokines. The intra-assay coefficients of variation were: $3.2 \%$ for rat IL $1 \beta, 3.5 \%$ for rat TNF $\alpha, 5.6 \%$ for rat IFN $\gamma, 5.2 \%$ for rat IL10 and $3.8 \%$ for TGF $\beta 1$, respectively.

Brain cytokine analysis. Brain cytokine analysis was done with the minor modification on the previously published methods $(41,42)$. Brain samples were thawed in an ice bath

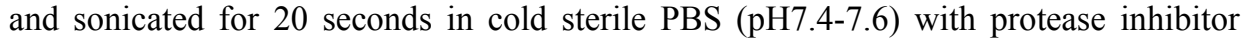
cocktail (Roche). The protein concentration was analysed by Lowry's method on sonicated samples $(43,44)$. The sonicated samples were centrifuged and the brain IL1 $\beta$, TNF $\alpha$, and IL10 were analysed in duplicate in the supernatant diluted with sterile PBS. The brain cytokine levels were analysed in duplicate using ELISA developed with 
DuoSet ELISA from R\&D System, UK for rat IL1 $\beta$, TNF $\alpha$, IFN $\gamma$ and IL10 and the concentrations were expressed as $\mathrm{pg} / \mathrm{g}$ protein. The detection limit for all cytokines was $62.5 \mathrm{pg} / \mathrm{ml}$. The intra-assay coefficients of variation were: $3.2 \%$ for rat IL $1 \beta, 3.5 \%$ for rat $\mathrm{TNF} \alpha$, and $5.2 \%$ for rat IL10, respectively.

\section{Data analysis}

The effect of treatment on behaviour and immune parameters were analysed using twoway ANOVA and Bonferroni or Scheffe post-hoc tests were used to perform the pairwise comparison. To determine the significant difference between the 4 groups for the data with high standard deviation, non-parametric Kruskal Wallis test was used. The analysis was carried out using SPSS version 11.5 and the probability of 0.05 or below was considered to be statistically significant.

\section{Results}

\section{Behaviour}

In the open-field test the effect of interaction between IFN $\alpha$ treatment and paroxetine treatment showed significant effect on mean distance moved $(\mathrm{F}=1.158, \mathrm{p}=0.043)$, velocity of movement in the open field $(\mathrm{F}=4.632, \mathrm{p}=0.041)$ and time spent in the corner $(\mathrm{F}=5.658, \mathrm{p}=0.025)($ Table-2).

The post-hoc Bonferroni test showed significant difference between saline control and IFN $\alpha$ treated group or paroxetine group in time spent in the corner $(p=0.031$ and 0.038 respectively). The IFN $\alpha$ treated group also showed difference in mean distance moved $(\mathrm{p}=0.041)$, and mean velocity of movement $(\mathrm{p}=0.047)$ in open field compared to saline controls.

However, no effects of IFN $\alpha$ treatment, paroxetine treatment and interaction were observed on home cage emergence test, Morris water maze test and object recognition test.

Table-2 - Descriptive data on behaviour in open field

\begin{tabular}{lcccc}
\hline Parameters & Saline & IFN & P+IFN $\alpha$ & P \\
\hline $\begin{array}{l}\text { Mean Distance Moved (m) } \\
\text { (mean } \pm \text { S.D) }\end{array}$ & $0.62 \pm 0.23$ & $2.61 \pm 1.8$ & $0.84 \pm 0.35$ & $1.34 \pm 0.69$ \\
$\begin{array}{l}\text { Mean Velocity }(\mathrm{cm} / \mathrm{sec}) \\
\text { (mean } \pm \text { S.D) }\end{array}$ & $6.25 \pm 1.06$ & $9.55 \pm 1.23$ & $7.94 \pm 1.58$ & $8.37 \pm 1.14$ \\
$\begin{array}{l}\text { Percent time spent in corner } \\
(\%)\end{array}$ & $17.39 \pm 3.27$ & $35.34 \pm 6.77$ & $18.99 \pm 4.5$ & $32.58 \pm 7.7$ \\
\hline
\end{tabular}

\section{Peripheral corticosterone and cytokines}

The descriptive values of the peripheral corticosterone and cytokines were shown in table-3. There was no significant difference in corticosterone concentrations between the groups. 
Regarding cytokine levels in stimulated and unstimulated whole blood culture supernatants, significant differences between all studied groups were shown in IL1 $\beta$ concentration in stimulated whole blood culture $\left(\chi^{2}=15.901, \mathrm{p}=0.001\right)$, TNF $\alpha$ concentration in both unstimulated and stimulated whole blood cultures $\left(\chi^{2}=29.715, \mathrm{p}=0.000\right.$; $\chi^{2}=19.669, \mathrm{p}=0.000$, respectively), INF $\gamma$ concentration in unstimulated and stimulated whole blood cultures $\left(\chi^{2}=12.426, \mathrm{p}=0.006 ; \chi^{2}=15.386, \mathrm{p}=0.002\right.$, respectively), IL10 in unstimulated and stimulated whole blood cultures $\left(\chi^{2}=8.352, p=0.039 ; \chi^{2}=20.381\right.$, $\mathrm{p}=0.000$, respectively $)$ and in IFN $\gamma / \operatorname{IL} 10$ ratio $\left(\chi^{2}=23.434, \mathrm{p}=0.000\right)$.

Table-3-Descriptive data on corticosterone concentration in plasma and cytokines concentrations in whole blood culture supernatants

\begin{tabular}{|c|c|c|c|c|}
\hline Parameters & Saline & IFN $\alpha$ & $\mathrm{P}+\mathrm{IFN} \alpha$ & $\mathrm{P}$ \\
\hline $\begin{array}{l}\text { Plasma Corticosterone } \\
(\mathrm{mmol} / \mathrm{l})(\text { mean } \pm \text { S.D })\end{array}$ & $200.64 \pm 116.25$ & $228.79 \pm 120.45$ & $218.61 \pm 125.58$ & $270.26 \pm 135.34$ \\
\hline \multicolumn{5}{|l|}{$\operatorname{IL} 1 \beta(\mathrm{pg} / \mathrm{l})(\mathrm{mean} \pm \mathrm{S} . \mathrm{D})$} \\
\hline Unstimulated & 0.00 & $16.56 \pm 12.05$ & 0.00 & 0.00 \\
\hline Stimulated & 0.00 & $200.74 \pm 75.15$ & $3.96 \pm 2.30$ & 0.00 \\
\hline \multicolumn{5}{|l|}{$\begin{array}{l}\mathrm{TNF} \alpha(\mathrm{pgl} / \mathrm{l}) \\
(\mathrm{mean} \pm \mathrm{S} . \mathrm{D})\end{array}$} \\
\hline Unstimulated & $664.16 \pm 14.51$ & $242.84 \pm 40.45$ & $199.14 \pm 32.66$ & $648.69 \pm 4.78$ \\
\hline Stimulated & $1899.9 \pm 547.01$ & $4582.7 \pm 1914.7$ & $2491.4 \pm 1599.1$ & $1345.05 \pm 291.1$ \\
\hline \multicolumn{5}{|l|}{$\begin{array}{l}\text { IFN } \gamma(\mathrm{pg} / \mathrm{l}) \\
(\text { mean } \pm \text { S.D) }\end{array}$} \\
\hline Unstimulated & $122.84 \pm 80.96$ & $446.97 \pm 112.97$ & $174.13 \pm 46.59$ & $435.91 \pm 138.31$ \\
\hline Stimulated & $186.55 \pm 89.32$ & $847.14 \pm 361.59$ & $560.15 \pm 187.72$ & $950.12 \pm 228.43$ \\
\hline \multicolumn{5}{|l|}{ IL10 $(\mathrm{pg} / \mathrm{l})($ mean \pm S.D $)$} \\
\hline Unstimulated & $547.48 \pm 159.96$ & 0.00 & $194.06 \pm 61.3$ & $62.41 \pm 62.41$ \\
\hline Stimulated & $8185.39 \pm 779.8$ & $3293.75 \pm 618.5$ & $6548.17 \pm 517.7$ & $4814.0 \pm 1401.1$ \\
\hline \multicolumn{5}{|l|}{$\begin{array}{l}\text { IFN } \gamma / \mathrm{IL} 10 \\
(\text { mean } \pm \text { S.D) }\end{array}$} \\
\hline Stimulated & $0.028 \pm 0.014$ & $0.804 \pm 0.49$ & $0.091 \pm 0.038$ & $0.213 \pm 0.137$ \\
\hline \multicolumn{5}{|l|}{$\begin{array}{l}\text { TGF } \beta 1(\mu \mathrm{g} / 1) \\
(m e a n \pm \text { S.D })\end{array}$} \\
\hline Unstimulated & $3.15 \pm 0.14$ & $3.55 \pm 0.25$ & $3.01 \pm 0.12$ & $3.05 \pm 0.18$ \\
\hline Stimulated & $4.35 \pm 0.24$ & $4.68 \pm 0.14$ & $4.15 \pm 0.2$ & $4.25 \pm 0.34$ \\
\hline
\end{tabular}

The IFN $\alpha$ treatment showed significant effects on (1) IL1 $\beta$ concentration in stimulated culture $(\mathrm{F}=6.125, \mathrm{p}=0.019)$, (2) $\mathrm{TNF} \alpha$ concentrations in stimulated and unstimulated cultures $(\mathrm{F}=18.45, \mathrm{p}=0.000$ and $\mathrm{F}=2143.55, \mathrm{p}=0.000$, respectively), and (3) IL10 concentration in stimulated culture $(\mathrm{F}=5.941, \mathrm{p}=0.020)$. 
The interaction between IFN $\alpha$ treatment and paroxetine treatment showed significant effects on (1) IL1 concentration in stimulated culture $(\mathrm{F}=5.66, \mathrm{p}=0.023)$, and (2) IL10 concentration in stimulated culture $(\mathrm{F}=26.158, \mathrm{p}=0.000)$.

The post-hoc Scheffe test showed significant difference between IFN $\alpha$ treated group and all other groups (saline control, paroxetine + IFN $\alpha$, and paroxetine alone) in mitogen stimulated peripheral IL1 production ( $p=0.013,0.011$ and 0.024 respectively), basal peripheral TNF $\alpha$ production ( $\mathrm{p}=0.016,0.000$ and 0.000 respectively), and mitogen stimulated peripheral TNF $\alpha$ production $(\mathrm{p}=0.015,0.001$ and 0.000$)$. The post-hoc Scheffe test also showed significant difference between IFN $\alpha$ treated group and saline control group or paroxetine + IFN $\alpha$ group in mitogen stimulated peripheral IL10 production ( $p=0.008$ and 0.000 respectively). The post-hoc Bonferroni test showed significant difference between IFN $\alpha$ treated group and saline control group or paroxetine + IFN $\alpha$ group in IFN $\gamma / \mathrm{IL} 10$ production ratio $(\mathrm{p}=0.004$ and 0.000 respectively). The TGF $\beta 1$ concentrations showed no significant difference between the groups.

\section{Brain cytokines}

Table-4-Descriptive data on cytokines concentrations in different brain regions

\begin{tabular}{|c|c|c|c|c|}
\hline Parameters & Saline & IFN & $\mathrm{P}+\mathrm{IFN}$ & $\mathrm{P}$ \\
\hline \multicolumn{5}{|l|}{$\begin{array}{l}\text { IL1 ( (pg/g) } \\
(\text { mean } \pm \text { S.D) }\end{array}$} \\
\hline Hippocampus & $2396.5 \pm 555.2$ & $2345.8 \pm 724.5$ & $1814.6 \pm 653.9$ & $2358.0 \pm 784.9$ \\
\hline Hypothalamus & $323.19 \pm 124.47$ & $884.95 \pm 277.9$ & $414.98 \pm 115.89$ & $290.62 \pm 73.09$ \\
\hline Prefrontal cortex & $107.78 \pm 22.19$ & $143.77 \pm 28.62$ & $118.77 \pm 10.27$ & $120.47 \pm 41.07$ \\
\hline \multicolumn{5}{|l|}{$\begin{array}{l}\text { TNF } \alpha(p g l / g) \\
(\text { mean } \pm \text { S.D) }\end{array}$} \\
\hline Hippocampus & $5477.1 \pm 1326.3$ & $4766.6 \pm 1645.1$ & $4231.6 \pm 1413.9$ & $5807.6 \pm 2232.2$ \\
\hline Hypothalamus & $22295.8 \pm 8212$ & $22008.2 \pm 6437.2$ & $22160.1 \pm 8222.4$ & $19682.9 \pm 6853.7$ \\
\hline Prefrontal cortex & $4946.2 \pm 1621.2$ & $5557.2 \pm 2127.3$ & $5345.7 \pm 1415.1$ & $5607.4 \pm 1674.2$ \\
\hline \multicolumn{5}{|l|}{$\begin{array}{l}\mathrm{IL} 10(\mathrm{pg} / \mathrm{g}) \\
(\text { mean } \pm \text { S.D })\end{array}$} \\
\hline Hippocampus & $11083.1 \pm 2636$ & $7899.2 \pm 2253.4$ & $8256.4 \pm 2859.6$ & $9176.1 \pm 2635.4$ \\
\hline Hypothalamus & $22482.8 \pm 7959.2$ & $54228.6 \pm 14269.9$ & $26226.7 \pm 7246$ & $20463.3 \pm 7474$ \\
\hline Prefrontal cortex & $5772.6 \pm 2309.2$ & $7148.1 \pm 1453.3$ & $6163.8 \pm 822.9$ & $6980.4 \pm 1617.7$ \\
\hline
\end{tabular}

The descriptive values of the brain cytokines were shown in table-4.

Regarding cytokine levels in brain, significant differences between all studied groups were shown in IL1 $\beta$ concentration $\left(\chi^{2}=23.03, \mathrm{p}=0.000\right)$ and IL10 concentration $\left(\chi^{2}=21.535, \mathrm{p}=0.000\right)$ in hypothalamus. 
The IFN $\alpha$ treatment showed significant effects on (1) IL10 concentration in hippocampus ( $\mathrm{F}=9.362, \mathrm{p}=0.005$, respectively), and (2) IL1 $\beta$ and IL10 concentrations in hypothalamus $(\mathrm{F}=35.162, \mathrm{p}=0.000$ and $\mathrm{F}=33.525, \mathrm{p}=0.000$, respectively).

The interaction between IFN $\alpha$ treatment and paroxetine treatment showed significant effects also on IL1 $\beta$ concentration and IL10 concentration in hypothalamus $(\mathrm{F}=15.785$, $\mathrm{p}=0.000$ and $\mathrm{F}=17.415, \mathrm{p}=0.000$, respectively).

The post-hoc Bonferroni test showed the significant difference in IL10 concentration in hippocampus between IFN $\alpha$ treated group and saline control group $(p=0.002)$. The post-hoc Scheffe test showed significant difference between IFN $\alpha$ treated group and all other groups (saline control, paroxetine+ IFN $\alpha$, and paroxetine alone) in IL1 $\beta$ concentration in hypothalamus $(\mathrm{p}=0.000,0.000$ and 0.001 respectively), and IL10 concentration in hypothalamus ( $\mathrm{p}=0.000$ for all compared groups).

\section{Discussion}

The IFN $\alpha$ rats treated with IFN $\alpha 50,000 \mathrm{IU} / \mathrm{kg}$ s.c for three days a week for 5 weeks showed anxiety behaviour in open field. The increased anxiety in open field is one of the depressive behaviours especially induced by LPS which stimulate the proinflammatory cytokine secretion (45). This explained the finding in our study in which the pro-inflammatory cytokine IFN $\alpha$ induced sickness behaviour which is equivalent to human depressive behaviour. The previous rodent studies also showed depressive like behaviour such as social anhedonia in sucrose preference test (32) or increased immobility in the forced swimming test (31) in IFN $\alpha$-treated rats. However, in our study, there was no difference in home cage emergence test, object recognition test and Morris water maze test. The behavioural results of our study indicated that IFN $\alpha$ injection can induce anxiety behaviour in open field but does not cause cognitive impairment. The effect of IFN $\alpha$ on cognitive function is still controversial. Though there appears to be little information available on the effect of IFN $\alpha$ on cognitive function in rats, a recent human study revealed no effect of IFN $\alpha$ on cognitive function after 6 month treatment in chronic hepatitis-C patients (46) whereas other investigator showed that the cognitive-depressive symptom score increased at 8th week of IFN $\alpha$ therapy (47).

The most pronounced changes in the cytokines were detected in the IFN $\alpha$ group. In the peripheral blood culture, IFN $\alpha$ appeared to suppress the basal TNF $\alpha$ secretion but enhance the response to mitogen stimulation. Our results also showed that IFN $\alpha$ enhanced the production of IL1 $\beta$ in both basal and stimulated peripheral blood. There is very limited literature available on the cytokines response in IFN $\alpha$ treatment in rats though one study on effect of IFN $\alpha$ on rat kupffer cells showed increased TNF $\alpha$ production but not on IL1 $\beta$ whereas another showed no effect of IFN $\alpha$ on plasma TNF $\alpha$ and IL6 (30). However, in a clinical study on changes in TNF $\alpha$ production during IFN $\alpha$ therapy, it was shown that the stimulated production of TNF $\alpha$ was significantly increased in those responding to the treatment (48). The paroxetine pre-treatment, in our study, significantly prevented the increase peripheral IL1 $\beta$ but not TNF $\alpha$ production by IFN $\alpha$.

Regarding the Th2 or anti-inflammatory cytokine IL10 production, our finding showed that mitogen stimulated IL10 production was significantly lower in IFN $\alpha$ group and IFN $\gamma /$ IL10 (Th1/Th2) was significantly higher also in this group. This is the first 
study in which the effect of IFN $\alpha$ on peripheral IL10 response was reported in rodents though there is clinical evidence that IL10 production declined with IFN $\alpha$ treatment (49, 50) in those who responding to the treatment. The paroxetine pre-treatment again prevented the decreased IL10 production in peripheral blood culture in our study. Taken together, the anxiety behaviour in IFN $\alpha$ treated rats in open field might be associated with the pro- versus anti-inflammatory cytokines imbalance in the blood since such an imbalance was well documented in clinical depression (25). However, those behavioural and immune changes were prevented by paroxetine pre-treatment. Unfortunately, this study failed to demonstrate the change in the Th3 cytokine, TGF $\beta 1$ which regulates the Th1 and Th2 balance by suppressing the Th1 cytokines like IFN $\gamma$ and TNF $\alpha(51,52)$, despite the beneficial effect of paroxetine that prevented the imbalance in Th1 versus Th2 or pro- versus anti-inflammatory cytokines.

In contrast to the changes in the blood, in the brain, IFN $\alpha$ induced decrease in IL10 (anti-inflammatory) cytokines in hippocampus whereas IFN $\alpha$ increased both IL1 $\beta$ (proinflammatory) and IL10 in hypothalamus. There was indeed immune activation in hypothalamus region of the brain in IFN $\alpha$ treated rats indicated by both high pro- and anti-inflammatory cytokines. That finding also indirectly indicated the minor change in pro- versus anti-inflammatory cytokines imbalance by decreasing the anti-inflammatory part in the hippocampus area of the brain in IFN $\alpha$ treated rats. However, there is no significant change in IL1 $\beta$ in the hippocampus. This finding is in agreement with the finding of the study by De La Garza and group (30) in which the IFN $\alpha$ treatment showed no effect on mRNA expression of IL1 $\beta$ and IL6 in the hippocampus of the Wistar rats. There was also no significant effect of both IFN $\alpha$ and paroxetine alone or in combination on TNF $\alpha$ concentrations in these three brain regions. This finding was in agreement with that of Gayle and group (53) which demonstrated that IFN $\alpha$ has no effect on TNF $\alpha$ mRNA expression. Nevertheless in the present study paroxetine pretreatment resulted in reduction of both IL1 $\beta$ and IL10 in hypothalamus.

Though we could demonstrate the changes in cytokines in both periphery and in the hypothalamus, we failed to demonstrate a change in the plasma corticosterone concentration. This was surprising as IL1 $\beta$ is considered to be a potent activator of the HPA axis. However, there was also high IL10 in hypothalamus which indicated the possibility of balancing the pro-inflammatory cytokine IL1 $\beta$ action by anti-inflammatory cytokine IL10. The lack of change in corticosterone might also be partly due to the disturbance in the system by anaesthetic injection before sample collection.

Taking altogether, these findings indicated that the brain cytokine changes may occur independently of the peripheral blood and also differ between the different brain regions. Nevertheless, both blood and brain cytokines indicated that there is inflammatory hyperactivity in IFN $\alpha$ treated rats that coincides with the increased anxiety in the open field.

In conclusion, this study has supported the clinical observation that the negative effects of IFN $\alpha$ on behaviour and blood and brain cytokine changes are largely prevented by chronic paroxetine pre-treatment. This suggests that SSRIs may prevent the immune system hyperactivity caused by IFN $\alpha$ treatment in both blood and brain and thereby prevents the depressive like changes shown in patients. 


\section{Acknowledgement}

This study was mainly funded by University of Maastricht and Schering Plough (Netherlands) and partially supported by Korea University. The work of Kubera M and KaimBasta A was partially supported by the grant 6P05A 07620 from the State Committee for Scientific Research (KBN), Poland.

\section{References}

1. Baron S, Tyring SK, Fleischmann WR, Jr., Coppenhaver DH, Niesel DW, Klimpel GR, et al. The interferons. Mechanisms of action and clinical applications. Jama 1991;266(10):1375-83.

2. Dusheiko G. Side effects of alpha interferon in chronic hepatitis C. Hepatology 1997;26(3 Suppl 1):112S-121S.

3. Valentine AD, Meyers CA, Kling MA, Richelson E, Hauser P. Mood and cognitive side effects of interferon-alpha therapy. Semin Oncol 1998;25(1 Suppl 1):39-47.

4. Meyers CA, Obbens EA, Scheibel RS, Moser RP. Neurotoxicity of intraventricularly administered alpha-interferon for leptomeningeal disease. Cancer 1991;68(1):88-92.

5. Iivanainen M, Laaksonen R, Niemi ML, Farkkila M, Bergstrom L, Mattson K, et al. Memory and psychomotor impairment following high-dose interferon treatment in amyotrophic lateral sclerosis. Acta Neurol Scand 1985;72(5):475-80.

6. Farkkila M, Iivanainen M, Roine R, Bergstrom L, Laaksonen R, Niemi ML, et al. Neurotoxic and other side effects of high-dose interferon in amyotrophic lateral sclerosis. Acta Neurol Scand 1984;70(1):42-6.

7. Poutiainen E, Hokkanen L, Niemi ML, Farkkila M. Reversible cognitive decline during high-dose alphainterferon treatment. Pharmacol Biochem Behav 1994;47(4):901-5.

8. Mattson K, Niiranen A, Iivanainen M, Farkkila M, Bergstrom L, Holsti LR, et al. Neurotoxicity of interferon. Cancer Treat Rep 1983;67(10):958-61.

9. Rohatiner AZ, Prior PF, Burton AC, Smith AT, Balkwill FR, Lister TA. Central nervous system toxicity of interferon. Br J Cancer 1983;47(3):419-22.

10. Niiranen A, Laaksonen R, Iivanainen M, Mattson K, Farkkila M, Cantell K. Behavioral assessment of patients treated with alpha-interferon. Acta Psychiatr Scand 1988;78(5):622-6.

11. Smedley H, Katrak M, Sikora K, Wheeler T. Neurological effects of recombinant human interferon. Br Med J (Clin Res Ed) 1983;286(6361):262-4.

12. Meyers CA, Scheibel RS, Forman AD. Persistent neurotoxicity of systemically administered interferonalpha. Neurology 1991;41(5):672-6.

13. Schaefer M, Engelbrecht MA, Gut O, Fiebich BL, Bauer J, Schmidt F, et al. Interferon alpha (IFNalpha) and psychiatric syndromes: a review. Prog Neuropsychopharmacol Biol Psychiatry 2002;26(4):731-46.

14. Le Quan-Bui KH, Plaisant O, Leboyer M, Gay C, Kamal L, Devynck MA, et al. Reduced platelet serotonin in depression. Psychiatry Res 1984;13(2):129-39.

15. Baudouin-Legros M, Le Quan-Bui KH, Guicheney P, Kamal LA, Meyer P. Platelet serotonin in essential hypertension and in mental depression. J Cardiovasc Pharmacol 1985;7 Suppl 7:S12-4.

16. Byerley WF, Reimherr FW, Wood DR, Grosser BI. Fluoxetine, a selective serotonin uptake inhibitor, for the treatment of outpatients with major depression. J Clin Psychopharmacol 1988;8(2):112-5.

17. Morikawa O, Sakai N, Obara H, Saito N. Effects of interferon-alpha, interferon-gamma and cAMP on the transcriptional regulation of the serotonin transporter. Eur J Pharmacol 1998;349(2-3):317-24.

18. Abe S, Hori T, Suzuki T, Baba A, Shiraishi H, Yamamoto T. Effects of chronic administration of interferon alpha A/D on serotonergic receptors in rat brain. Neurochem Res 1999;24(3):359-63.

19. Recht M, Borden EC, Knight E, Jr. A human 15-kDa IFN-induced protein induces the secretion of IFNgamma. J Immunol 1991;147(8):2617-23.

20. Heyes MP, Saito K, Crowley JS, Davis LE, Demitrack MA, Der M, et al. Quinolinic acid and kynurenine pathway metabolism in inflammatory and non-inflammatory neurological disease. Brain 1992;115 (Pt 5):1249-73.

21. Myint AM, Kim YK. Cytokine-serotonin interaction through IDO: a neurodegeneration hypothesis of depression. Med Hypotheses 2003;61(5-6):519-25.

22. Wichers M, Maes M. The psychoneuroimmuno-pathophysiology of cytokine-induced depression in humans. Int J Neuropsychopharmacol 2002;5(4):375-88.

23. Wichers MC, Koek GH, Robaeys G, Verkerk R, Scharpe S, Maes M. IDO and interferon-alpha-induced depressive symptoms: a shift in hypothesis from tryptophan depletion to neurotoxicity. Mol Psychiatry 2005;10(6):538-44. 
24. Kubera M, Lin AH, Kenis G, Bosmans E, van Bockstaele D, Maes M. Anti-Inflammatory effects of antidepressants through suppression of the interferon-gamma/interleukin-10 production ratio. J Clin Psychopharmacol 2001;21(2):199-206.

25. Myint AM, Leonard BE, Steinbusch HW, Kim YK. Th1, Th2, and Th3 cytokine alterations in major depression. J Affect Disord 2005;88(2):167-73.

26. Kraus MR, Schafer A, Faller H, Csef H, Scheurlen M. Paroxetine for the treatment of interferon-alphainduced depression in chronic hepatitis C. Aliment Pharmacol Ther 2002;16(6):1091-9.

27. Capuron L, Neurauter G, Musselman DL, Lawson DH, Nemeroff CB, Fuchs D, et al. Interferon-alphainduced changes in tryptophan metabolism. relationship to depression and paroxetine treatment. Biol Psychiatry 2003;54(9):906-14.

28. Kraus MR, Schafer A, Scheurlen M. Paroxetine for the prevention of depression induced by interferon alfa. N Engl J Med 2001;345(5):375-6.

29. Musselman DL, Lawson DH, Gumnick JF, Manatunga AK, Penna S, Goodkin RS, et al. Paroxetine for the prevention of depression induced by high-dose interferon alfa. N Engl J Med 2001;344(13):961-6.

30. De La Garza R, 2nd, Asnis GM, Pedrosa E, Stearns C, Migdal AL, Reinus JF, et al. Recombinant human interferon-alpha does not alter reward behavior, or neuroimmune and neuroendocrine activation in rats. Prog Neuropsychopharmacol Biol Psychiatry 2005;29(5):781-92.

31. Makino M, Kitano Y, Komiyama C, Takasuna K. Human interferon-alpha increases immobility in the forced swimming test in rats. Psychopharmacology (Berl) 2000;148(1):106-10.

32. Sammut S, Bethus I, Goodall G, Muscat R. Antidepressant reversal of interferon-alpha-induced anhedonia. Physiol Behav 2002;75(5):765-72.

33. Sammut S, Goodall G, Muscat R. Acute interferon-alpha administration modulates sucrose consumption in the rat. Psychoneuroendocrinology 2001;26(3):261-72.

34. Kennett GA, Lightowler S, de Biasi V, Stevens NC, Wood MD, Tulloch IF, et al. Effect of chronic administration of selective 5-hydroxytryptamine and noradrenaline uptake inhibitors on a putative index of 5-HT2C/2B receptor function. Neuropharmacology 1994;33(12):1581-8.

35. Lightowler S, Kennett GA, Williamson IJ, Blackburn TP, Tulloch IF. Anxiolytic-like effect of paroxetine in a rat social interaction test. Pharmacol Biochem Behav 1994;49(2):281-5.

36. Lieben CK, van Oorsouw K, Deutz NE, Blokland A. Acute tryptophan depletion induced by a gelatinbased mixture impairs object memory but not affective behavior and spatial learning in the rat. Behav Brain Res 2004;151(1-2):53-64.

37. Ennaceur A, Delacour J. A new one-trial test for neurobiological studies of memory in rats. 1: Behavioral data. Behav Brain Res 1988;31(1):47-59.

38. Prickaerts J, Honig W, Schmidt BH, Blokland A. Metrifonate improves working but not reference memory performance in a spatial cone field task. Eur J Pharmacol 1999;380(2-3):61-5.

39. Prickaerts J, Raaijmakers W, Blokland A. Effects of myocardial infarction and captopril therapy on anxiety-related behaviors in the rat. Physiol Behav 1996;60(1):43-50.

40. O’Mahony SM, Myint AM, Steinbusch H, Leonard BE. Efavirenz induces depressive-like behaviour, increased stress response and changes in the immune response in rats. Neuroimmunomodulation 2005;12(5):293-8.

41. Cai Z, Pang Y, Lin S, Rhodes PG. Differential roles of tumor necrosis factor-alpha and interleukin-1 beta in lipopolysaccharide-induced brain injury in the neonatal rat. Brain Res 2003;975(1-2):37-47.

42. O’Connor KA, Johnson JD, Hansen MK, Wieseler Frank JL, Maksimova E, Watkins LR, et al. Peripheral and central proinflammatory cytokine response to a severe acute stressor. Brain Res 2003;991(1-2):123-32.

43. Upreti GC, Ratcliff RA, Riches PC. Protein estimation in tissues containing high levels of lipid: modifications to Lowry's method of protein determination. Anal Biochem 1988;168(2):421-7.

44. Kirazov LP, Venkov LG, Kirazov EP. Comparison of the Lowry and the Bradford protein assays as applied for protein estimation of membrane-containing fractions. Anal Biochem 1993;208(1):44-8.

45. Lacosta S, Merali Z, Anisman H. Behavioral and neurochemical consequences of lipopolysaccharide in mice: anxiogenic-like effects. Brain Res 1999;818(2):291-303.

46. Hilsabeck RC, Hassanein TI, Ziegler EA, Carlson MD, Perry W. Effect of interferon-alpha on cognitive functioning in patients with chronic hepatitis C. J Int Neuropsychol Soc 2005;11(1):16-22.

47. Wichers MC, Koek GH, Robaeys G, Praamstra AJ, Maes M. Early increase in vegetative symptoms predicts IFN-alpha-induced cognitive-depressive changes. Psychol Med 2005;35(3):433-41.

48. Kishihara Y, Hayashi J, Yoshimura E, Yamaji K, Nakashima K, Kashiwagi S. IL1 beta and TNF-alpha produced by peripheral blood mononuclear cells before and during interferon therapy in patients with chronic hepatitis C. Dig Dis Sci 1996;41(2):315-21.

49. Torre F, Rossol S, Pelli N, Basso M, Delfino A, Picciotto A. Kinetics of soluble tumour necrosis factor (TNF)-alpha receptors and cytokines in the early phase of treatment for chronic hepatitis C: comparison 
between interferon (IFN)-alpha alone, IFN-alpha plus amantadine or plus ribavirin. Clin Exp Immunol 2004;136(3):507-12.

50. Marinho RT, Pinto R, Santos ML, Lobos IV, Moura MC. Effects of interferon and ribavirin combination therapy on CD4+ proliferation, lymphocyte activation, and Th1 and Th2 cytokine profiles in chronic hepatitis C. J Viral Hepat 2004;11(3):206-16.

51. Schmitt E, Hoehn P, Huels C, Goedert S, Palm N, Rude E, et al. T helper type 1 development of naive $\mathrm{CD} 4+\mathrm{T}$ cells requires the coordinate action of interleukin- 12 and interferon-gamma and is inhibited by transforming growth factor-beta. Eur J Immunol 1994;24(4):793-8.

52. Prud'homme GJ, Piccirillo CA. The inhibitory effects of transforming growth factor-beta-1 (TGF-beta1) in autoimmune diseases. J Autoimmun 2000;14(1):23-42.

53. Gayle D, Ilyin SE, Miele ME, Plata-Salaman CR. Modulation of TNF-alpha mRNA production in rat C6 glioma cells by TNF-alpha, IL-1beta, IL-6, and IFN-alpha: in vitro analysis of cytokine-cytokine interactions. Brain Res Bull. 1998;47(3):231-5. 


\section{Chapter 4}

\section{Effect of peripheral interferon- $\alpha$ injection on astrocytes and microglial changes in hippocampus of male Wistar rats}

Aye Mu Myint, Christoph Schmitz, Hellen P Steinbusch, Sofi Vossius, Dirk Luchtman, Marjo Van den Waarenburg, Brian E Leonard, Harry WM Steinbusch Experimental Neurology. 2006. Submitted 


\begin{abstract}
Background: The interferon- $\alpha$ (IFN $\alpha$ ), a cytokine used to treat the chronic viral infections and certain cancers can induce depression in some patients and part of them get persistent moderate cognitive deficit. This cytokine enhances the tryptophan breakdown and kynurenine metabolism. This leads to an increase in neurotoxic metabolites such as quinolinic acid which can induce apoptosis of astrocytes. The increase in astrocyte apoptosis in hippocampus may be a prelude to the onset of depression. The purpose of this study was to examine the impact of chronic IFN $\alpha$ on density of astrocytes and microglia in the rat hippocampus. As the selective serotonin reuptake inhibitor (SSRI), fluoxetine attenuates the symptoms of depression the effect of fluoxetine pre-treatment on effect of chronic IFN $\alpha$ was also investigated.

Method: To test the above hypothesis, 4 groups of 6 male Wistar rats were assigned into (1) saline control group, (2) fluoxetine (F) group, (3) interferon- $\alpha$ group and (4) F+ interferon- $\alpha$ group. After 7 weeks of above treatment, animals were processed for immunohistochemistry of glial fibrillary acid protein (GFAP) and tomato-lectin to detect the astrocyte and microglial densities respectively. The sections were quantified with image analysis system in hippocampal dentate gyrus and CA3 region.

Result: The astrocyte density was significantly reduced in both interferon- $\alpha$ treated group and SSRI+ interferon- $\alpha$ group in dentate gyrus whereas the additional reduction was observed only in interferon- $\alpha$ treated group in CA3 region. The microglial activity showed no difference between the groups.

Conclusion: INF- $\alpha$ treatment reduced the density of astrocytes in the hippocampus especially in the DG and CA3 region without effect on the density of microglia. Chronic fluoxetine pre-treatment did not fully prevent the changes in astrocytes density. These results suggest that the decrease of astrocytes density by IFN $\alpha$ may contribute to the depressive episodes with persistent cognitive deficit seen in some patients treated with IFN $\alpha$.
\end{abstract}




\section{Introduction}

Interferon- $\alpha$ (IFN $\alpha)$ is a cytokine used for the treatment of chronic viral diseases such as chronic hepatitis $\mathrm{B}$ and $\mathrm{C}$ and for the treatment of different malignancies (1). Following chronic treatments, there are severe side effects involving the immune system and the brain $(2,3)$. In short term applications of high doses of IFN $\alpha, 20$ to 60 percent of patients, after short latency of several days, developed organic psychosis and severe depression which generally subsided promptly after cessation of treatment (4-11) though moderate deficits in cognitive function occasionally persisted even after cessation of therapy (12). Less severe neuropsychiatric side effects such as mild depression was reported to occur after a longer latency in 4 to 16 percent of patients treated with low-dose IFN $\alpha$ (13). Since in IFN $\alpha$ treatment, $10-20 \%$ of discontinuation of treatment is due to neuropsychiatric side effects, there is a growing interest for a better understanding of possible underlying mechanisms (13).

The human IFNa induced protein (15-kDa protein) that stimulates IFN $\gamma$ synthesis (14). As a consequence the enzyme indolamine 2-3, dioxygenase (IDO) was induced and this catabolises tryptophan to kynurenine and its metabolites through the kynurenine pathway (15). There is evidence that the resulting reduction in the availability of tryptophan for serotonin synthesis contributes to the depressed state seen in patients treated with IFN $\alpha$ (16). Kynurenine is further catabolised into 3-hydroxy kynurenine $(3 \mathrm{OHK})$ and quinolinic acid (QA) $(17,18)$. However, kynurenine is also catabolised into kynurenic acid (KA) (19) that could counteract the action of QA (20, 21). The imbalance between the above QA and KA metabolites was hypothesised to play a role in pathophysiology of major depression $(22,23)$ and in patients treated with IFN $\alpha(16)$.

In the brain, the tryptophan catabolism through IDO activity takes place in astrocytes and microglia (24-27). When IFN $\alpha$ stimulates the activity of IDO, the kynurenine metabolism is also enhanced and the high QA and KA will be produced. The high QA is proven to be apoptotic specifically to astrocytes (28).

In experimental study it has been shown that chronic stress causes a decrease in glial fibrillary acidic protein (GFAP) immunoreactive astrocytes in the hippocampal formation (29). This effect was partly ameliorated by SSRI fluoxetine. Astrocytes are known to synthesise a number of neurotrophic factors that are involved in maintenance of neuroplasticity $(30,31)$. Moreover, they play important role in glutamatergic system (32). In addition, astrocytes, unlike microglia, are protective against neurotoxic quinolinic acid (20,33-35). Thus, reduction in astrocyte number or function that leads to impaired protection would be anticipated to enhance the neurotoxic impact (23).

In our previous experimental study, it was demonstrated that chronic IFN- $\alpha$ treatment in rats could induce sickness behaviour and increased in pro-inflammatory cytokines in the blood and the brain and all these effects were prevented by paroxetine pretreatment (36) that indicated the preventive effect on immune changes in both blood and the brain.

The purpose of this study was to test the hypothesis that parenteral administration of IFN- $\alpha$ causes reduction in density of astrocytes in the rat hippocampus. The possible neuroprotective effect of fluoxetine pre-treatment was also investigated. 


\section{Materials and methods}

\section{Animals}

Twenty-four male Wistar-rats (Charles River Nederland, Maastricht, The Netherlands) of 320 to 360 grams were divided in four groups of six animals. Animals were housed in single in standard Makrolon cages and fed with standard rat chow (Charles River Nederland, Maastricht, The Netherlands) and drinking water ed lib. The first group was the control group, in which animals were treated with subcutaneous injection of normal saline $1 \mathrm{ml} /$ day, 3 days/week for 7 weeks. The second group was treated with fluoxetine (F) $10 \mathrm{mg} /$ day (orally) for 2 weeks followed by normal saline injection $1 \mathrm{ml} /$ day, 3 days/week for 5 weeks. The rats of the third group were treated with normal saline injection $1 \mathrm{ml} /$ day, 3 days/week for 2 weeks followed by subcutaneous injection of interferon- $\alpha$ (INF- $\alpha$ ) (Interon A, Schering-Plough B.V., Utrecht, The Netherlands) 5000 $\mathrm{IU} / \mathrm{kg} /$ day, 3 days/week for 5 weeks. The last group was treated with fluoxetine (F) 10 $\mathrm{mg} / \mathrm{kg}$ (orally) for 2 weeks followed by INF- $\alpha$ injection $5000 \mathrm{IU} / \mathrm{kg} /$ day for 3 days/week for 5 weeks.

The oral fluoxetine was given in the small bottle of drinking water in which the medicine was dissolved and completion of the intake of daily dose was checked everyday. The injections were given in the morning between 9 to 10 am by the same technical assistant in the order of the rats by systematic randomization to avoid the variability.

\section{Immunohistochemistry}

Preparation of tissue

The rats were euthanized with a pentobarbitone sodium injection $(150 \mathrm{mg} / \mathrm{kg})$, intraperitoneally. The rats were perfused with Tyrode and afterwards with Somogyi fixative (37) consisting of $4 \%$ depolymerised paraformaldehyde (Merck KGaA, Darmstadt, Germany), $0.05 \%$ gluteraldehyde (Merck KGaA, Darmstadt, Germany) and $15 \%$ picric acid (Fluka Chemie GmbH, Deisenhoten, Germany) in 0.1M PBS (pH7.4). The brain was dissected out and postfixated with the same fixative for 2 hours. After that the brain was immersed in PBS with $15 \%$ sucrose overnight and was frozen using $\mathrm{CO}_{2}$ gas. The frozen brains were kept in $-80^{\circ} \mathrm{C}$ and then cut into $30 \mu \mathrm{M}$ sections using the cryostat (Leica CM 3050, Leica Microsystem, Heidelberg, Germany).

\section{Immunohistochemical procedure}

To detect the astrocytes density, GFAP staining was used. For the GFAP-staining (G3893, Sigma-Aldrich Chemie GmbH, Munich, Germany), again free-floating hippocampal sections were used. The sections were washed 3 times for 10 minutes with TBST, TBS and TBS-T, respectively. The first antibody (GFAP) was diluted 1:1600 times in TBS-T. After incubating with the first antibody on the shaker overnight in the cold room $\left(4^{\circ} \mathrm{C}\right)$, the sections were rinsed for 3 times. After that, the second antibody, donkey anti-mouse alexa $(488 \mathrm{~nm})$ antibody (Jackson ImmunoResearch Europe Ltd, Cambridgeshire, UK), diluted 1:100 times in TBS-T was added and incubated for an hour and a half at room temperature on the shaker. The sections were rinsed 3 times 
with TBS. After that the sections were mounted on gelatine-coated glasses $(0,5 \%$ gelatine $+0,05 \%$ potassium) and closed in with $80 \%$ glycerol and glass cover slips.

To detect the microglia density, tomato-lectin staining was used. For the tomatolectin (B-1175, Vector Labs, Peterborough, England) staining, free-floating hippocampal sections were used. The sections were rinsed 3 times for 5 minutes with TBS, and then were incubated with the tomato-lectin glycoprotein for 2 hours at room temperature on the shaker. The tomato-lectin was diluted 2000 times in TBS-T. After incubation, the sections were again rinsed 3 times for 5 minutes with TBS. Streptavidin alexa $(488 \mathrm{~nm})$ was added to the sections at a dilution of 1 to 2000 in TBS-T. This had to incubate for an hour and a half, again at room temperature and on the shaker. After 3 more rinsing steps with TBS, an additional Hoechst-staining (1:500 dilution) was added to visualize the nuclei. After the incubation time of 30 minutes sections were rinsed for 3 times again with TBS. The free-floating brain sections were then mounted on gelatine-coated object glasses $(0.5 \%$ gelatine $+0,05 \%$ potassium $)$ and closed in with $80 \%$ glycerol and glass cover slips.

\section{Quantification and data analysis}

From each animal, the photos were taken from three different bregma's $(-3.14,-4.30$ and $-5.60 \mathrm{~nm}$ ) using an Olympus AX 70 microscope equipped with Lympus F-view cooled CCD camera. For the epifluorescence detection we used a narrow band pass MNIBA filter for Alexa Fluor 488 (from Chroma Technology Corp., Rockingham, USA). For the GFAP staining, the photos were taken with 100 times magnification, and for tomato-lectine staining, the photos were taken with 400 times magnification. For both staining, grey values were analyzed in order to detect the overall density which may reflect either number or stromal volume of astrocytes or microglia. For GFAP staining, the grey value analysis was performed on dentate gyrus (DG) area and CA3 area whereas for tomato-lectin staining, only DG area was used. To analyze the greyvalues the software program cell ${ }^{\wedge} \mathrm{p}$ (Olympus Nederland B.V., Zoeterwoude, The Netherlands) was used. The thresholds for the GFAP analysis were set at 65 (low) and 200 (high) to get an equal intensity and as less background signal as possible, and for the tomato-lectin, the thresholds were set at 802 and 2838. After defining the area of interest, the program measures the area $\left(\mu \mathrm{m}^{2}\right)$ and the mean grey values. For the tomatolectin photos, blood vessels shadows were left out of the area of interest.

\section{Statistical analysis}

For statistical analysis, one-way ANOVA statistics was used to see whether there was difference between the groups for either the DG or the CA3 areas. Afterwards post-hoc Bonferroni test was performed to find out the difference between each group. $\mathrm{P}$ values $<$ 0.05 were considered as statistical significance. Statistical analysis was done using SPSS version 11.0 (SPSS; Chicago, IL, USA). 


\section{Results}

\section{Astrocytes density}

The GFAP-staining for astrocytes gave the following photos (Figure 1) when viewed with the Olympus AX 70 microscope (100X).

The descriptive statistics of the mean grey values for DG areas and CA3 areas were shown in figures 2 and 3 , respectively.

There one-way ANOVA showed significant differences in mean grey values between the four groups for both the $\mathrm{DG}$ area $(\mathrm{F}$-value $=17.230 ; \mathrm{p}$-value $=0.00)$ and the CA3 area $(\mathrm{F}$-value $=13.497$; $\mathrm{p}$-value $=0.00)$.

The post-hoc Bonferroni test showed that the mean grey values of GFAP staining of the DG area of the INF- $\alpha$ treated group and fluoxetine followed by INF- $\alpha$ group differed significantly from the saline control ( $\mathrm{p}=0.028$ and 0.022 respectively).

In CA3 area, the post hoc test showed the significant difference only between the INF- $\alpha$ treated group and the saline control group $(p=0.000)$. In CA3 area, the fluoxetine pre-treatment showed no difference from the saline control though there was a trend $(\mathrm{p}=0.078)$.
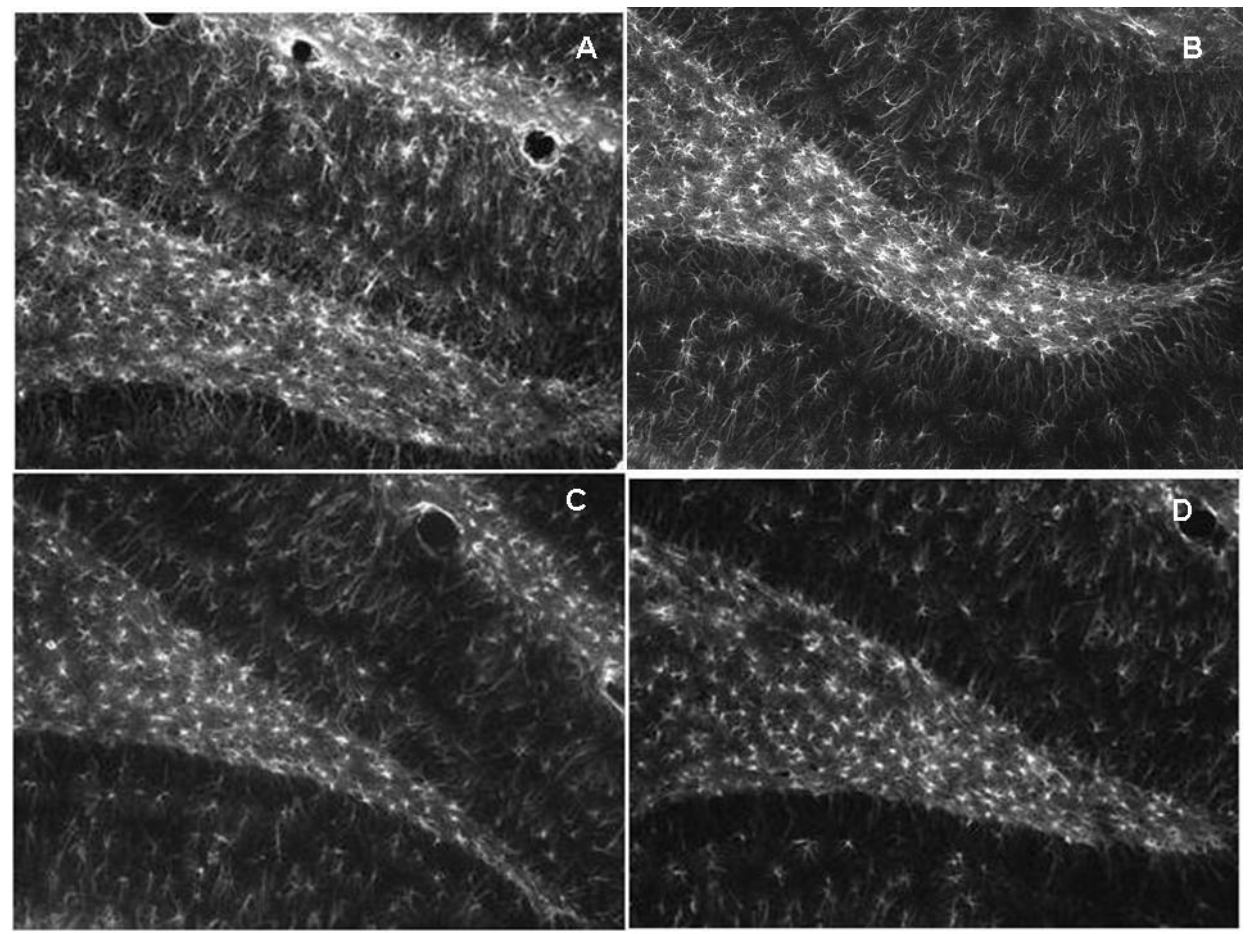

Figure 1 Pictures were taken with the Olympus F-view II microscope with magnification 100X. GFAP was used together with a donkey anti-mouse alexa $(488 \mathrm{~nm})$ to stain the astrocytes. All pictures are of bregma 3,14 and of the DG area. A) group 1 (control); B) group 2 (fluoxetine); C) group 3 (INF- $\alpha$ ); D) group 4 (INF- $\alpha$ + fluoxetine). 
Figure 2 The mean grey values of the GFAP staining of the DG areas of four different groups. The * indicated the significant difference from the Saline Control group.

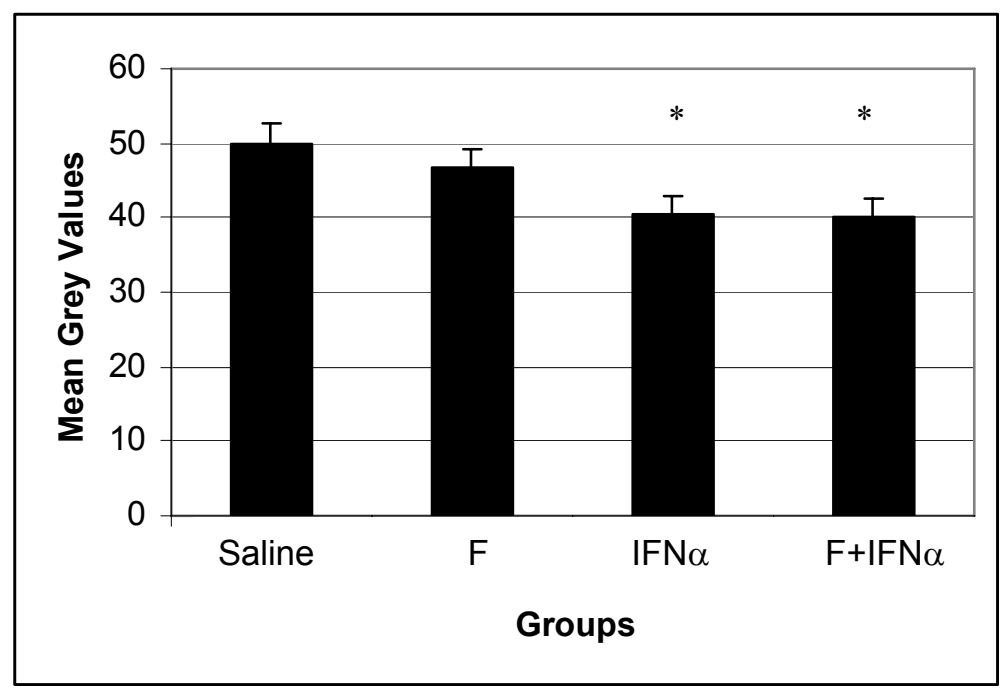

Figure 3 The mean grey values of the GFAP staining of the CA3 areas of all four different groups. The * indicated the significant difference from the Saline Control group.

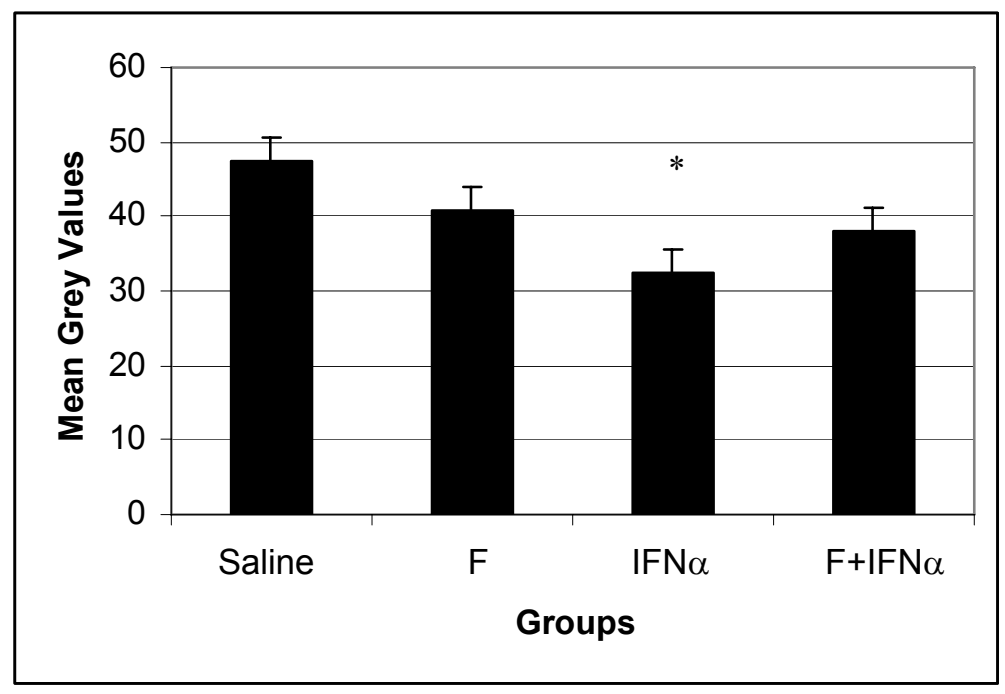




\section{Microglia density}

The descriptive values of the mean grey values of tomato-lectin were given in figure 4 . One-way ANOVA statistics showed no significant difference in mean grey values for tomato-lectin staining that indicates the activity of microglia $(\mathrm{F}=0.619$ and $\mathrm{p}=0.605)$.

Figure 4 The mean grey values of the tomato-lectin staining of the DG areas of all four different groups.

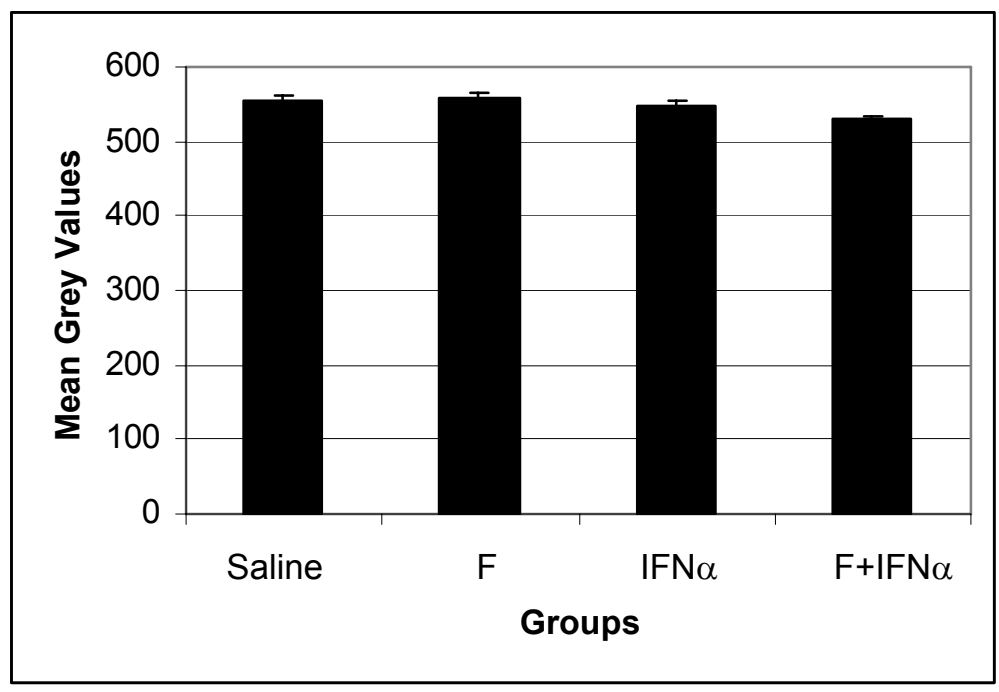

\section{Discussion}

\section{Astrocyte density}

It is apparent from the mean grey values of GFAP stained sections that, in the DG and $\mathrm{CA} 3$ regions of the rat hippocampus, treatment with INF- $\alpha$, either alone or in combination with fluoxetine pre-treatment, results in a reduction in the density of the astrocytes. Other investigators have also reported a reduction in astrocyte density in the hippocampus in experimental study in chronic exposure to stress (29) and in human post-mortem study in steroid-treated and depressed patients (38).

In the present study, although pre-treatment with fluoxetine did not prevent the reduction in astrocytes density in the DG region, there was a slight preventive effect of fluoxetine pre-treatment in CA3 region. Czeh and group (29) also demonstrate the reversal of chronic stress induced reduction in astrocyte number but not reduction in stromal volume with fluoxetine treatment.

Since astrocytes regulate the synaptogenesis and synaptic strength and control the adult neurogenesis in DG area (39-43). this impaired astrocytes density could have 
negative impact on glia-neuron connection and neuron-neuron connection (29) and impaired hippocampal repair following a neurotoxic assault.

These preliminary findings lend credibility to the hypothesis that IFN- $\alpha$ treatment causes a decrease in astrocyte density.

\section{Microglia density}

No significant difference was found in the mean grey values in the hippocampus of the tomato-lectin staining between any of the treatment groups. This contrasts with the experimental findings of the others who reported that the challenge with a single dose of the inflammatory mediator lipopolysaccharide caused an activation of microglia in hippocampus (44), an effect that was qualitatively similar to that reported to occur in rats after exposure to an acute inescapable shock (45). The differences in the experimental procedures between the acute and chronic effect of the stressors used may be the explanation for the lack of change in the microglia density seen in present study. It is possible that the adaptive changes occur following the chronic challenge with IFN- $\alpha$, an initial increase being followed by a return to control values.

\section{Role of above changes in pathophysiology of INF- $\alpha$-induced depression}

Like other pro-inflammatory cytokines, INF- $\alpha$ enhances the IDO activity (15) and kynurenine-3-hydroxylase which in turn resulted in the increase of neurotoxic metabolite QA that induced apoptosis of astrocytes (28). The increase in the neurodegenerative arm of neuroprotection-neurodegeneration challenge in kynurenine pathway, as reflected in a reduction in the neuroprotective kynurenic acid plasma concentration in INF- $\alpha$-treated patients with depressive symptoms (16) and in patients with major depression (23) could lead to the damage to the astrocytes in the hippocampus. The neuroprotective activity of the astrocytes is attributed to their ability to metabolite quinolinic acid (33), through glutamate transporter mechanism (46) and by production of extracellular S100B (47) thereby reducing the effect of QA in hippocampus. Thus the impaired astrocyte densiity that results from chronic INF- $\alpha$ treatment, increase the vulnerability of hippocampal neurones to excitotoxic damage.

\section{Conclusion}

This investigation suggest that INF- $\alpha$ induces a reduction astrocyte density in the rat hippocampus. If a similar mechanism occurs in patients treated with this cytokine, it might predispose patients treated with INF- $\alpha$ to depression. The cognitive dysfunction seen in some patients might also be a reflection of this hippocampal damage. Chronic pre-treatment with fluoxetine did not prevent these changes.

\section{Acknowledgements}

We would like to acknowledge our heartfelt thanks to Schering-Plough B.V. (Utrecht, The Netherlands) for its generosity to provide IFN $\alpha$ injections. 


\section{References}

1. Baron S, Tyring SK, Fleischmann WR, Jr., Coppenhaver DH, Niesel DW, Klimpel GR, et al. The interferons. Mechanisms of action and clinical applications. Jama 1991;266(10):1375-83.

2. Dusheiko G. Side effects of alpha interferon in chronic hepatitis C. Hepatology 1997;26(3 Suppl 1):112S-121S.

3. Valentine AD, Meyers CA, Kling MA, Richelson E, Hauser P. Mood and cognitive side effects of interferon-alpha therapy. Semin Oncol 1998;25(1 Suppl 1):39-47.

4. Meyers CA, Obbens EA, Scheibel RS, Moser RP. Neurotoxicity of intraventricularly administered alpha-interferon for leptomeningeal disease. Cancer 1991;68(1):88-92.

5. Iivanainen M, Laaksonen R, Niemi ML, Farkkila M, Bergstrom L, Mattson K, et al. Memory and psychomotor impairment following high-dose interferon treatment in amyotrophic lateral sclerosis. Acta Neurol Scand 1985;72(5):475-80.

6. Farkkila M, Iivanainen M, Roine R, Bergstrom L, Laaksonen R, Niemi ML, et al. Neurotoxic and other side effects of high-dose interferon in amyotrophic lateral sclerosis. Acta Neurol Scand 1984;70(1):42-6.

7. Poutiainen E, Hokkanen L, Niemi ML, Farkkila M. Reversible cognitive decline during high-dose alphainterferon treatment. Pharmacol Biochem Behav 1994;47(4):901-5.

8. Mattson K, Niiranen A, Iivanainen M, Farkkila M, Bergstrom L, Holsti LR, et al. Neurotoxicity of interferon. Cancer Treat Rep 1983;67(10):958-61.

9. Rohatiner AZ, Prior PF, Burton AC, Smith AT, Balkwill FR, Lister TA. Central nervous system toxicity of interferon. Br J Cancer 1983;47(3):419-22.

10. Niiranen A, Laaksonen R, Iivanainen M, Mattson K, Farkkila M, Cantell K. Behavioral assessment of patients treated with alpha-interferon. Acta Psychiatr Scand 1988;78(5):622-6.

11. Smedley H, Katrak M, Sikora K, Wheeler T. Neurological effects of recombinant human interferon. Br Med J (Clin Res Ed) 1983;286(6361):262-4.

12. Meyers CA, Scheibel RS, Forman AD. Persistent neurotoxicity of systemically administered interferonalpha. Neurology 1991;41(5):672-6.

13. Schaefer M, Engelbrecht MA, Gut O, Fiebich BL, Bauer J, Schmidt F, et al. Interferon alpha (IFNalpha) and psychiatric syndromes: a review. Prog Neuropsychopharmacol Biol Psychiatry 2002;26(4):731-46.

14. Recht M, Borden EC, Knight E, Jr. A human 15-kDa IFN-induced protein induces the secretion of IFNgamma. J Immunol 1991;147(8):2617-23.

15. Heyes MP, Saito K, Crowley JS, Davis LE, Demitrack MA, Der M, et al. Quinolinic acid and kynurenine pathway metabolism in inflammatory and non-inflammatory neurological disease. Brain 1992;115 (Pt 5):1249-73.

16. Wichers MC, Koek GH, Robaeys G, Verkerk R, Scharpe S, Maes M. IDO and interferon-alpha-induced depressive symptoms: a shift in hypothesis from tryptophan depletion to neurotoxicity. Mol Psychiatry 2005;10(6):538-44.

17. Chiarugi A, Calvani M, Meli E, Traggiai E, Moroni F. Synthesis and release of neurotoxic kynurenine metabolites by human monocyte-derived macrophages. J Neuroimmunol 2001;120(1-2):190-8.

18. Bender DA, McCreanor GM. Kynurenine hydroxylase: a potential rate-limiting enzyme in tryptophan metabolism. Biochem Soc Trans 1985;13(2):441-3.

19. Perkins MN, Stone TW. An iontophoretic investigation of the actions of convulsant kynurenines and their interaction with the endogenous excitant quinolinic acid. Brain Res 1982;247(1):184-7.

20. Kim JP, Choi DW. Quinolinate neurotoxicity in cortical cell culture. Neuroscience 1987;23(2):423-32.

21. Stone TW, Darlington LG. Endogenous kynurenines as targets for drug discovery and development. Nat Rev Drug Discov 2002;1(8):609-20.

22. Myint AM, Kim YK. Cytokine-serotonin interaction through IDO: a neurodegeneration hypothesis of depression. Med Hypotheses 2003;61(5-6):519-25.

23. Myint A, Kim, YK., Verkerk, R., Scharpe, S., Steinbusch, HWM., Leonard, BE. Kynurenine pathway in major depression: Evidence of impaired neuroprotection. J Affect Disord 2006.

24. Grant R, Kapoor V. Inhibition of indoleamine 2,3-dioxygenase activity in IFN-gamma stimulated astroglioma cells decreases intracellular NAD levels. Biochem Pharmacol 2003;66(6):1033-6.

25. Grant RS, Naif H, Espinosa M, Kapoor V. IDO induction in IFN-gamma activated astroglia: a role in improving cell viability during oxidative stress. Redox Rep 2000;5(2-3):101-4.

26. Grant RS, Kapoor V. Murine glial cells regenerate NAD, after peroxide-induced depletion, using either nicotinic acid, nicotinamide, or quinolinic acid as substrates. J Neurochem 1998;70(4):1759-63.

27. Heyes MP, Achim CL, Wiley CA, Major EO, Saito K, Markey SP. Human microglia convert 1tryptophan into the neurotoxin quinolinic acid. Biochem J 1996;320 (Pt 2):595-7. 
28. Guillemin GJ, Wang L, Brew BJ. Quinolinic acid selectively induces apoptosis of human astrocytes: potential role in AIDS dementia complex. J Neuroinflammation 2005;2:16.

29. Czeh B, Simon M, Schmelting B, Hiemke C, Fuchs E. Astroglial Plasticity in the Hippocampus is Affected by Chronic Psychosocial Stress and Concomitant Fluoxetine Treatment. Neuropsychopharmacology 2006;31(8):1616-26.

30. Friedman WJ, Black IB, Kaplan DR. Distribution of the neurotrophins brain-derived neurotrophic factor, neurotrophin-3, and neurotrophin-4/5 in the postnatal rat brain: an immunocytochemical study. Neuroscience 1998;84(1):101-14.

31. Alderson RF, Curtis R, Alterman AL, Lindsay RM, DiStefano PS. Truncated TrkB mediates the endocytosis and release of BDNF and neurotrophin- $4 / 5$ by rat astrocytes and schwann cells in vitro. Brain Res 2000;871(2):210-22.

32. Anderson CM, Swanson RA. Astrocyte glutamate transport: review of properties, regulation, and physiological functions. Glia 2000;32(1):1-14.

33. Guillemin GJ, Smythe G, Takikawa O, Brew BJ. Expression of indoleamine 2,3-dioxygenase and production of quinolinic acid by human microglia, astrocytes, and neurons. Glia 2005;49(1):15-23.

34. Guillemin GJ, Kerr SJ, Smythe GA, Smith DG, Kapoor V, Armati PJ, et al. Kynurenine pathway metabolism in human astrocytes: a paradox for neuronal protection. J Neurochem 2001;78(4):842-53.

35. Guillemin GJ, Smith DG, Kerr SJ, Smythe GA, Kapoor V, Armati PJ, et al. Characterisation of kynurenine pathway metabolism in human astrocytes and implications in neuropathogenesis. Redox Rep 2000;5(2-3):108-11.

36. Myint AM, O’Mahony, S., Kubera, M, Kim, YK., Kenny, C., Kaim-Basta, A., Steinbusch, HWM., Leonard, BE. Role of paroxetine in interferon induced immune and behavioural changes in male Wistar rats. Psychopharmachology 2006.

37. Somogyi P, Takagi H. A note on the use of picric acid-paraformaldehyde-glutaraldehyde fixative for correlated light and electron microscopic immunocytochemistry. Neuroscience 1982;7(7):1779-83.

38. Muller MB, Lucassen PJ, Yassouridis A, Hoogendijk WJ, Holsboer F, Swaab DF. Neither major depression nor glucocorticoid treatment affects the cellular integrity of the human hippocampus. Eur J Neurosci 2001;14(10):1603-12.

39. Goldman S. Glia as neural progenitor cells. Trends Neurosci 2003;26(11):590-6.

40. Horner PJ, Palmer TD. New roles for astrocytes: the nightlife of an 'astrocyte'. La vida loca! Trends Neurosci 2003;26(11):597-603.

41. Nedergaard M, Ransom B, Goldman SA. New roles for astrocytes: redefining the functional architecture of the brain. Trends Neurosci 2003;26(10):523-30.

42. Newman EA. New roles for astrocytes: regulation of synaptic transmission. Trends Neurosci 2003;26(10):536-42.

43. Slezak M, Pfrieger FW. New roles for astrocytes: regulation of CNS synaptogenesis. Trends Neurosci 2003;26(10):531-5.

44. Herber DL, Maloney JL, Roth LM, Freeman MJ, Morgan D, Gordon MN. Diverse microglial responses after intrahippocampal administration of lipopolysaccharide. Glia 2006;53(4):382-91.

45. Frank MG, Baratta MV, Sprunger DB, Watkins LR, Maier SF. Microglia serve as a neuroimmune substrate for stress-induced potentiation of CNS pro-inflammatory cytokine responses. Brain Behav Immun 2006.

46. Reagan LP, Rosell DR, Wood GE, Spedding M, Munoz C, Rothstein J, et al. Chronic restraint stress upregulates GLT-1 mRNA and protein expression in the rat hippocampus: reversal by tianeptine. Proc Natl Acad Sci U S A 2004;101(7):2179-84.

47. Tramontina F, Tramontina AC, Souza DF, Leite MC, Gottfried C, Souza DO, et al. Glutamate uptake is stimulated by extracellular S100B in hippocampal astrocytes. Cell Mol Neurobiol 2006;26(1):81-6. 


\section{Chapter 5}

\section{Effect of COX-2 inhibitor celecoxib on behavioural and immune changes in Olfactory bulbectomised rat model of depression}

Aye Mu Myint, Harry WM Steinbusch, Liam Goeghegan, Dirk Luchtman, Yong Ku Kim, Brian E Leonard

Neuroimmunomodulation. 2006. Submitted. 


\begin{abstract}
Background: The olfactory bulbectomised (OBX) rat model is a chronic model of depression in which behavioural and neuro-immuno-endocrine changes are reversed only after chronic anti-depressant treatment. The cyclooxygenase 2 (COX-2) inhibitor celecoxib has been shown to improve the depressive symptoms in patients with major depression.

Method: The association between blood and brain immunological changes and behavioural changes in chronic treatment with COX-2 inhibitor was explored in the OBX rats and their sham operated controls.

Result: The OBX group showed significantly higher locomotor activity than the other groups in the first 5 minutes in the open field. In the home cage emergence test, the OBX group showed significantly shorter latency period compared to sham group ( $\mathrm{z}=-$ $3.192, \mathrm{p}=0.001$ ) but there is no difference between the other three groups. In the brain, (1) in the hypothalamus, the OBX group had a significantly higher IL1 $\beta$ and IL10 concentrations than OBX+ celecoxib group $(z=-1.89, p=0.05)$ and in $\operatorname{IL10}(z=-1.995$, $\mathrm{p}=0.046)$; and (2) in prefrontal cortex, OBX group showed significantly higher concentrations of $\operatorname{TNF} \alpha(\mathrm{z}=-2.205, \mathrm{p}=0.028)$ and $\operatorname{IL} 1 \beta(\mathrm{z}=-3.361, \mathrm{p}=0.001)$ than $\mathrm{OBX}+$ celecoxib group but the OBX group showed a significantly lower concentration of IL10 $(p=-3.361, p=0.001)$ than that of the OBX + celecoxib group.

Conclusion: The results of this study supported the potential therapeutic role of COX-2 inhibitor celecoxib. It is possible that the behavioural changes following the chronic administration of celecoxib to the OBX rats are associated with an attenuation of the increase in the pro-inflammatory cytokines in the brain.
\end{abstract}




\section{Introduction}

The olfactory bulbectomised (OBX) rat model of depression is one of the well known rat models of depression in which all behavioural (1-3), anatomical $(4,5)$, biochemical (3, 6-9), and immunological changes (10-15) were shown to be similar to those observed in major depression. Moreover, those changes were reversed by chronic, but not acute, antidepressant treatments $(3,8,10,14-18)$.

Studies of the changes in humoral immunity in OBX rat model, demonstrated an increased serum interleukin (IL) $1 \beta$ and prostaglandin (PG)E2 release from the whole blood cultures $(15,19)$, and a suppression of basal anti-inflammatory cytokine IL10 production $(15,19)$. It was also reported that the OBX rats showed a more pronounced increase of early gene expression of $c$-fos gene, prostaglandin receptor (EP4), tumour necrosis factor- $\alpha(\mathrm{TNF} \alpha)$ and corticotrophin releasing factor (CRF) after immunostimulant lipopolysaccharide (LPS) treatment compared to sham operated controls (6, 12). It was shown that these parameters increased in several brain regions particularly in the cortical and limbic regions $(6,12)$. These changes in serum PGE2, and decrease in IL10, in OBX rats were attenuated by in vivo treatment with venlafaxine (20).

In major depression, an increase of PGE2 in the saliva, serum and the cerebrospinal fluid has been reported (21-23). There was also evidence of an increased in vitro PGE2 secretion from lymphocytes of depressed patients compared to their controls (24). Cyclooxygenase (COX) is the key enzyme involved in prostaglandin synthesis that exists in two forms, of which COX-2 is cytokine-inducible and is expressed in inflammatory cells and also responsible for PGs produced in inflammation (25-30). The possible antidepressant effect of COX-2 inhibitor rofecoxib has already been observed in osteoarthritis patients with comorbid depression (31). In a prospective, 6-week, double-blind, add-on clinical trial with reboxetine with or without COX-2 inhibitor celecoxib has been reported that celecoxib significantly enhanced the antidepressant response to reboxetine (32).

As the association between behavioural improvement and inflammatory changes in blood and brain following COX-2 inhibitor therapy has not been explored, this preliminary study explored the effect of COX-2 inhibitor celecoxib on behaviour and blood and brain cytokine changes in OBX rat model of depression.

\section{Materials and Methods}

\section{Animals}

Male Sprague-Dawley rats (Charles River Laboratory, The Netherlands) weighing 260$300 \mathrm{gm}$ were housed individually in standard Makrolon cage and kept one week before operation under 12-hour reversed light-dirk cycle with food (standard diet, Charles River) and water ad libitum. The olfactory bulbectomy operation was done after one week adaptation and the rats were returned to their same home cages again after 8 hours post-operative observation. The study was approved by the Institutional Ethical Committee for animal experimentation, University of Maastricht, The Netherlands. 


\section{Operation procedure}

Surgery was performed according to van Riezen \& Leonard (1990) (3). In summary, the rats were anesthetized s.c. with ketamine $\mathrm{HCl}$ (Nimatek, $60 \mathrm{mg} / \mathrm{kg}$ ) and xylazine $\mathrm{HCl}$ (Xylazin, $30 \mathrm{mg} / \mathrm{kg}$ ). The animals were positioned on a heating pad during the surgical procedures. Under anaesthesia and aseptic conditions, the scalp was shaved and excised. A $2 \mathrm{~cm}$ midline incision centred on bregma was made and the surface of the skull was cleaned and marked for burr holes at $5 \mathrm{mms}$ anterior to bregma and $2 \mathrm{~mm}$ on either side of the midline. Two holes were then drilled and the olfactory bulbs were removed by suction provided by an aspirator pump. Burr holes were then plugged with absorbable hemostatic sponges and the incision was sutured. For sham operation, the same procedure was followed except aspirating olfactory bulbs. After surgery, the animals were kept under a close observation for 6 to 8 hours to recover. At the first signs of recovery, buprenorphine (Temgesic, $0.03 \mathrm{mg} / \mathrm{ml}$ ) was injected s.c. to relieve the pain for surgery. After recovery, animals were returned to their home cages and allowed to recover for 2 weeks.

\section{Treatment}

Table. 1. Table showing the different treatment groups of animals

\begin{tabular}{ll}
\hline Group & Treatment (N=8/group) \\
\hline OBX & Olfactory bulbectomy + normal drinking water \\
OBX + C & Olfactory bulbectomy + celecoxib (Cerebrex) orally $10 \mathrm{mg} / \mathrm{kg} /$ day x 2 weeks \\
Sham & Sham operation + normal drinking water \\
Sham $+\mathrm{C}$ & Sham operation + celecoxib (Cerebrex) orally $10 \mathrm{mg} / \mathrm{kg} /$ day x 2 weeks \\
\hline
\end{tabular}

The rats were assigned to 4 different groups of 8 rats each as followed (Table 1). The medication of celecoxib (Cerebrex from Pfizer, Korea) was given orally in the small bottle of drinking water in which the drink was dissolved. The completeness of intake of medication per day was checked everyday.

\section{Behavioural procedures}

The treatment started at 2 weeks after operation. The rats were handled every day in the first week to prevent the unnecessary aggressiveness that can affect the behavioural procedures. The following behavioural studies were undertaken commencing 14 days after starting the celecoxib treatment. The body weight was recorded once a week.

Exposure to the open field arena for $20 \mathrm{~min}$. Open Field testing (33) was conducted in a square, clear Plexiglas box $(100 \mathrm{~cm} \times 100 \mathrm{~cm} \times 30 \mathrm{~cm})$, with an open top and a dark floor. The arena of the open field was subdivided in four equal areas (quadrants), which reduced the anxiety component of this OF set-up, as the open space, which is normally aversive to rodents, was reduced in this set-up. Four rats could be tested simultaneously. 
The OF apparatus was placed on the floor of an experimental room. A camera was installed $2.5 \mathrm{~m}$ above the centre of the field. Rats were randomly assigned a quadrant. After the rats were placed in each quadrant, the session started until 20 minutes had passed. The movements and positions of the animal were recorded and registered automatically by a computerized system (EthoVision Color Pro, Noldus, The Netherlands). After each session, the floor was cleaned with $97 \%$ ethanol to remove odor cues. The session duration of 20 minutes was subdivided in 4 equal intervals of 5 minutes for later data analyses. The total distance moved $(\mathrm{cm})$ and velocity $(\mathrm{cm} / \mathrm{s})$ were measured.

Home Cage Emergence Test. The home cage emergence test was applied once a week throughout the experimental period. In this test, the home cage with the rat was placed in the middle of the open field (33). The cage top was left open so that the rat could emerge via an easily accessible grid. The latency (in seconds) to emerge from the home cage (i.e., the time taken until a rat was on the grid outside its cage with all four legs) was scored.

\section{Biochemical analyses}

Sample collection. One week after cessation of behavioural experiment and drug treatments, the rats were euthanized with thiopentone $(150 \mathrm{mg} / \mathrm{kg}$ i.p). The blood was collected from the aorta in heparinised tubes within 3 to 5 minutes later. The procedure was undertaken between 09:00 to 10:00 hours. One $\mathrm{ml}$ of whole blood was taken for the whole blood stimulation culture, the remainder of the blood was centrifuged, and the plasma was collected and stored at $-70^{\circ} \mathrm{C}$ for subsequent corticosterone analysis.

Immediately after blood collection, the rats were decapitated and three brain areas (hippocampus, hypothalamus and pre-frontal cortex) were dissected on a frosted glass plate and put in sterile chilled PBS (pH7.4-7.6) containing protease inhibitor cocktail (Roche) and stored at $-70^{\circ} \mathrm{C}$ for analysis of cytokines at a later date.

Plasma corticosterone analysis. Plasma corticosterone was analysed using EIA kit for rat and mouse corticosterone from IDS. The detection limit was $18 \mathrm{ng} / \mathrm{ml}$ and the intraassay coefficient of variation was $3.1 \%$.

Blood culture and cytokine analysis. The pro-inflammatory IL1 $\beta$ and TNF $\alpha$, and antiinflammatory IL10 cytokines were analysed in both supernatants from stimulated and unstimulated cultures. The whole blood was collected at room temperature to prepare cultures. Whole blood was cultured in 24-well Costar plate and for each rat, 2 stimulated culture wells and 2 unstimulated culture wells were prepared. In each well $250 \mu \mathrm{l}$ of whole blood was incubated at $37^{\circ} \mathrm{C}$ for 48 hours with $750 \mu \mathrm{l}$ of RPMI 1640 medium containing $50 \mu \mathrm{g} / \mathrm{ml}$ LPS (Sigma) and $10 \mu \mathrm{g} / \mathrm{ml}$ Concanavalin A (Sigma) for the stimulated cultures $(34,35)$. The RPMI 1640 without mitogens was used for unstimulated culture. The supernatants were collected after 48 -hour incubation and kept at $-70^{\circ} \mathrm{C}$ for the analysis of cytokines at a later date. The blood cytokines were analysed in duplicate using ELISA developed with DuoSet ELISA from R\&D System, UK for rat IL1 $\beta$, TNF $\alpha$ and IL10 according to the instructions of the manufacturer. The detection limits were $39.06 \mathrm{pg} / \mathrm{ml}$ for IFN $\gamma$ and $62.5 \mathrm{pg} / \mathrm{ml}$ for the other cytokines. The intra-assay coefficients of variation were: $3.2 \%$ for rat IL $1 \beta, 3.5 \%$ for rat $\mathrm{TNF} \alpha$ and $5.2 \%$ for rat IL10, respectively.

Brain cytokine analysis. Brain cytokine analysis was undertaken with the minor modification of the previously published methods $(36,37)$. Brain samples were thawed in an 
ice bath and sonicated for 20 seconds in cold sterile PBS (pH7.4-7.6) with protease inhibitor cocktail (Roche, The Netherlands). The protein concentration was analysed by Lowry's method on sonicated samples $(38,39)$. The sonicated samples were centrifuged and the brain IL1 $\beta$, TNF $\alpha$, and IL10 were analysed in duplicate in the supernatant diluted with sterile PBS. The brain cytokine levels were were analysed in duplicate using ELISA developed with DuoSet ELISA from R\&D System, UK for rat IL1 $\beta$, TNF $\alpha$ and IL10 and the concentrations were expressed as $\mathrm{pg} / \mathrm{mg}$ protein. The detection limit for all cytokines was $62.5 \mathrm{pg} / \mathrm{ml}$. The intra-assay coefficients of variation were: $3.2 \%$ for rat IL $1 \beta, 3.5 \%$ for rat TNF $\alpha$ and $5.2 \%$ for rat IL 10 , respectively.

\section{Data analysis}

The effect of treatment on behaviour and immune parameters were analysed using one-way ANOVA and Bonferroni post-hoc tests were used to perform the pair-wise comparison. To determine the significant difference between the 4 groups for the data with unequal distribution on K-S D test, non-parametric tests, Mann-Whitney test and Kruskal-Wallis test were used. The analysis was carried out using SPSS version 11.5 and the probability of 0.05 or below was considered to be statistically significant.

\section{Result}

\section{Behavioural tests}

In open field experiment, there was a significant difference between the groups in both distance moved in the first 5 minutes $(\mathrm{F}=7.66, \mathrm{p}=0.001)$ and the velocity of movement in the first 5 minutes $(\mathrm{F}=7.57, \mathrm{p}=0.001)$. In post hoc Bonferroni test, the OBX group showed significantly higher distance moved and velocity moved in the first 5 minutes in the open field than the $\mathrm{OBX}+\mathrm{C}$ group $(\mathrm{p}=0.008$ and 0.008$)$, sham group $(\mathrm{p}=0.002$ and $0.003)$ and sham $+\mathrm{C}$ group $(\mathrm{p}=0.004$ and 0.002$)$ respectively.

In home cage emergence test, the Kruskal-Wallis test showed the significant difference in latency period between the groups $(\chi 2=9.199, \mathrm{p}=0.027)$. The OBX group showed significantly shorter latency period compared to sham group $(\mathrm{z}=-3.192, \mathrm{p}=0.001)$ but there is no difference between the other three groups.

\section{Biochemical parameters}

The cytokines concentrations in the supernatant of unstimulated whole blood culture and mitogen stimulated whole blood culture of olfactory bulbectomised (BOX) rat group, OBX + celecoxib (C) group, sham operated group and sham $+\mathrm{C}$ group. No statistically significant difference was observed between the groups.

Though there was no statistically significant difference in plasma corticosterone concentrations between the groups it was slightly higher in OBX group (table 2).

No significant difference was found in plasma cytokine concentrations between $\mathrm{OBX}$ and $\mathrm{OBX}+\mathrm{C}$ or sham or sham $+\mathrm{C}$ groups (table 2 ). 
Table-2-Descriptive data on corticosterone concentration in plasma and cytokines concentrations in whole blood culture supernatants

\begin{tabular}{|c|c|c|c|c|}
\hline Parameters & $\begin{array}{l}\mathrm{OBX} \\
\mathrm{N}=8\end{array}$ & $\begin{array}{c}\mathrm{OBX}+\mathrm{C} \\
\mathrm{N}=8\end{array}$ & $\begin{array}{l}\text { sham } \\
\mathrm{N}=8\end{array}$ & $\begin{array}{c}\text { sham }+\mathrm{C} \\
\mathrm{N}=8\end{array}$ \\
\hline $\begin{array}{l}\text { Plasma Corticosterone } \\
(\mathrm{mmol} / \mathrm{l})(\text { mean } \pm \text { S.D })\end{array}$ & $280.65 \pm 180.55$ & $238.79 \pm 140.35$ & $228.52 \pm 125.55$ & $240.56 \pm 130.23$ \\
\hline \multicolumn{5}{|l|}{$\begin{array}{l}\mathrm{IL} 1 \beta(\mathrm{pg} / \mathrm{l}) \\
(\mathrm{mean} \pm \mathrm{S} . \mathrm{D})\end{array}$} \\
\hline Unstimulated & 0.00 & 0.00 & 0.00 & 0.00 \\
\hline Stimulated & $89.04 \pm 14.18$ & $71.17 \pm 6.07$ & $86.16 \pm 14.82$ & $94.77 \pm 28.55$ \\
\hline \multicolumn{5}{|l|}{$\begin{array}{l}\mathrm{TNF} \alpha(\mathrm{pgl} / \mathrm{l}) \\
(\mathrm{mean} \pm \mathrm{S} . \mathrm{D})\end{array}$} \\
\hline Unstimulated & $20.13 \pm 37.97$ & 0.00 & 0.00 & 0.00 \\
\hline Stimulated & $411.68 \pm 334.29$ & $359.94 \pm 148.84$ & $436.69 \pm 185.88$ & $504.85 \pm 338.80$ \\
\hline \multicolumn{5}{|l|}{$\begin{array}{l}\text { IL10 (pg/l) } \\
(\text { mean } \pm \text { S.D) }\end{array}$} \\
\hline Unstimulated & 0.00 & 0.00 & $19.99 \pm 37.47$ & $19.57 \pm 36.46$ \\
\hline Stimulated & $265.28 \pm 95.61$ & $363.82 \pm 129.82$ & $424.04 \pm 231.25$ & $379.99 \pm 75.12$ \\
\hline
\end{tabular}

However, in the brain, Kruskal-Wallis test showed significant difference in all three cytokines between overall groups in all three brain areas except TNF $\alpha$ in prefrontal cortex (table 3 ). For IL1 $\beta$, the overall differences between all 4 groups were observed in both hypothalamus $(\mathrm{p}=0.05)$, hippocampus $(\mathrm{p}=0.000)$, and in prefrontal cortex $(p=0.000)$ areas. For TNF $\alpha$, the overall differences between all 4 groups were observed in both hypothalamus $(\mathrm{p}=0.05)$, hippocampus $(\mathrm{p}=0.000)$, but not in prefrontal cortex $(p=0.067)$ areas. For IL10, the overall differences between all 4 groups were observed in both hypothalamus $(\mathrm{p}=0.049)$, hippocampus $(\mathrm{p}=0.000)$, and in prefrontal cortex $(\mathrm{p}=0.000)$ areas.

The results from Mann-Whitney test showed (1) in hypothalamus area, OBX group showed significantly higher concentration than $\mathrm{OBX}+\mathrm{C}$ group in IL1 $\beta$ concentrations $(\mathrm{z}=-1.89, \mathrm{p}=0.05)$ and in IL10 $(\mathrm{z}=-1.995, \mathrm{p}=0.046)$; $(2)$ in hippocampus area, the main differences were only between two OBX groups which showed higher concentrations in both pro- and anti-inflammatory cytokines and two sham operated groups which showed lower cytokines concentrations but no difference between celecoxib treated groups and non-treated groups; (3) in prefrontal cortex, OBX group showed significantly higher concentrations of $\operatorname{TNF} \alpha \quad(\mathrm{z}=-2.205, \mathrm{p}=0.028)$ and $\operatorname{IL} 1 \beta \quad(\mathrm{z}=-3.361$, $\mathrm{p}=0.001)$ than $\mathrm{OBX}+\mathrm{C}$ group whereas $\mathrm{OBX}$ showed significantly lower concentration of IL10 $(p=-3.361, p=0.001)$ than $\mathrm{OBX}+\mathrm{C}$ group. 
Table-3 - Descriptive data on cytokines concentrations in different brain regions

\begin{tabular}{|c|c|c|c|c|}
\hline Parameters & $\begin{array}{l}\mathrm{OBX} \\
\mathrm{N}=10\end{array}$ & $\begin{array}{l}\mathrm{OBX}+\mathrm{C} \\
\mathrm{N}=10\end{array}$ & $\begin{array}{l}\text { sham } \\
\mathrm{N}=10\end{array}$ & $\begin{array}{c}\text { Sham }+\mathrm{C} \\
\mathrm{N}=10\end{array}$ \\
\hline \multicolumn{5}{|l|}{$\begin{array}{l}\text { IL1 ( (pg/mg) } \\
\text { (mean } \pm \text { S.D) }\end{array}$} \\
\hline Hippocampus** & $52.42 \pm 24.58$ & $95.85 \pm 51.78$ & $15.49 \pm 5.7$ & $14.49 \pm 6.13$ \\
\hline Hypothalamus* & $157.65 \pm 81.5$ & $107.39 \pm 46.95$ & $108.26 \pm 34.67$ & $263.09 \pm 205.99$ \\
\hline Prefrontal cortex ${ }^{* *}$ & $62.51 \pm 29.46$ & $16.60 \pm 5.11$ & $29.93 \pm 14.27$ & $18.89 \pm 8.39$ \\
\hline \multicolumn{5}{|l|}{$\begin{array}{l}\text { TNF } \alpha(p g / m g) \\
(\text { mean } \pm \text { S.D) }\end{array}$} \\
\hline Hippocampus** & $34.28 \pm 18.13$ & $50.57 \pm 28.41$ & $7.32 \pm 3.3$ & $8.29 \pm 3.83$ \\
\hline Hypothalamus* & $111.37 \pm 68.12$ & $74.19 \pm 31.32$ & $66.73 \pm 24.38$ & $176.38 \pm 135.84$ \\
\hline Prefrontal cortex & $71.32 \pm 29.56$ & $34.15 \pm 16.04$ & $39.50 \pm 28.49$ & $37.12 \pm 18.74$ \\
\hline \multicolumn{5}{|l|}{$\begin{array}{l}\text { IL10 (pg/mg) } \\
(\text { mean } \pm \text { S.D) }\end{array}$} \\
\hline Hippocampus** & $129.53 \pm 60.14$ & $177.49 \pm 95.58$ & $37.28 \pm 10.72$ & $33.14 \pm 10.71$ \\
\hline Hypothalamus* & $337.30 \pm 217.71$ & $249.53 \pm 108.24$ & $273.92 \pm 98.5$ & $603.37 \pm 446.07$ \\
\hline Prefrontal cortex $* *$ & $36.69 \pm 11.26$ & $113.94 \pm 45.09$ & $70.26 \pm 29.24$ & $40.30 \pm 16.67$ \\
\hline
\end{tabular}

\section{Discussion}

The behavioural results in this study showed that the hyperactive behaviour of the OBX in the first five minutes in the open field was reversed by the chronic celecoxib treatment. In addition, OBX rats also showed similar hyperactive behaviour in home cage emergence test compared to sham operated rats and was also reversed by celecoxib treatment. The increased exploratory behaviour in the open field apparatus is one of the earliest and more robust indices of OBX-related behavioural change $(1,3)$. However, we observed this behaviour only in the first 5 minutes of the 20 minutes in the open field and there was no difference in habituation in the later 5-minute sessions. This might be due to the less stressful paradigm of our open field arena (40). Nevertheless, our data indicated that the increased exploratory behaviour of OBX rats was not observed in those OBX rats treated with celecoxib.

Regarding the peripheral cytokine production, both basal and mitogen stimulated culture showed no significant difference between the groups. However, in the hypothalamus, both pro-inflammatory IL1 $\beta$ and anti-inflammatory IL10 concentrations were increased in the OBX group, but not in $\mathrm{OBX}+\mathrm{C}$ group. In addition, in prefrontal cortex, OBX group showed significantly higher pro-inflammatory cytokines concentrations but 
lower anti-inflammatory cytokine concentrations compared to $\mathrm{OBX}+\mathrm{C}$ group. In contrast to these areas, in the hippocampus, all three cytokines concentrations were increased in both OBX group and $\mathrm{OBX}+\mathrm{C}$ group compared to two sham groups. Taken together, our results showed that there was an increased inflammatory activity in the OBX animals in hypothalamus and prefrontal cortex and that was reversed in the $\mathrm{OBX}+\mathrm{C}$ group in hypothalamus and prefrontal cortex.

In macrophage theory of depression (41) it was proposed that the high IL1 $\beta$ produced by macrophages may stimulate the CRF secretion and induce a hyperactive HPA axis. However, in the present study we did not find an increased plasma corticosterone secretion in OBX group even though we observed high IL1 $\beta$ concentration in hypothalamus of the OBX rats. The reason might be due to simultaneous increased in IL1 $\beta$ and IL10 concentrations in the hypothalamus that produced a balance between pro- and anti-inflammatory cytokines which in turn prevented the significant increase in HPA axis activity. It is also possible that, as we collected the blood samples for biochemical analyses during the day time under euthanasia, and that might mask the difference in plasma corticosterone concentrations. A hypersecretion of corticosterone in OBX rats during the dark phase of the light-dark cycle, but not during the light phase, has also been reported previously (11).

The high pro-inflammatory cytokines concentrations and low anti-inflammatory cytokine IL10 concentration in prefrontal cortex might be the reason for the behavioural changes in OBX rats in our study. In patients with major depression, neuroimaging and post-mortem studies have identified neurobiological and neurophysiological abnormalities in multiple areas of the prefrontal cortex and its linked brain regions (42-46). The COX-2 inhibitor celecoxib was also proven to improve the depressive symptoms in patients with major depression (32). Those findings supported our findings that the chronic celecoxib treatment reversed both the behavioural and prefrontal cortex cytokine changes in $\mathrm{OBX}+\mathrm{C}$ group.

It may be concluded that the COX-2 inhibitor celecoxib reverses these changes induced by the lesions of the olfactory bulb by blocking the pro-inflammatory cytokines in prefrontal cortex that might result in the reduction in PGE2. In addition, the synergistic effect of reduction in both IL1 and TNF may also impact on the release of PGE2 (47). The possible link between the change in PGE2 following COX-2 inhibitor and the synthesis of serotonin in the cortex of the rat brain has been reported (48). It therefore seems possible in the rat that the normalisation of the behaviour of the OBX rats in the present study could be associated with the increase in the brain serotonin since low brain serotonergic activity OBX rat model has been reported (49).

Nevertheless, the results of our study supported the clinical observation that the COX-2 inhibitor celecoxib may exhibit antidepressant properties by reducing the inflammatory changes in the brain.

\section{Acknowledgement}

This study is mainly funded by Brain and Behaviour Research Institute of the University of Maastricht and partly contributed by Ansan Korea University Medical Centre, Korea University. 


\section{References}

1. Klein D, Brown TS. Exploratory behavior and spontaneous alternation in blind and anosmic rats. J Comp Physiol Psychol 1969;68(1):107-10.

2. Thorne BM, Aaron M, Latham EE. Effects of olfactory bulb ablation upon emotionality and muricidal behavior in four rat strains. J Comp Physiol Psychol 1973;84(2):339-44.

3. van Riezen H, Leonard BE. Effects of psychotropic drugs on the behavior and neurochemistry of olfactory bulbectomized rats. Pharmacol Ther 1990;47(1):21-34.

4. Jancsar SM, Leonard BE. Behavioural and neurochemical interactions between chronic reserpine and chronic antidepressants. A possible model for the detection of atypical antidepressants. Biochem Pharmacol 1983;32(10):1569-71.

5. Wrynn AS, Sebens JB, Koch T, Leonard BE, Korf J. Prolonged c-Jun expression in the basolateral amygdala following bulbectomy: possible implications for antidepressant activity and time of onset. Brain Res Mol Brain Res 2000;76(1):7-17.

6. Song C, Earley B, Leonard BE. Behavioral, neurochemical, and immunological responses to CRF administration. Is CRF a mediator of stress? Ann N Y Acad Sci 1995;771:55-72.

7. Redmond AM, Kelly JP, Leonard BE. Behavioural and neurochemical effects of dizocilpine in the olfactory bulbectomized rat model of depression. Pharmacol Biochem Behav 1997;58(2):355-9.

8. Kelly JP, Wrynn AS, Leonard BE. The olfactory bulbectomized rat as a model of depression: an update. Pharmacol Ther 1997;74(3):299-316.

9. Hozumi S, Nakagawasai O, Tan-No K, Niijima F, Yamadera F, Murata A, et al. Characteristics of changes in cholinergic function and impairment of learning and memory-related behavior induced by olfactory bulbectomy. Behav Brain Res 2003;138(1):9-15.

10. Song C, Killeen AA, Leonard BE. Catalase, superoxide dismutase and glutathione peroxidase activity in neutrophils of sham-operated and olfactory-bulbectomised rats following chronic treatment with desipramine and lithium chloride. Neuropsychobiology 1994;30(1):24-8.

11. Song C, Leonard BE. Interleukin-2-induced changes in behavioural, neurotransmitter, and immunological parameters in the olfactory bulbectomized rat. Neuroimmunomodulation 1995;2(5):26373.

12. Song C, Earley B, Leonard BE. The effects of central administration of neuropeptide $\mathrm{Y}$ on behavior, neurotransmitter, and immune functions in the olfactory bulbectomized rat model of depression. Brain Behav Immun 1996;10(1):1-16.

13. Song C, Earley B, Leonard BE. Behavioural and immunological effects of the antihistamine terfenadine in olfactory bulbectomized rats. Eur Neuropsychopharmacol 1996;6(3):157-62.

14. Leonard BE, Song C. Changes in the immune system in rodent models of depression. Int J Neuropsychopharmacol 2002;5(4):345-56.

15. Song C, Li X, Leonard BE, Horrobin DF. Effects of dietary n-3 or n-6 fatty acids on interleukin-1betainduced anxiety, stress, and inflammatory responses in rats. J Lipid Res 2003;44(10):1984-91.

16. Song C, Leonard BE. The olfactory bulbectomised rat as a model of depression. Neurosci Biobehav Rev 2005;29(4-5):627-47.

17. Butler J, Tannian M, Leonard BE. The chronic effects of desipramine and sertraline on platelet and synaptosomal 5-HT uptake in olfactory bulbectomised rats. Prog Neuropsychopharmacol Biol Psychiatry 1988;12(5):585-94.

18. Jesberger JA, Richardson JS. Effects of antidepressant drugs on the behavior of olfactory bulbectomized and sham-operated rats. Behav Neurosci 1986;100(2):256-74.

19. Connor TJ, Harkin A, Kelly JP, Leonard BE. Olfactory bulbectomy provokes a suppression of interleukin-1beta and tumour necrosis factor-alpha production in response to an in vivo challenge with lipopolysaccharide: effect of chronic desipramine treatment. Neuroimmunomodulation 2000;7(1):27-35.

20. Song C. The effect of thymectomy and IL1 on memory: implications for the relationship between immunity and depression. Brain Behav Immun 2002;16(5):557-68.

21. Calabrese JR, Skwerer RG, Barna B, Gulledge AD, Valenzuela R, Butkus A, et al. Depression, immunocompetence, and prostaglandins of the E series. Psychiatry Res 1986;17(1):41-7.

22. Ohishi K, Ueno R, Nishino S, Sakai T, Hayaishi O. Increased level of salivary prostaglandins in patients with major depression. Biol Psychiatry 1988;23(4):326-34.

23. Nishino S, Ueno R, Ohishi K, Sakai T, Hayaishi O. Salivary prostaglandin concentrations: possible state indicators for major depression. Am J Psychiatry 1989;146(3):365-8.

24. Song C, Lin A, Bonaccorso S, Heide C, Verkerk R, Kenis G, et al. The inflammatory response system and the availability of plasma tryptophan in patients with primary sleep disorders and major depression. $\mathrm{J}$ Affect Disord 1998;49(3):211-9. 
25. Hla T, Neilson K. Human cyclooxygenase-2 cDNA. Proc Natl Acad Sci U S A 1992;89(16):7384-8.

26. Masferrer JL, Seibert K, Zweifel B, Needleman P. Endogenous glucocorticoids regulate an inducible cyclooxygenase enzyme. Proc Natl Acad Sci U S A 1992;89(9):3917-21.

27. O'Banion MK, Winn VD, Young DA. cDNA cloning and functional activity of a glucocorticoidregulated inflammatory cyclooxygenase. Proc Natl Acad Sci U S A 1992;89(11):4888-92.

28. Sirois J, Richards JS. Purification and characterization of a novel, distinct isoform of prostaglandin endoperoxide synthase induced by human chorionic gonadotropin in granulosa cells of rat preovulatory follicles. J Biol Chem 1992;267(9):6382-8.

29. Kujubu DA, Fletcher BS, Varnum BC, Lim RW, Herschman HR. TIS10, a phorbol ester tumor promoter-inducible mRNA from Swiss 3T3 cells, encodes a novel prostaglandin synthase/cyclooxygenase homologue. J Biol Chem 1991;266(20):12866-72.

30. Masferrer JL, Zweifel BS, Seibert K, Needleman P. Selective regulation of cellular cyclooxygenase by dexamethasone and endotoxin in mice. J Clin Invest 1990;86(4):1375-9.

31. Collantes-Estevez E, Fernandez-Perez C. Improved control of osteoarthritis pain and self-reported health status in non-responders to celecoxib switched to rofecoxib: results of PAVIA, an open-label postmarketing survey in Spain. Curr Med Res Opin 2003;19(5):402-10.

32. Muller N, Schwarz MJ, Dehning S, Douhe A, Cerovecki A, Goldstein-Muller B, et al. The cyclooxygenase-2 inhibitor celecoxib has therapeutic effects in major depression: results of a doubleblind, randomized, placebo controlled, add-on pilot study to reboxetine. Mol Psychiatry 2006;11(7):6804.

33. Prickaerts J, Raaijmakers W, Blokland A. Effects of myocardial infarction and captopril therapy on anxiety-related behaviors in the rat. Physiol Behav 1996;60(1):43-50.

34. Myint AM, O’Mahony, S., Kubera, M, Kim, YK., Kenny, C., Kaim-Basta, A., Steinbusch, HWM., Leonard, BE. Role of paroxetine in interferon-a-induced immune and behavioural changes in male Wistar rats. Psychopharmachology 2006.

35. O’Mahony SM, Myint AM, Steinbusch H, Leonard BE. Efavirenz induces depressive-like behaviour, increased stress response and changes in the immune response in rats. Neuroimmunomodulation 2005;12(5):293-8.

36. Cai Z, Pang Y, Lin S, Rhodes PG. Differential roles of tumor necrosis factor-alpha and interleukin-1 beta in lipopolysaccharide-induced brain injury in the neonatal rat. Brain Res 2003;975(1-2):37-47.

37. O'Connor KA, Johnson JD, Hansen MK, Wieseler Frank JL, Maksimova E, Watkins LR, et al. Peripheral and central proinflammatory cytokine response to a severe acute stressor. Brain Res 2003;991(1-2):123-32.

38. Upreti GC, Ratcliff RA, Riches PC. Protein estimation in tissues containing high levels of lipid: modifications to Lowry's method of protein determination. Anal Biochem 1988;168(2):421-7.

39. Kirazov LP, Venkov LG, Kirazov EP. Comparison of the Lowry and the Bradford protein assays as applied for protein estimation of membrane-containing fractions. Anal Biochem 1993;208(1):44-8.

40. Stockert M, Serra J, De Robertis E. Effect of olfactory bulbectomy and chronic amitryptiline treatment in rats. $3 \mathrm{H}$-imipramine binding and behavioral analysis by swimming and open field tests. Pharmacol Biochem Behav 1988;29(4):681-6.

41. Smith RS. The macrophage theory of depression. Med Hypotheses 1991;35(4):298-306.

42. Sibille E, Arango V, Galfalvy HC, Pavlidis P, Erraji-Benchekroun L, Ellis SP, et al. Gene expression profiling of depression and suicide in human prefrontal cortex. Neuropsychopharmacology 2004;29(2):351-61.

43. Drevets WC. Functional anatomical abnormalities in limbic and prefrontal cortical structures in major depression. Prog Brain Res 2000;126:413-31.

44. Drevets WC. Neuroimaging studies of mood disorders. Biol Psychiatry 2000;48(8):813-29.

45. Drevets WC. Prefrontal cortical-amygdalar metabolism in major depression. Ann N Y Acad Sci 1999;877:614-37.

46. Drevets WC, Videen TO, Price JL, Preskorn SH, Carmichael ST, Raichle ME. A functional anatomical study of unipolar depression. J Neurosci 1992;12(9):3628-41.

47. Conti P, Reale M, Fiore S, Cancelli A, Angeletti PU, Dinarello CA. Recombinant interleukin 1 and tumor necrosis factor acting in synergy to release thromboxane, 6-KETO-PGF1 alpha and PGE2 by human neutrophils. Scand J Rheumatol Suppl 1988;75:318-24.

48. Sandrini M, Vitale G, Pini LA. Effect of rofecoxib on nociception and the serotonin system in the rat brain. Inflamm Res 2002;51(3):154-9.

49. Connor TJ, Song C, Leonard BE, Anisman H, Merali Z. Stressor-induced alterations in serotonergic activity in an animal model of depression. Neuroreport 1999;10(3):523-8. 


\section{Chapter 6}

\section{Kynurenine pathway in Major Depression: Evidence of impaired neuroprotection}

Aye Mu Myint, Yong Ku Kim, Robert Verkerk, Simon Scharpé, Harry WM Steinbusch, Brian E Leonard

Juornal of Affective Disorder. 2006. doi:10.1016/j.jad.2006.07.013[EPubAhead of print] 


\begin{abstract}
Background: The neurodegeneration hypothesis proposed major depression as a consequence of imbalance between neuroprotective and neurodegenerative metabolites in kynurenine pathway.

Method: To test the hypothesis, the plasma tryptophan and kynurenine pathway metabolites were studied in 58 patients with major depression and 189 normal controls. Result: The mean tryptophan breakdown index was higher $(p=0.036)$, and mean kynurenic acid concentration and mean neuroprotective ratios were lower, in depressed patients ( $\mathrm{p}=0.003$ and 0.003 , respectively). In receiver-operating characteristic analysis, the kynurenic acid concentrations and the neuroprotective ratio showed clear discrimination between depressed patients and control with area under the curve $79 \%$ and $76.3 \%$ respectively. The neuroprotective ratio did not change after treatment in those with repeated episodes of depression but it increased significantly $(p=0.044)$ in those with first episodes.

Conclusion: The results suggested that the reduction in neuroprotective markers, which indicated an impaired neuroprotection, may play an important role in pathophysiology of major depression.
\end{abstract}




\section{Introduction}

It has been documented that pro-inflammatory cytokines such as interferon- $\alpha$ could induce depression (1-3) and there is a body of evidence that pro-inflammatory cytokines are higher in depressed patients compared to their controls $(4,5)$.The high tryptophan breakdown, and a low kynurenic acid concentration, in the blood of the patients with hepatitis $\mathrm{C}$ who had been treated with the pro-inflammatory cytokine interferon- $\alpha$ and suffered from depressive like symptoms, was recently reported $(6,7)$.

Tryptophan depletion is the result of enhanced tryptophan catabolism by the tryptophan 2,3-dioxygenase (TDO) in the liver (8) and the indoleamine 2,3-dioxygenase (IDO) in the lungs, placenta, blood and the brain $(9,10)$. The TDO specifically metabolises tryptophan only (8) whereas IDO also metabolises serotonin and melatonin (11). Recently, TDO2 immunoreactivity was demonstrated in frontal cortex of the schizophrenic brain (12) though its exact role in the brain is still controversial. The activity of TDO is enhanced by the tryptophan concentration (13-15) and by high cortisol (16) whereas IDO activity is enhanced by the pro-inflammatory cytokines such as interferon$\gamma(17-21)$ and inhibited by anti-inflammatory cytokine, IL4 (22). Both persistent hypercortisolaemia (23-26) and the increased pro-inflammatory cytokines $(4,5,27-32)$ have been reported in patients with major depression.

After tryptophan is first catabolised into kynurenine, there is further catabolic pathway, the kynurenine pathway, in which the metabolites contribute to the neuroprotective-neurodegenerative changes in the brain. Kynurenine is further catabolised into 3hydroxy kynurenine $(3 \mathrm{OHK})$ and the NMDA receptor agonist quinolinic acid $(33,34)$ (figure 1). The $3 \mathrm{OHK}$ causes neuronal apoptosis (35) while quinolinic acid causes excitotoxic neurodegenerative changes (36). However, kynurenine can also be catabolised into kynurenic acid (figure 1) which is NMDA receptor antagonist (37) and is protective against excitotoxic action of quinolinic acid $(38,39)$.

In the brain, tryptophan catabolism occurs in the astrocytes and microglia (40-42) though $60 \%$ of brain kynurenine was contributed from the periphery (43). The astrocytes were shown to produce mainly kynurenic acid whereas microglia and macrophages produced mainly quinolinic acid (44-46). The astrocytes were also demonstrated to metabolise the quinolinic acid produced by the neighbouring microglia (45). The protective effect of kynurenic acid against excitotoxic effect of quinolinic acid has also been detected in neuronal cell cultures (38).

A study of quinolinic acid concentration in the blood of patients with different major psychiatric disorders and neurodegenerative disorders failed to show high quinolinic acid concentration in depressed patients (47). However, the importance of the disturbance in the balance between the kynurenic acid and quinolinic acid, the neuroprotective-neurodegenerative balance in the brain of the patients chronic depression, has been proposed in the neurodegeneration hypothesis of depression (48).

Though the cytokine changes in depression have been well documented, the role of tryptophan metabolism in terms of the balance between neuroprotection and neurodegeneration in major depression has never been explored. To test whether the enhanced tryptophan breakdown, and the imbalance in neurodegenerative and neuroprotective metabolites in kynurenine pathway, are involved in the pathophysiology major depression, the changes in tryptophan and kynurenine pathway metabolites were therefore explored in the plasma of depressed patients and healthy controls. 


\section{CHAPTER 6}

Figure 1. Kynurenine pathway

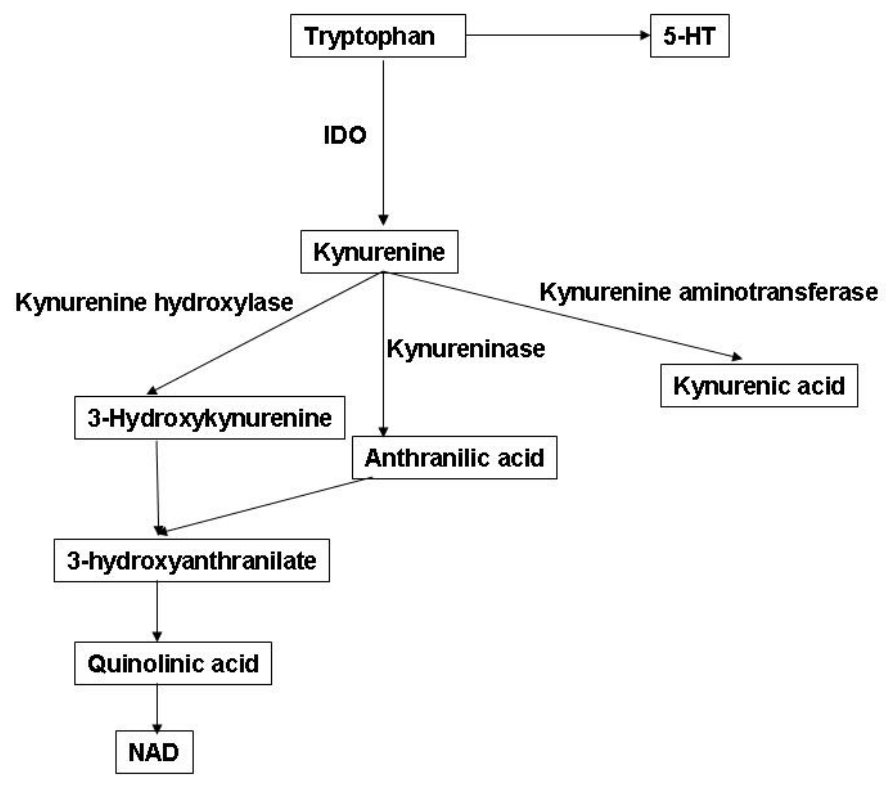

Above figure explains briefly on tryptophan catabolic pathway. It demonstrates that after tryptophan is catabolised into kynurenine, it is further catabolised into quinolinic acid and kynurenic acid.

5-HT $=5$-hydroxy tryptamine $($ serotonin $)$ IDO = indoleamine 2,3-dioxygenase; NAD = nicotinamide adenine dinucleotide

\section{Materials and Methods}

\section{Subjects}

Among psychiatric patients admitted to the Psychiatry Department, Korea University Medical Centre, during the period from 2002 to 2004, 58 patients with major depression, who met the Diagnostic and Statistical Manual (DSM-IV) criteria based on clinical interviews using a Structured Clinical Interview for DSM-IV (49), were recruited. Among them, 52\% were drug naïve, 10\% were drug free for at least 4 months and 38\% were on antidepressant treatment. This study was approved by the institutional ethical committee of Korea University and informed consent was taken from each subject and patient. 
The psychopathological status of the patients was assessed by a trained physician using the Brief Psychiatric Rating Scale (BPRS) (50) and the Hamilton Depression Rating Scale (HDRS) (51) on admission and at the end of 6 weeks anti-depressant trial.

Out of the 58 patients, 40 patients (male:female, 1.2:1; age, $44.62 \pm 14.67$ years) who agreed to be hospitalised during the 6-week study were included in the second part of the study to compare the change in the tryptophan metabolism after antidepressant treatment. Among these, $60 \%$ were treated with selective serotonin reuptake inhibitors (SSRI), 21.3\% with tricyclic antidepressants, 8.4\% with Serotonin Noradrenalin Reuptake Inhibitor (SNRI), 6.4\% with SSRIs and mood stabilizer and 4.3\% with SSRIs and antipsychotics (risperidone or olanzapine).

The patients who had history of any concomitant psychiatric illness, such as substance or alcohol abuse, or history of infection or known autoimmune disease were excluded. The patients found to have any abnormality in blood (blood glucose, cholesterol, renal, thyroid and liver function, Venereal Disease Research Laboratory tests) and urine tests or in electrocardiogram (ECG) and electroencephalogram (EEG), were also excluded. The laboratory tests were rechecked after 6 weeks.

A total of 189 healthy controls (male:female, 1:1.2; age, $32.49 \pm 10.69$ years) were recruited among apparently healthy individuals who visited the hospital for regular health screening during the same period. Those with any history of past psychiatric illness, diagnosed autoimmune disease, or substance or alcohol abuse were excluded. All subjects were free from any physical illness for at least 2 weeks before the study. They showed normal laboratory findings in blood chemistry (blood glucose, cholesterol, renal, thyroid and liver function), Venereal Disease Research Laboratory tests, chest Xray, and ECG.

\section{Biochemical analysis}

Fasting venous blood $(10 \mathrm{ml})$ was withdrawn with a lithium heparin vacuum tube between 8:00-9:00 A.M. Plasma was separated immediately and stored at $-70^{\circ} \mathrm{C}$. For the depressed patients, blood was sampled again at 6 weeks later. The high performance liquid chromatography was used to measure plasma tryptophan, competing aminoacids (tyrosine, valine, phenylalanine, leucine, isoleucine) according to the method of Cooper et al (52), to measure plasma kynurenine, kynurenic acid and 3-hydroxyanthranilic acid (3HAA) (the metabolite from degenerative pathway, one step before quinolinic acid) according to the method of Hervé et al (53).

The tryptophan and competing aminoacids were analysed in the plasma samples using reversed phase high performance liquid chromatography (HPLC) with Chromolith Performance PR-18e, 4.7x100mm column (Merck, Darmstadt, Germany). Amino acids were detected fluorimetrically at an excitation wavelength of $340 \mathrm{~nm}$ and an emission wavelength of $440 \mathrm{~nm}$ after derivatisation with o-phtalicdialdehyde and on-line microdialysis by an ASTED autosampler (Gilson, Viliers le Bel, France). The mobile phase was set in gradient by mixing Solvent A $\left(57.2 \mathrm{~g} \mathrm{Na}_{2} \mathrm{HPO}_{4} .12 \mathrm{H}_{2} \mathrm{O}\right.$ and $160 \mathrm{ml}$ of Acetonitrile in Milli Q water which is made to total 2 litres, $\mathrm{pH}$ 6.5) and Solvent B (420 water $/ 280 \mathrm{ACN} / 320 \mathrm{MeOH}$ ). The different aminoacid standards (tyrosine, valine, tryptophan, phenylalanine, isoleusine and leusine) are prepared as stock by weighing off $100 \mathrm{mg}$ of each compound and dissolving in Milli Q water in a $100 \mathrm{ml}$ measuring flasks. For Working Standard solution, $5 \mathrm{ml}$ of those aminoacid stock standards are diluted 
with Milli Q water. Norvaline $0.5 \mathrm{mg} / \mathrm{ml}$ was used as internal standard. Borate buffer $(\mathrm{pH} 9.5)$ was used for dialysis of the sample.

The kynurenine, kynurenic acid and 3HAA were analysed in the deproteinised plasma samples using reversed phase high performance liquid chromatography (HPLC) with Chromolith performance PR-18e, 4.7x100mm column (Merck, Darmstadt, Germany). Kynurenine was detected spectrophotometrically at $365 \mathrm{~nm}$, kynurenic acid was detected fluorimetrically at an excitation wavelength of $334 \mathrm{~nm}$ and an emission wavelength of $388 \mathrm{~nm}$ and 3HAA was detected fluorimetrically at an excitation wavelength of $316 \mathrm{~nm}$ and an emission wavelength of $420 \mathrm{~nm}$. The mobile phase was prepared with $250 \mathrm{mM}$ Zinc-acetate in distilled water $(27.4 \mathrm{~g}$ in $500 \mathrm{ml})$ and $\mathrm{pH}$ was brought to 5.8 with acetic acid and made up to a volume of $455 \mathrm{ml}$ with water. A total of $45 \mathrm{ml}$ acetonitrile was added into this mixture. The kynurenine standards were prepared by dissolving kynurenine in water and kynurenic acid standards were prepared by dissolving kynurenic acid ethanol and hydrochloric acid. For working standards, the stock standards of $5 \mu \mathrm{M}$ for kynurenine $(500 \mu \mathrm{l})$ and $100 \mathrm{nM}$ for kynurenic acid $(10.0 \mu \mathrm{l})$ were diluted in distilled water. Perchloric acid was used for deproteinization.

The intra- and inter-assay coefficient of variations ranged from 5\% to $7 \%$ for all the metabolites. To avoid the effect of inter-assay variation, the samples from both depressed patients and normal controls were mixed alternately in each set of analyses. To avoid the operator bias the samples' order was arranged by the investigator and the laboratory technician was blind to the information of the sample whether depressed or normal. For each 20 samples 3 standards and one quality control sample (pooled drug free EDTA plasma) were used as quality control.

\section{Calculations}

The tryptophan index that indicated the tryptophan availability in the brain was taken as the ratio between plasma tryptophan and the competing amino acids.

Tryptophan index $=\underline{100 \times \text { plasma tryptophan }(\mu \mathrm{mol} / \mathrm{l})}$

Sum of plasma CAA $(\mu \mathrm{mol} / \mathrm{l})$

The plasma CAA value was the sum of plasma tyrosine, valine, phenylalanine, leucine, isoleucine values.

The tryptophan breakdown index, that indirectly indicated the sum of the activities of TDO and IDO, was calculated as shown;

Tryptophan breakdown index = plasma kynurenine $(\mu \mathrm{mol} / \mathrm{l})$ plasma tryptophan $(\mu \mathrm{mol} / \mathrm{l})$

The ratio between plasma kynurenic acid and plasma kynurenine, from which kynurenic acid and quinolinic acid are formed, enabled the neuroprotective ratio to be determined;

Neuroprotective ratio $=\underline{1000 \times \text { plasma kynurenic acid }(\mathrm{nmol} / \mathrm{l})}$

plasma kynurenine (nmol/l)

\section{Data analysis}

Since the means of the age of controls and depressed were significantly different, the data was analysed in whole group by controlling age and gender in multivariate and 
univariate analyses and also by dividing the 2 different age groups (younger than 40 year age group and between 40 to 50 year age group). The comparison of the mean values of the parameters, that showed normal distributions between depressed patients and controls, were analysed using Students ' $t$ ' test. The comparison of the parameters with normal distribution in the patients on admission and at the time of discharge, were analysed using paired ' $t$ ' test. For the parameters which are not normally distributed in $\mathrm{K}-\mathrm{S} \mathrm{D}$ test, the comparison within group was analysed using Wilcoxon signed rank test and the comparison between groups was analysed using Mann-Whitney test. Multivariate analysis was used to determine the differences in kynurenic acid and neuroprotective ratio between depressed patients and controls when age and gender were controlled. Univariate analysis was applied to determine the effect of body mass index, subtype of depression, number of previous episodes of depression, medication before admission and suicidal attempts on the plasma tryptophan, kynurenine, 3HAA, kynurenic acid and the neuroprotective ratio on admission when age and gender were controlled. This analysis was also applied to the effect of the type of antidepressant administered on the plasma tryptophan, kynurenine, 3HAA, kynurenic acid and the neuroprotective ratio at the time of discharge. The Receiver Operating Characteristic (ROC) Curve analysis was used to find the cut-off point and to determine the discrimination between depressed patients and controls using kynurenic acid and the neuroprotective ratio. The SPSS 11.05 version was used for the statistical analyses and the ' $p$ ' value of 0.05 and below was considered significant.

\section{Results}

\section{General characteristics}

Table 1. General characteristics of the depressed patients

\begin{tabular}{lcc}
\hline Parameters & $\begin{array}{c}\text { Depressed } \\
\mathrm{n}=58\end{array}$ & $\begin{array}{c}\text { Controls } \\
\mathrm{N}=189\end{array}$ \\
\hline Gender (Male:Female) & $1.2: 1$ & $1: 1.2$ \\
Age (years) (mean $\pm \mathrm{SD})$ & $44.62 \pm 14.67$ & $32.49 \pm 10.69$ \\
BMI (mean $\pm \mathrm{SD})$ & $21.44 \pm 3.03$ & $22.11 \pm 2.99$ \\
Subtypes of depression (\%) & 60.3 & \\
$\quad$ Melancholic & 15.5 & \\
$\quad$ Atypical & 22.4 & 1.7 \\
$\quad$ Psychotic & $27.21 \pm 7.26$ \\
$\quad$ Disthymic & 48 & \\
HDRS (mean \pm SD) & $10-62$ & \\
Previous history of depression (\%) & 17.2 \\
Onset of major depression (months) (range) & \\
Suicidal attempt (\%) & & \\
\hline
\end{tabular}


Table 1 shows the general characteristics of the patients and the control subjects. There was no significant difference between body mass index $(\mathrm{t}=-1.36, \mathrm{p}=0.175)$ and gender ratio (male:female, 1.2:1 vs 1:1.2) between the depressed patients and the controls. However, the mean age was higher in depressed patients than the controls $(t=5.840$, $\mathrm{p}=0.000)$.

\section{Depressed patients versus normal controls}

Though the mean plasma CAA and mean plasma tryptophan concentrations showed no difference between the patients and controls, the mean tryptophan index in the depressed patients was significantly lower than that of the controls $(p=0.045)$. The mean tryptophan breakdown index of the depressed patients was significantly higher than in the controls $(p=0.036)$. The mean plasma kynurenine values showed no difference between the groups. The mean plasma kynurenic acid values and the mean neuroprotective ratios, showed highly significant differences between the depressed patients and the controls ( $p=0.003$ and $p=0.003$, respectively) when age and gender were controlled. A comparison of the biochemical parameters between the depressed patients and the controls were shown in the table 2 .

The univariate analyses showed that there were no effects of body mass index, subtype of depression, number of previous episodes of depression, duration of illness, medication before admission and suicidal attempts on plasma kynurenic acid values and neuroprotective ratios when age and gender were controlled. The HDRS score showed no significant correlation with the plasma kynurenic acid values or the neuroprotective ratios.

Table 2. Biochemical parameters of depressed patients on admission vs normal controls

\begin{tabular}{|c|c|c|c|}
\hline Parameters & $\begin{array}{l}\text { Depression } \\
\qquad \mathrm{N}=58\end{array}$ & $\begin{array}{l}\text { Normal control } \\
\qquad \mathrm{N}=189\end{array}$ & 'p' value \\
\hline $\begin{array}{l}\text { Plasma CAA } \\
(\mu \mathrm{mol} / 1)\end{array}$ & $664.91 \pm 123.25$ & $650.73 \pm 132.21$ & 0.453 \\
\hline Plasma Tryptophan $(\mu \mathrm{mol} / \mathrm{l})$ & $65.80 \pm 15.57$ & $69.71 \pm 13.65$ & 0.066 \\
\hline Tryptophan index & $9.99 \pm 1.88$ & $10.87 \pm 1.67$ & 0.045 \\
\hline Tryptophan breakdown $\dagger$ & $0.025 \pm 0.012$ & $0.017 \pm 0.014$ & 0.036 \\
\hline $\begin{array}{l}\text { Plasma Kynurenine } \\
(\mu \mathrm{mol} / \mathrm{l})\end{array}$ & $1.81 \pm 0.56$ & $1.87 \pm 0.43$ & 0.475 \\
\hline $\begin{array}{l}\text { Plasma hydroxyanthranilic acid } \\
(\mu \mathrm{mol} / \mathrm{l})\end{array}$ & $24.53 \pm 11.91$ & $24.12 \pm 7.3$ & 0.851 \\
\hline Plasma Kynurenic acid $\$(\mathrm{nmol} / \mathrm{l})$ & $24.29 \pm 8.09$ & $35.95 \pm 13.4$ & 0.003 \\
\hline Neuroprotective ratio $\$$ & $14.08 \pm 4.37$ & $19.36 \pm 5.89$ & 0.003 \\
\hline
\end{tabular}


Note: All the parameters were expressed in mean $\pm \mathrm{SD}$ and were compared using ' $\mathrm{t}$ ' test except those indicated with $\dagger$ for which Mann-Whitney test was used and $\ddagger$ for which multivariate analysis was used.

The ROC curve analysis for the plasma kynurenic acid showed that the area under the curve was $79 \%$. With the cut-off point of $27.625 \mathrm{nmol} / 1$ of plasma kynurenic acid, the depressed patients and normal controls could be differentiated with the sensitivity of $74.5 \%$ and the specificity of $70.5 \%$. The ROC curve analysis for the neuroprotective ratio showed that the area under the curve was $76.3 \%$. With the cut-off point of 16.05 of plasma kynurenic acid, the depressed patients and normal controls could be differentiated with the sensitivity of $70.5 \%$ and the specificity of $68.1 \%$.

Even though patients and controls were subdivided into two age groups, the significance of the parameters did not change (table 3).

Table 3. Biochemical parameters of depressed patients on admission vs normal controls in two different age matched groups.

\begin{tabular}{|c|c|c|c|c|}
\hline \multirow[t]{2}{*}{ Parameters } & \multicolumn{2}{|c|}{ Age below 40} & \multicolumn{2}{|c|}{ Age 40 to 50} \\
\hline & Depression & Normal control & Depression & Normal control \\
\hline & $\mathrm{N}=25$ & $\mathrm{~N}=145$ & $\mathrm{~N}=30$ & $\mathrm{~N}=44$ \\
\hline Age (years) & $30.39 \pm 7.02$ & $27.84 \pm 6.40$ & $44.28 \pm 3.29$ & $44.00 \pm 2.95$ \\
\hline $\begin{array}{l}\text { Plasma Tryptophan } \\
(\mu \mathrm{mol} / 1)\end{array}$ & $66.46 \pm 13.46$ & $68.36 \pm 15.06$ & $66.51 \pm 15.88$ & $67.49 \pm 13.05$ \\
\hline Tryptophan index & $10.01 \pm 1.61 *$ & $10.81 \pm 1.80$ & $10.72 \pm 2.13 *$ & $11.05 \pm 1.87$ \\
\hline Tryptophan breakdown $\dagger$ & $0.026 \pm 0.005^{*}$ & $0.017 \pm 0.013$ & $0.025 \pm 0.011 *$ & $0.017 \pm 0.016$ \\
\hline $\begin{array}{l}\text { Plasma Kynurenine } \\
(\mu \mathrm{mol} / 1)\end{array}$ & $1.80 \pm 0.67$ & $1.83 \pm 0.38$ & $1.65 \pm 0.42 *$ & $2.05 \pm 0.61$ \\
\hline $\begin{array}{l}\text { Plasma hydroxyanthranilic } \\
\text { acid }(\mu \mathrm{mol} / 1) \dagger\end{array}$ & $29.16 \pm 13.74$ & $24.68 \pm 7.64$ & $22.51 \pm 13.67$ & $25.20 \pm 6.08$ \\
\hline $\begin{array}{l}\text { Plasma Kynurenic acid } \\
(\mathrm{nmol} / \mathrm{l})\end{array}$ & $24.22 \pm 9.92 * *$ & $35.47 \pm 12.93$ & $24.43 \pm 5.27^{* *}$ & $41.24 \pm 14.76$ \\
\hline Neuroprotective ratio & $14.12 \pm 4.32 * *$ & $19.34 \pm 5.97$ & $15.69 \pm 4.89 * *$ & $20.88 \pm 5.38$ \\
\hline
\end{tabular}

Note: All the parameters were expressed in mean \pm SD and were compared using ' $t$ ' test except those indicated with ' $\dagger$ ' which were analysed using Mann-Whitney test. (*) indicated the difference from age matched normal control at 'p' value $<0.05$ and $(* *)$ indicated the difference from age matched normal control at 'p' value of 0.001 . 


\section{Depressed on admission versus depressed at discharge}

There were no significant differences in mean tryptophan index, mean plasma kynurenine and mean plasma kynurenic acid though there was an increase in tryptophan breakdown index. In general, the mean neuroprotective ratio in all the depressed patients between admission and discharge showed no significant difference (table 4). However, the neuroprotective ratio of those patients with first episode of depression increased significantly after treatment $(12.43 \pm 3.01$ before vs $15.24 \pm 4.98$ after, $t=2.234$, $\mathrm{p}=0.044$ ) whereas in those with repeated episodes, there was no change.

The change of neuroprotective ratio showed no correlation with change of HDRS after treatment $(\mathrm{r}=-0.088, \mathrm{p}=0.552)$. The HDRS after treatment was 7.56 \pm 6.67 . The univariate analysis showed no effect of type of antidepressant given on the plasma kynurenic acid values and neuroprotective ratios when age and gender were controlled.

Table 4. Biochemical parameters of depressed patients on admission vs discharge

\begin{tabular}{|c|c|c|c|}
\hline Parameters & $\begin{array}{l}\text { Depressed patients } \\
\text { (admission) } \\
\mathrm{N}=40\end{array}$ & $\begin{array}{l}\text { Depressed patients } \\
\text { (discharge) } \\
\mathrm{N}=40\end{array}$ & $\begin{array}{c}\text { 'p' value } \\
\text { (Paired't' test) }\end{array}$ \\
\hline $\begin{array}{l}\text { Plasma CAA } \\
(\mu \mathrm{mol} / 1)\end{array}$ & $657.88 \pm 134.95$ & $691.73 \pm 147.16$ & 0.290 \\
\hline Plasma Tryptophan $(\mu \mathrm{mol} / \mathrm{l})$ & $67.0 \pm 16.29$ & $67.48 \pm 17.87$ & 0.846 \\
\hline Tryptophan index & $10.27 \pm 1.78$ & $9.84 \pm 2.05$ & 0.937 \\
\hline Tryptophan breakdown index $\dagger \dagger$ & $0.028 \pm 0.11$ & $0.035 \pm 0.19$ & 0.033 \\
\hline $\begin{array}{l}\text { Plasma Kynurenine } \\
(\mu \mathrm{mol} / \mathrm{l})\end{array}$ & $1.90 \pm 0.61$ & $2.04 \pm 0.58$ & 0.220 \\
\hline Plasma Kynurenic acid (nmol/l) & $24.02 \pm 9.08$ & $27.80 \pm 9.98$ & 0.122 \\
\hline Neuroprotective ratio & $13.12 \pm 4.06$ & $14.01 \pm 4.45$ & 0.356 \\
\hline
\end{tabular}

Note: All the parameters were expressed in mean \pm SD and were compared using paired ' $t$ ' test except Tryptophan breakdown index indicated with $\dagger \dagger$ for which Wilcoxon signed rank test was used.

\section{Discussion}

The results of this study showed that there was a lower tryptophan availability and higher tryptophan breakdown in the depressed patients even though there was no significant difference in plasma tryptophan concentration. However, while there was no significant difference in plasma kynurenine concentrations between the patients and the controls, there was a significantly lower mean plasma kynurenic acid concentration in the depressed patients. Moreover, there was no difference in plasma 3-hydroxyanthranilic acid concentration. 
Since there is no difference in BMI, plasma tryptophan and plasma CAA concentrations between depressed and their controls, the low tryptophan index is unlikely to be due to the poorer nutritional status of the depressed patients. Furthermore, while there was no significant difference in plasma kynurenine concentrations, there was a higher tryptophan breakdown index in the depressed patients. This suggests that the kynurenine formed by tryptophan breakdown was further metabolised at a faster rate in the depressed patients. Kynurenine is again metabolised either into the toxic quinolinic pathway, in which $3 \mathrm{OHK}, 3 \mathrm{HAA}$ and finally quinolinic acid were produced, or into kynurenic pathway, in which neuroprotective kynurenic acid is the final metabolite (33, 34, 36-38). However, as the plasma kynurenic acid concentration in the depressed patients was significantly lower than the control subjects, it is suggested that the metabolism of kynurenine is preferentially directed into quinolinic pathway. The reduced formation of the neuroprotective metabolite, kynurenic acid, thereby may contribute to an imbalance in the neuroprotection and neurodegeneration pathways. As it was not possible to determine the plasma 3-hydroxykynurenine and quinolinic acid concentration in this study, only 3HAA was measured. The plasma 3HAA acid concentrations in patients and controls were not different. However, the conclusion could not be drawn as there was no increase in degenerative metabolites. That may also indicate the faster formation of neurotoxic quinolinic acid from 3HAA or slower degradation of neurotoxic 3OHK. Moreover, the kynurenic acid/kynurenine ratio was taken as the index of neuroprotection and this ratio was found to be significantly lower in depressed patients.

The above finding is in agreement with that of Wichers et al (6), in which the neurotoxic challenge was higher in those hepatitis $\mathrm{C}$ patients treated with interferon- $\alpha$ and developed symptoms of depression.

In ROC curve analyses, both the plasma kynurenic acid concentration and the neuroprotective ratio showed high discrimination between depressed patients and their controls with high sensitivities and specificities. Moreover, there was no relationship between the subtypes of depression, previous medication and episodes and duration of onset of depression, on the plasma kynurenic acid concentration and neuroprotective ratio. In addition, it was well documented that $60 \%$ of the kynurenine in the brain was contributed from the periphery (43). Therefore, based on the findings in this study, the impaired neuroprotection in depression could clearly be considered.

In addition, overall these markers did not show significant change after the 6-weeks of antidepressant treatment regardless of the HDRS score in depressed patients. Whereas the tryptophan breakdown was increased after treatment, which explained the slight increase in plasma kynurenine and kynurenic acid concentrations, the mean neuroprotective ratio did not change. When analyses were performed on the subgroups in terms whether they had the first episode or repeated episodes of depression, the mean neuroprotective ratio significantly increased in those patients with first episode though it was still below the values of controls, whereas there was no change in those with repeated episodes. This indicates that though the antidepressants corrected the depressed symptoms they did not correct the impaired neuroprotection in patients who had suffered repeated episodes of depression. This suggests that the chance of the reversibility of impaired neuroprotection become less with recurrence and chronicity.

It was reported that quinolinic acid selectively induces apoptosis of human astrocytes (54). In major depression, shrinkage of hippocampus $(55,56)$, astrocytes and neuronal loss in prefrontal cortex $(57-59)$ and in striatum $(60,61)$ have been reported. These observations supported the present findings since astrocytes are the important 
source of kynurenic acid in the brain (44-46) and apoptosis of astrocytes could result in lower neuroprotective action against neurodegenerative quinolinic acid and thus contributes to loss of neurones and to the likelihood of treatment resistance. This might lead to further apoptosis of astrocytes, further decrease in kynurenic acid and further loss in neuroprotective activity as depression enters a chronic phase. The elevated astrocyte marker protein S100B in plasma (62-66) and cerebrospinal fluid (67) of depressed patients was also observed and those findings further supported the possibility of the involvement of astrocytes in pathophysiology of depression. Moreover, the effect of chronic stress on astroglial plasticity in hippocampus was observed and inability of fluoxetine to normalise this defect was documented in an animal experimental study (68).

The limitation in this study was that the strong neurotoxic metabolites, plasma quinolinic acid and $3 \mathrm{OHK}$ could not be measured. A future study has been planned to measure plasma $3 \mathrm{OHK}$ together with the enzymes responsible for the synthesis and metabolism of the components of the kynurenine pathway.

In conclusion, the findings of this study support the neurodegeneration hypothesis (48) in which an impairment in neuroprotective components of the kynurenine metabolic pathway contributes to chronic depression.

\section{Acknowledgement}

This study was mainly funded by Institute of Brain and Behaviour, University of Maastricht and partly supported by Institute of Pharmaceutical Sciences, University of Antwerp and Korea Health 21 R\&D Project, Ministry of Health and Welfare, Republic of Korea (A040042).

\section{References}

1. Beratis S, Katrivanou A, Georgiou S, Monastirli A, Pasmatzi E, Gourzis P, et al. Major depression and risk of depressive symptomatology associated with short-term and low-dose interferon-alpha treatment. J Psychosom Res 2005;58(1):15-8.

2. Wichers MC, Koek GH, Robaeys G, Praamstra AJ, Maes M. Early increase in vegetative symptoms predicts IFN-alpha-induced cognitive-depressive changes. Psychol Med 2005;35(3):433-41.

3. Capuron L, Raison CL, Musselman DL, Lawson DH, Nemeroff CB, Miller AH. Association of exaggerated HPA axis response to the initial injection of interferon-alpha with development of depression during interferon-alpha therapy. Am J Psychiatry 2003;160(7):1342-5.

4. Myint AM, Leonard BE, Steinbusch HW, Kim YK. Th1, Th2, and Th3 cytokine alterations in major depression. J Affect Disord 2005;88(2):167-73.

5. Kim YK, Suh IB, Kim H, Han CS, Lim CS, Choi SH, et al. The plasma levels of interleukin-12 in schizophrenia, major depression, and bipolar mania: effects of psychotropic drugs. Mol Psychiatry 2002;7(10):1107-14.

6. Wichers MC, Koek GH, Robaeys G, Verkerk R, Scharpe S, Maes M. IDO and interferon-alpha-induced depressive symptoms: a shift in hypothesis from tryptophan depletion to neurotoxicity. Mol Psychiatry 2005;10(6):538-44.

7. Capuron L, Neurauter G, Musselman DL, Lawson DH, Nemeroff CB, Fuchs D, et al. Interferon-alphainduced changes in tryptophan metabolism. relationship to depression and paroxetine treatment. Biol Psychiatry 2003;54(9):906-14.

8. Hayaishi O. Biochemical and Medical Aspects of Tryptophan Metabolism. Amsterdam: Elsevier/NorthHolland Biomedical Press; 1980.

9. Heyes MP, Saito K, Major EO, Milstien S, Markey SP, Vickers JH. A mechanism of quinolinic acid formation by brain in inflammatory neurological disease. Attenuation of synthesis from L-tryptophan by 6-chlorotryptophan and 4-chloro-3-hydroxyanthranilate. Brain 1993;116 (Pt 6):1425-50. 
10. Mellor AL, Munn DH. Tryptophan catabolism and T-cell tolerance: immunosuppression by starvation? Immunol Today 1999;20(10):469-73.

11. Hayaishi O. Properties and function of indoleamine 2,3-dioxygenase. $\mathrm{J}$ Biochem (Tokyo) 1976;79(4):13P-21P.

12. Miller CL, Llenos IC, Dulay JR, Barillo MM, Yolken RH, Weis S. Expression of the kynurenine pathway enzyme tryptophan 2,3-dioxygenase is increased in the frontal cortex of individuals with schizophrenia. Neurobiol Dis 2004;15(3):618-29.

13. Saito K, Ohta Y, Nagamura Y, Sasaki E, Ishiguro I. Relationship between L-tryptophan uptake and Ltryptophan 2,3-dioxygenase activity in rat hepatocytes. Biochem Int 1990;20(1):71-80.

14. Satyanarayana U, Rao BS. Dietary tryptophan level and the enzymes of tryptophan NAD pathway. Br J Nutr 1980;43(1):107-13.

15. Smith SA, Carr FP, Pogson CI. The metabolism of L-tryptophan by isolated rat liver cells. Quantification of the relative importance of, and the effect of nutritional status on, the individual pathways of tryptophan metabolism. Biochem J 1980;192(2):673-86.

16. Salter M, Pogson CI. The role of tryptophan 2,3-dioxygenase in the hormonal control of tryptophan metabolism in isolated rat liver cells. Effects of glucocorticoids and experimental diabetes. Biochem $\mathrm{J}$ $1985 ; 229(2): 499-504$.

17. Carlin JM, Borden EC, Sondel PM, Byrne GI. Biologic-response-modifier-induced indoleamine 2,3dioxygenase activity in human peripheral blood mononuclear cell cultures. J Immunol 1987;139(7):2414-8.

18. Carlin JM, Borden EC, Sondel PM, Byrne GI. Interferon-induced indoleamine 2,3-dioxygenase activity in human mononuclear phagocytes. J Leukoc Biol 1989;45(1):29-34.

19. $\mathrm{Hu} \mathrm{B}$, Hissong $\mathrm{BD}$, Carlin JM. Interleukin-1 enhances indoleamine 2,3-dioxygenase activity by increasing specific mRNA expression in human mononuclear phagocytes. J Interferon Cytokine Res 1995;15(7):617-24.

20. Taylor MW, Feng GS. Relationship between interferon-gamma, indoleamine 2,3-dioxygenase, and tryptophan catabolism. Faseb J 1991;5(11):2516-22.

21. Yasui H, Takai K, Yoshida R, Hayaishi O. Interferon enhances tryptophan metabolism by inducing pulmonary indoleamine 2,3-dioxygenase: its possible occurrence in cancer patients. Proc Natl Acad Sci U S A 1986;83(17):6622-6.

22. Musso T, Gusella GL, Brooks A, Longo DL, Varesio L. Interleukin-4 inhibits indoleamine 2,3dioxygenase expression in human monocytes. Blood 1994;83(5):1408-11.

23. Asnis GM, Sachar EJ, Halbreich U, Nathan RS, Novacenko H, Ostrow LC. Cortisol secretion in relation to age in major depression. Psychosom Med 1981;43(3):235-42.

24. Cohen MR, Pickar D, Extein I, Gold MS, Sweeney DR. Plasma cortisol and beta-endorphin immunoreactivity in nonmajor and major depression. Am J Psychiatry 1984;141(5):628-32.

25. Lin SC, Maruta T, Newman DC, Kao PC. Plasma levels of cortisol, corticotropin, and beta-endorphin in patients with major depression. J Clin Psychiatry 1986;47(8):413-4.

26. Sher L, Oquendo MA, Galfalvy HC, Zalsman G, Cooper TB, Mann JJ. Higher cortisol levels in spring and fall in patients with major depression. Prog Neuropsychopharmacol Biol Psychiatry 2005;29(4):52934.

27. Kaestner F, Hettich M, Peters M, Sibrowski W, Hetzel G, Ponath G, et al. Different activation patterns of proinflammatory cytokines in melancholic and non-melancholic major depression are associated with HPA axis activity. J Affect Disord 2005;87(2-3):305-11.

28. Thomas AJ, Davis S, Morris C, Jackson E, Harrison R, O’Brien JT. Increase in interleukin-1beta in latelife depression. Am J Psychiatry 2005;162(1):175-7.

29. Mikova O, Yakimova R, Bosmans E, Kenis G, Maes M. Increased serum tumor necrosis factor alpha concentrations in major depression and multiple sclerosis. Eur Neuropsychopharmacol 2001;11(3):203-8.

30. Connor TJ, Leonard BE. Depression, stress and immunological activation: the role of cytokines in depressive disorders. Life Sci 1998;62(7):583-606.

31. Anisman H, Ravindran AV, Griffiths J, Merali Z. Endocrine and cytokine correlates of major depression and dysthymia with typical or atypical features. Mol Psychiatry 1999;4(2):182-8.

32. Lanquillon S, Krieg JC, Bening-Abu-Shach U, Vedder H. Cytokine production and treatment response in major depressive disorder. Neuropsychopharmacology 2000;22(4):370-9.

33. Chiarugi A, Calvani M, Meli E, Traggiai E, Moroni F. Synthesis and release of neurotoxic kynurenine metabolites by human monocyte-derived macrophages. J Neuroimmunol 2001;120(1-2):190-8.

34. Bender DA, McCreanor GM. Kynurenine hydroxylase: a potential rate-limiting enzyme in tryptophan metabolism. Biochem Soc Trans 1985;13(2):441-3. 
35. Okuda S, Nishiyama N, Saito H, Katsuki H. 3-Hydroxykynurenine, an endogenous oxidative stress generator, causes neuronal cell death with apoptotic features and region selectivity. J Neurochem 1998;70(1):299-307.

36. Schwarcz R, Whetsell WO, Jr., Mangano RM. Quinolinic acid: an endogenous metabolite that produces axon-sparing lesions in rat brain. Science 1983;219(4582):316-8.

37. Perkins MN, Stone TW. An iontophoretic investigation of the actions of convulsant kynurenines and their interaction with the endogenous excitant quinolinic acid. Brain Res 1982;247(1):184-7.

38. Kim JP, Choi DW. Quinolinate neurotoxicity in cortical cell culture. Neuroscience 1987;23(2):423-32.

39. Stone TW, Darlington LG. Endogenous kynurenines as targets for drug discovery and development. Nat Rev Drug Discov 2002;1(8):609-20.

40. Grant RS, Naif H, Espinosa M, Kapoor V. IDO induction in IFN-gamma activated astroglia: a role in improving cell viability during oxidative stress. Redox Rep 2000;5(2-3):101-4.

41. Grant RS, Kapoor V. Murine glial cells regenerate NAD, after peroxide-induced depletion, using either nicotinic acid, nicotinamide, or quinolinic acid as substrates. J Neurochem 1998;70(4):1759-63.

42. Heyes MP, Achim CL, Wiley CA, Major EO, Saito K, Markey SP. Human microglia convert 1tryptophan into the neurotoxin quinolinic acid. Biochem J 1996;320 (Pt 2):595-7.

43. Gal EM, Sherman AD. L-kynurenine: its synthesis and possible regulatory function in brain. Neurochem Res 1980;5(3):223-39.

44. Guillemin GJ, Smythe G, Takikawa O, Brew BJ. Expression of indoleamine 2,3-dioxygenase and production of quinolinic acid by human microglia, astrocytes, and neurons. Glia 2005;49(1):15-23.

45. Guillemin GJ, Kerr SJ, Smythe GA, Smith DG, Kapoor V, Armati PJ, et al. Kynurenine pathway metabolism in human astrocytes: a paradox for neuronal protection. J Neurochem 2001;78(4):842-53.

46. Guillemin GJ, Smith DG, Kerr SJ, Smythe GA, Kapoor V, Armati PJ, et al. Characterisation of kynurenine pathway metabolism in human astrocytes and implications in neuropathogenesis. Redox Rep 2000;5(2-3):108-11.

47. Heyes MP, Saito K, Crowley JS, Davis LE, Demitrack MA, Der M, et al. Quinolinic acid and kynurenine pathway metabolism in inflammatory and non-inflammatory neurological disease. Brain 1992;115 (Pt 5):1249-73.

48. Myint AM, Kim YK. Cytokine-serotonin interaction through IDO: a neurodegeneration hypothesis of depression. Med Hypotheses 2003;61(5-6):519-25.

49. APA. Diagnostic and statistical manual of mental disorders. 4th Ed ed. Washington DC: American Psychiatric Press; 1994.

50. Overall JE, Gorham DR. The brief psychiatric rating scale. Psychol Rep 1962;10:799-812.

51. Hamilton M. A rating scale for depression. J Neurol Neurosurg Psychiatry 1960;23:56-62.

52. Cooper JD, Turnell DC, Green B, Verillon F. Automated sequential trace enrichment of dialysates and robotics. A technique for the preparation of biological samples prior to high-performance liquid chromatography. J Chromatogr 1988;456(1):53-69.

53. Herve C, Beyne P, Jamault H, Delacoux E. Determination of tryptophan and its kynurenine pathway metabolites in human serum by high-performance liquid chromatography with simultaneous ultraviolet and fluorimetric detection. J Chromatogr B Biomed Appl 1996;675(1):157-61.

54. Guillemin GJ, Wang L, Brew BJ. Quinolinic acid selectively induces apoptosis of human astrocytes: potential role in AIDS dementia complex. J Neuroinflammation 2005;2:16.

55. Sheline YI, Sanghavi M, Mintun MA, Gado MH. Depression duration but not age predicts hippocampal volume loss in medically healthy women with recurrent major depression. J Neurosci 1999;19(12):503443.

56. Bremner JD, Narayan M, Anderson ER, Staib LH, Miller HL, Charney DS. Hippocampal volume reduction in major depression. Am J Psychiatry 2000;157(1):115-8.

57. Cotter DR, Pariante CM, Everall IP. Glial cell abnormalities in major psychiatric disorders: the evidence and implications. Brain Res Bull 2001;55(5):585-95.

58. Ongur D, Drevets WC, Price JL. Glial reduction in the subgenual prefrontal cortex in mood disorders. Proc Natl Acad Sci U S A 1998;95(22):13290-5.

59. Rajkowska G, Miguel-Hidalgo JJ, Wei J, Dilley G, Pittman SD, Meltzer HY, et al. Morphometric evidence for neuronal and glial prefrontal cell pathology in major depression. Biol Psychiatry 1999;45(9):1085-98.

60. Krishnan KR, McDonald WM, Escalona PR, Doraiswamy PM, Na C, Husain MM, et al. Magnetic resonance imaging of the caudate nuclei in depression. Preliminary observations. Arch Gen Psychiatry 1992;49(7):553-7.

61. Husain MM, McDonald WM, Doraiswamy PM, Figiel GS, Na C, Escalona PR, et al. A magnetic resonance imaging study of putamen nuclei in major depression. Psychiatry Res 1991;40(2):95-9. 
62. Dietrich DE, Hauser U, Peters M, Zhang Y, Wiesmann M, Hasselmann M, et al. Target evaluation processing and serum levels of nerve tissue protein S100B in patients with remitted major depression. Neurosci Lett 2004;354(1):69-73.

63. Arolt V, Peters M, Erfurth A, Wiesmann M, Missler U, Rudolf S, et al. S100B and response to treatment in major depression: a pilot study. Eur Neuropsychopharmacol 2003;13(4):235-9.

64. Hetzel G, Moeller O, Evers S, Erfurth A, Ponath G, Arolt V, et al. The astroglial protein S100B and visually evoked event-related potentials before and after antidepressant treatment. Psychopharmacology (Berl) 2005;178(2-3):161-6.

65. Rothermundt M, Arolt V, Wiesmann M, Missler U, Peters M, Rudolf S, et al. S-100B is increased in melancholic but not in non-melancholic major depression. J Affect Disord 2001;66(1):89-93.

66. Schroeter ML, Abdul-Khaliq H, Diefenbacher A, Blasig IE. S100B is increased in mood disorders and may be reduced by antidepressive treatment. Neuroreport 2002;13(13):1675-8.

67. Grabe HJ, Ahrens N, Rose HJ, Kessler C, Freyberger HJ. Neurotrophic factor S100 beta in major depression. Neuropsychobiology 2001;44(2):88-90.

68. Czeh B, Simon M, Schmelting B, Hiemke C, Fuchs E. Astroglial Plasticity in the Hippocampus is Affected by Chronic Psychosocial Stress and Concomitant Fluoxetine Treatment. Neuropsychopharmacology 2005. 


\section{Chapter 7}

\section{Changes in the immune system in depression and dementia: causal or co-incidental effects?}




\section{Summary}

Epidemiological studies show that there is a correlation between chronic depression and the likelihood of dementia in later life. There is evidence that inflammatory changes in the brain are pathological features of both depression and dementia. This suggests that an increase in inflammation induced apoptosis, together with a reduction in the synthesis of neurotrophic factors caused by a rise in brain glucocorticoids, may play a role in the pathology of these disorders. A reduction in the neuroprotective components of the kynurenine pathway, such as kynurenic acid, and an increase in the neurodegenerative components, 3- hydroxykynurenine and quinolinic acid, contribute to the pathological changes. Such changes are postulated to cause neuronal damage and thereby predispose chronically depressed patients to dementia. 


\section{Introduction}

Epidemiological studies have implicated chronic depression as an important predisposing factor for dementia in later life. Depression has been shown to be a common antecedent of Alzheimer's disease, and may be an early manifestation of dementia before the cognitive symptoms become apparent $(1,2)$. In particular, patients with depression who later develop dementia, usually have a poorer base-line performance in cognitive tasks (3).

Several studies have shown that depression is a risk factor for dementia, particularly Alzheimer's disease, and this may be particularly important if the depressive episode occurs within 2 years of the diagnosis of dementia (3). Indeed, it has been estimated that patients with mild cognitive impairment and depression have more than twice the risk of developing dementia than those of the same age but who do not have depression. This suggests that depression may be a prodrome of dementia (4).

Both depression and dementia are associated with inflammatory changes in the brain. The chronic inflammatory diseases such as rheumatoid arthritis are frequently associated with depression (5), while pro-inflammatory cytokines such as interferon $\alpha$ (IFN $\alpha$ ), used therapeutically in the treatment of hepatitis for example, are known to precipitate depressive episodes in psychiatrically non-depressed patients (6). An experimental study have also been reported in rats treated with IFN $\alpha$ showed anxiety behaviour in open field and changes in cytokines in both periphery blood and in certain brain regions (7). Numerous clinical studies, supported by clinical evidence, have shown that pro-inflammatory cytokines are raised in the blood of depressed patients (8). Such observations supported the macrophage theory of depression (9).

The possible link between depression, dementia and inflammatory changes in the brain is also supported by clinical and experimental studies of acquired immune deficiency syndrome (AIDS). It is well established that when human immunodeficiency virus (HIV)-infected patients develop AIDS, a substantial proportion of the patients also develop depression (10). Depression is one of the early manifestations of HIV dementia (11). Antiretroviral therapy was also one of those early manifestations (11). The experimental study in rodent showed that Efavirenz, the antiretroviral drug used in treatment of HIV infection induced increased proinflammatory cytokines in the peripheral blood and was associated with anxiety behaviour and impaired spacial memory (7). Thus both depression and dementia are associated with inflammatory changes.

As there is pathological evidence that increased apoptosis occurs in both chronic depression and dementia resulting in atrophic changes in the hippocampus, frontal cortex and other brain regions (12-14), it has been speculated that the increase in inflammatory mediators, such as interleukin (IL)1, TNF $\alpha$ and prostaglandin E2 (PGE2), play a central role in the pathology of these conditions. The results of clinical and experimental research therefore lead to the conclusion that an increase in apoptosis caused by inflammation, together with a reduction in the synthesis of neurotrophic factors such as brain derived neurotrophic factor (BDNF) that assists in the repair of damaged neuronal networks, provide a basis for the pathological changes that are common to depression and dementia. The following reviews the evidence in favour of this hypothesis. 


\section{Changes in the hypothalamic-pituitary-adrenal axis in depression and dementia}

Stressful life events trigger neurotransmitter changes in the brain via an activation of the corticotrophin releasing factor (CRF) pathway that terminates not only within the hypothalamus and other parts of the central endocrine system but also on the locus coeruleus and raphe nuclei (15). This provides a biological link between stressful stimuli and the changes in the endocrine, immune and neurotransmitter systems that are involved in the psychopathology of depression (figure 1).

Investigations of the role of the hypothalamo-pituitary-adrenal (HPA) axis in the psychopathology of depression commenced over 40 years ago when it was reported that depressed patients have a higher circulating plasma cortisol concentration than those that are not depressed $(16,17)$. At this time, the dexamethasone suppression test (DST) was developed to provide a functional assessment of HPA axis activity. It was discovered that this synthetic glucocorticoid would normally suppress the secretion of cortisol

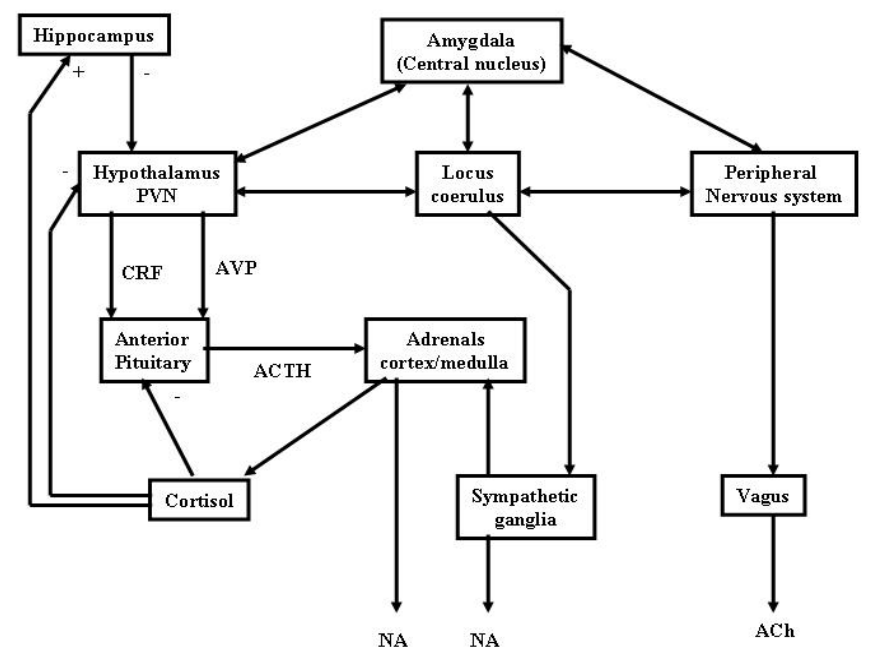

Figure 1-Relationship between stress, activation of limbic regions of the brain by CRF, and the consequent changes in the adrenal cortex and the sympathetic system. $(+)$, activation, $(-)$, inhibition. In chronic stress or depression, the feedback inhibitory loop malfunctions following the desensitization of the central glucocorticoid receptors in the brain and immune cells. This results in hypercortisolaemia, a common feature of both major depression and Alzheimer's disease. Anxiety, a common comorbidity symptom with major depression, is associated with the increased activity of the central and peripheral sympathetic systems. CRF, corticotrophin releasing factor; NA, noradrenaline; AVP, arginine vasopressin; Ach, acetylcholine; ACTH, adrenocortico-trophic hormone; PVN, paraventricular nucleus. 
by activating hypothalamic and pituitary glucocorticoid receptors thereby suppressing the secretion of CRF and adrenocorticotrophic hormone (ACTH) which, in turn, reduced the activation of the adrenal cortex and the release of cortisol. The mechanism whereby these changes occurred was explained in terms of a negative feed-back loop whereby the raised plasma glucocorticoid concentration controls the further release of the steroid. However, it soon became apparent that in patients with major depression, the negative feed-back loop ceased to function due to the desensitisation of the central glucocorticoid receptors. The negative DST thereby became a diagnostic marker of melancholic depression (18).

Nevertheless, it is now apparent that the DST lacks both specificity and sensitivity for depression (19) even though it may still offer 'reliability in the assessment of the severity of depression (20). Hypercortisolism and a negative DST are now known to occur in patients with Alzheimer's disease and alcoholism for example (21). Furthermore, it has been estimated that only $60 \%$ of patients with major depression show a negative DST. Nevertheless, these findings do serve to emphasise the importance of the HPA axis in psychiatric disorders.

It is frequently assumed that the synthetic glucocorticoids such as dexamethasone, act on glucocorticoid receptors in an identical manner to the natural glucocorticoids such as cortisol. However, this may not be the case. Dexamethasone acts primarily on the glucocorticoid receptors in the anterior pituitary, does not readily enter the brain and therefore differs substantially from natural glucocorticoids that activate both mineralocorticoid and glucocorticoid receptors (22). There is also evidence that while dexamethasone may reduce the release of CRF, it does not suppress the release of arginine vasopressin (AVP). There is evidence that AVP, not CRF, is the main activator of the HPA axis due to chronic stress and major depression $(23,24)$. The increased action of AVP is further exacerbated by the action of IL $1 \beta$; chronically administered IL $1 \beta$ has been shown to cause a shift in the role of CRF to AVP in the activation of the anterior pituitary (25). In addition, it has been shown that there is an age-related increase in the co-localisation of AVP in CRF neurons in patients with major depression and dementia (26). Thus it seems reasonable to conclude that the hypersecretion of cortisol in patients with depression or dementia may at least be partly a consequence of an increased activation of the HPA axis by AVP.

Additional evidence for the change in the functional activity of the pituitary gland is provided by the finding that the adrenals and the pituitary are enlarged in those with depression $(27,28)$, these changes being associated with a hypersecretion of CRF (29). Furthermore, the density of the CRF receptors in the frontal cortex is reduced, presumably as a consequence of the hypersecretion of CRF $(30,31)$. The hypersecretion of CRF would appear to be a state, rather than a trait, marker of depression (32).

If hypercortisolaemia is a common feature of major depression and some types of dementia, it would be anticipated that immunosuppression would be a common feature of these conditions. However, it is apparent that both immunosuppression (for example, of natural killer cell [NKC] activity) and immune activation (for example, macrophage activation) are common features of depression. One possible explanation is that an increased vulnerability to environmental stress, which is a common feature of both depression and dementia (33), elicits a bi-directional, homeostatic interaction between the endocrine and immune system. Thus CRF has been associated with humoral activation that results in an increased release of pro-inflammatory cytokines. By activating the HPA axis, pro-inflammatory cytokines not only further release of CRF but also lead to 
glucocorticoid resistance thereby impairing the regulatory feedback mechanism . Conversely, the increase in the concentration of plasma cortisol, together with the increased sympathetic activity that is a normal feature of the stress response, suppresses NKC and $\mathrm{T}$-cell replication. There is evidence that activation of the $\beta$-adrenoceptors on the NKC membrane, and that results in the decrease in activity of the NKCs, occurs independently of the activation of the HPA axis (33). Clearly the interaction between the immune system and the HPA axis is both complex and interdependent.

In the past 20 years, attention has focussed on changes in the hypothalamicpituitary-adrenal axis, together with the biogenic amine neurotransmitters noradrenaline, serotonin and, to a lesser extent dopamine $(34,35)$. More recently however it has become apparent that both major depression and chronic stress result in more persistent structural changes in the brain as a consequence of the decrease in the synthesis of neurotrophic factors, such as brain derived neurotrophic factor (BDNF) and the antiapoptotic factor bcl-2 (36). These changes are attributed to the chronic increase in brain glucocorticoids that arise due to the desensitisation of central glucocorticoid Type 2 receptors that occur as a consequence of the reduction in the inhibitory feedback mechanism (37). Such effects contribute to the failure in brain repair mechanisms which is indicated by a reduction in dendritic branching and a decrease in neurogenesis particularly in the hippocampus and, to some extent, in the frontal cortex $(38,39)$. Such changes, together with an activation of the pro-inflammatory cytokines by chronic stress and depression, also enhance apoptosis through their indirect excitotoxic and metabolic actions (40). Thus stress induced hypercortisolaemia and pro-inflammatory cytokines share a final common pathway that leads to impaired neuronal plasticity and deficits in central neurotransmission.

The possible link between hypercortisolaemia and depression is further provided by the changes induced by antidepressants and glucocorticoid receptor antagonists such as mifepristone (41). Thus preliminary clinical evidence has shown that the sensitisation of the central glucocorticoid receptors by such treatments, that results in the reestablishment of the feedback inhibition of cortisol release, are correlated with the attenuation of the symptoms of depression (42).

\section{Is there a link between depression and dementia: the clinical perspective}

There is overwhelming evidence that inflammatory changes are an important causative factor in the pathology of Alzheimer's disease and related dementias (43). The increase in beta amyloid $(A \beta)$ is not only a major pathological feature of such dementias but is also responsible for stimulating inflammatory responses in the brain. These changes include an increased expression of cell adhesion molecules, pro-inflammatory cytokines and the activation of microglia in the brain parenchyma (44). In vitro studies have also demonstrated that $A \beta$ induces IL1 $\beta$ and IFN $\gamma$ from vascular cells thereby inducing a cascade of inflammatory changes $(45,46)$. In addition, the infiltration of macrophages together with CD4+ and CD8+ T-cells, from the periphery have been detected in A $\beta$ deposits in cerebral vessels in patients with cerebral amyloid angiopathy (47).

The combination of $\mathrm{A} \beta$ and pro-inflammatory cytokines is linked to the increase in apoptosis in the brains of patients with dementia (48). For example, there is evidence that lymphocytes show a significant increase in DNA fragmentation in Alzheimer 
patients when compared to aged, but normal, controls (49). This change has been linked to an increase in the intracellular concentration of calcium ions, a prerequisite for apoptosis (50) that has not been recorded in lymphocytes from aged control subjects. Furthermore, apoptotic cell death is preceded by the expression of apoptosis-associated molecules such as p53, Fas (CD95/APO-1) and IL1 $\beta$ converting enzyme. Whereas the normal brain is partly immunologically privileged, in patients with inflammatory diseases such as multiple sclerosis, stroke, Alzheimer's disease and possibly major depression, Fas is widely expressed in the brain (51). This apoptotic protein is expressed on CD4+ and CD8+ T-cells and on NK cells. Such observations provide a further link between the inflammatory changes in the brain and increased apoptosis that preludes dementia.

Despite these convincing observations regarding the inflammatory changes in patients with Alzheimer's disease, it is somewhat surprising to find that IL6, a major pro-inflammatory cytokine that is elevated in the plasma and CSF of patients with major depression, has been reported to be unchanged $(52)$ or even decreased $(53,54)$ in the blood of Alzheimer's patients. Some investigators have, however, reported that IL6 is increased in these patients (55). Some of these differences may be accounted for by the methods used to assay IL6. Thus the concentration of IL6 in the serum and CSF is often at the limit of detection while in in-vitro studies, in which stimulated lymphocytes are isolated by gradient centrifugation, the cells are stressed which may alter their phenotype.

It has also been argued that the decrease in pro-inflammatory cytokines in Alzheimer's disease is a consequence of the hypercortisolaemia (53) although this does not explain why cytokines such as IL6 remain elevated in depressed patients where hypercortisolaemia also commonly occurs.

The cognitive changes and dysphoria that are common symptoms in the early stages of Alzheimer's disease have been correlated with the increase in pro-inflammatory cytokines such as IFN $\alpha$ (6). Despite the equivocal evidence regarding the rise in plasma IL6 concentration in Alzheimer patients, there are reports that the IL6 concentration correlates with the severity of dementia (56).From the numerous studies of the changes in the immune system of patients with dementias, it would appear that the inflammatory changes can trigger an increased synthesis and accumulation of $A \beta$ (57). The accumulation of $A \beta$ then initiates a further cascade of inflammatory changes in the brain involving pro-inflammatory cytokines and neurotoxic free radicals such as 'nitric oxide (NO) (58); this involves the activation of the NFkbeta pathway and the complement system. Neuronal COX 2 expression is also increased in Alzheimer's disease and the resulting increase in PGE2 contributes to the subsequent deterioration in the clinical state of the patient (59). In addition, the rise in IL1 $\beta$ may also indirectly contribute to the cognitive deficit by inhibiting cholinergic function (60); a deficit in acetylcholine is generally accepted as the primary neurotransmitter that is causally involved in the cognitive and memory deficits in the dementias (42).

The question arises whether the increase in $A \beta$ is a reflection of the rise in proinflammatory cytokines, an important consideration if major depression predisposes to dementia. In support of this connection, there is evidence that severe head trauma in young persons can result in a large number of amyloid plaques shortly after the traumatic event (61). The accumulation of $A \beta$ was shown to occur secondarily to the stress induced activation of the microglia that precipitate the release of IL1; the A $\beta$ formed 
then stimulated the "cytokine cascade", a key element in the pathogenesis of dementia (62).

Further evidence in support of the hypothesis linking the outcome of chronic depression with dementia, comes from studies on the progression of an HIV infection to AIDS. It is well known that severe life-stress, and bereavement of a partner with AIDS, is associated with a rapid progression of HIV to AIDS and a consequent increase in mortality (63). For example, it has been reported that changes in immune function, such as a reduction in NK cells correlates with the incidence of depression and the progressive deterioration in the clinical status of the patients with HIV/AIDS $(10,64,65)$ although not all investigators have found such an association (66). Nevertheless, such studies do provide possible support for the hypothesis that impaired immune function associated with the symptoms of depression may act not only in the progression of an AIDS infection but also to the onset of AIDS dementia in those patients that do not die as a consequence of secondary infections or cancer.

\section{Changes in pro-inflammatory cytokines in depression and dementia}

Evidence implicating a role for the pro-inflammatory cytokines in the aetiology of depression has been provided by studies on the changes in IL1, IL6 and TNF $\alpha$ in depressed patients and also by the effects of IFN $\alpha$ on psychiatrically normal individuals being treated for hepatitis or a malignancy. Such studies have implicated these cytokines as causative factors in the symptoms of major depression.

These symptoms include depressed mood, anxiety, cognitive impairment, lack of motivation, loss of libido, sleep disturbance and deficits in short-term memory. Such symptoms usually disappear once the plasma cytokine concentrations return to normal (67). These changes appear to be a consequence of the neurotransmitter and endocrine changes induced by the cytokines rather than the pathological condition for which the treatment has been administered (67-69). It is perhaps not surprising therefore to find that the symptoms of depression frequently occur in patients recovering from a chronic infection, those with multiple sclerosis (70), allergies (71) and rheumatoid arthritis (72). In all these situations, pro-inflammatory cytokines are known to be over-expressed (73). The initial studies linking depression with an abnormality of the immune system (74), impaired mitogen stimulated lymphocyte proliferation (75) and reduced NK cell activity (76) in untreated depressed patients, changes that largely returned to normal once the patient recovered from the depressive episode.

Recent research into the immune changes occurring in depression has concentrated on cytokines, soluble cytokine receptors and plasma acute phase proteins. For example, positive acute phase proteins have been shown to increase while the negative acute phase proteins decreased in depression, changes that are known to be a consequence of the action of IL6 on liver function (77). In addition, complement proteins (C3,C4 ) and immunoglobulin $\mathrm{M}$ are increased in depressed patients. Such changes are evidence of immune activation involving both the inflammatory cytokines and B-cells that are activated by the pro-inflammatory cytokines. Further evidence of immune activation in depressed patients is provided by the studies showing that the plasma concentration of IL1, IL6, IFN $\gamma$, soluble IL6 and IL2 receptors, and the IL1 receptor antagonist, are raised. These changes are correlated with a rise in plasma acute phase proteins (78). Effective antidepressant treatments largely attenuated such immune changes. In addition to the increases in pro-inflammatory cytokines, there is also evidence of an increased 
number of T-helper, T-memory, activated T-cells and B-cells that act as a source of the plasma cytokines (79-81).

From these changes, it would appear that in depression there is an imbalance between the inflammatory and the anti-inflammatory arms of the immune system, the cytokines from the T1 pathway (such as IFN $\gamma$ ) becoming predominant over those of the anti-inflammatory T2 (for example, IL4) pathway. A recent study has shown that the T3 cytokine, transforming growth factor $\beta 1$ (TGF $\beta 1$ ) whose function is to re-establish the balance between the T1 and T2 pathways, is increased in depressed patients following effective antidepressant treatment (82). Though TGF $\beta 1$ is reported as a regulatory cytokine that keeps the balance between Th1 and Th2 cytokines (83), precisely how the increases in the pro-inflammatory cytokines are attenuated by TGF $\beta 1$ in depressed patients is unclear.

\section{The role of the microglia in inflammatory changes in the brain}

Localised inflammatory responses in the brain parenchyma have been associated with the pathogenesis of a number of neurological disorders including Alzheimer's disease and Parkinson's disease $(84,85)$. At these lesion sites, activated microglia release such inflammatory mediators as TNF $\alpha$ and PGE2 (86).It is well-known that PGE2 is an important mediator of inflammation. In vitro evidence shows that PGE2 secretion from lymphocytes of depressed patients is increased (87), as is the PGE2 content of the saliva, serum and CSF of such patients $(88,89)$. Of the pro-inflammatory cytokines, IL6 appears to play a key role in the synthesis of this prostaglandin both in vitro and in vivo $(89,90)$.

Conversely, different types of antidepressants have been shown to inhibit the secretion of pro-inflammatory cytokines and to reduce the synthesis of PGE2 (91-93). This raises the interesting possibility that the reduction in pro-inflammatory cytokines and inflammatory mediators such as PGE2 in the brain may be associated with the therapeutic actions of antidepressants (94). As it appears that the pro-inflammatory cytokines increase the inducible form of cyclo-oxygenase (COX2) in the brain, it would be expected that COX2 inhibitors would not only attenuate the central inflammatory changes but also exert an antidepressant effect. There is some clinical evidence to support this view. Thus rofecoxib, when administered to a large group of patients suffering from osteoarthritis, was found to reduce the symptoms of those who were suffering from co-morbid depression; $15 \%$ of the patients had depression at the start of the study which decreased to $3 \%$ at the end of the period of treatment (95). Other clinical studies have suggested that the COX2 inhibitor celecoxib has positive effects on cognitive function in depressed patients (95). It should be noted that celecoxib has also been shown to have beneficial effects as an "add-on" component to resperidone in the treatment of schizophrenia $(96,97)$.

There are several mechanisms that are postulated to be involved in the aetiology of depression. It is commonly assumed that a decrease in both the noradrenergic and serotonergic functions are causally related to the changes in the mood, motivation and cognitive changes associated with the disorder, There is now experimental evidence to show that the inhibition of COX 2 is associated with a rise in the synthesis of serotonin in the cortex of the rat brain (98). In addition, PGE2 has been shown to reduce the release of noradrenaline from central noradrenergic neurons, an effect that would be blocked by the COX2 inhibitors. Thus inhibition of COX2 activity in the brain contrib- 
utes not only to the reduction in inflammatory changes but also to an enhancement of biogenic amine function. PGE2 is probably one of the most potent inflammatory mediators in terms of the initiation and propagation of inflammation within the brain (99). Both clinical $(89,100)$ and experimental studies have shown that there is an increase in the tissue concentrations of PGE2 in depression and in an animal model of depression (87). In the brain, the microglia act as macrophages. On activation, they release proinflammatory cytokines, PGE2 and neurotoxic metabolites of the kynurenine pathway (101). Recent experimental evidence has shown that lipopolysaccharide (LPS), an activator of macrophage activity and a cause of brain inflammation, induces mitochondrial PGE2 synthase and cyclo-oxygenase-2 (COX2) activity in activated microglia thereby increasing the synthesis of PGE2 at sites of inflammation in the brain (102). This provides a possible mechanism to explain the inflammatory changes in patients with depression or dementia, changes that contribute to neurodegeneration. Nitric oxide (NO) can also act as an inflammatory mediator that contributes to neurodegeneration (103) and is raised in the plasma of depressed patients (104). NO is produced by both the constitutive and inducible forms of NO synthase that are associated with neurons and microglia (105-107). Recent evidence suggests that pro-inflammatory cytokines activate inducible NOS thereby increasing NO; apoptosis results from the nitrosylation of DNA (108). The increase in peripheral and central macrophage activity associated with the inflammatory changes initiate, via the activated microglia, increases in PGE2 and NO that further potentiate the inflammatory changes (figure 2).

\section{$\underline{\text { Possible Mechanisms of Neurodegeneration }}$}

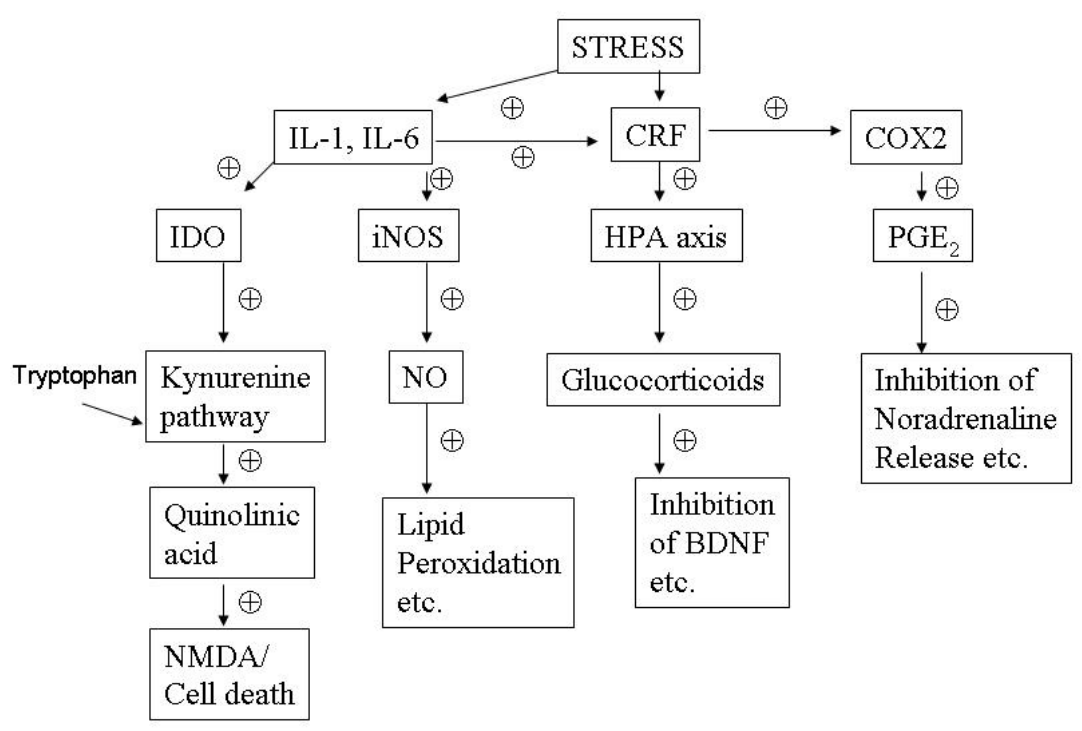


Figure 2-Relationship between the main neurodegenerative pathwaysin the brain and depression. $(+)$ Pathways that are increased in depression, and probably dementia. IDO, indoleamine 2,3-dioxygenase; iNOS, inducible nitric oxide synthase; CRF, corticotrophin releasing factor; COX2, inducible cyclo-oxygenase 2; PGE, prostaglandin E; HPA, hypothalamic pituitary adrenal; NO, nitrous oxide; IL, interlaukin; NOS, nitrous oxide synthase; BDNF, brain derived neurotrophic factor.

Thus in both depression and dementia, PGE2, NO and neurotoxic metabolites from kynurenine pathway appear to play an important role central inflammatory processes that contribute to neurodegeneration.

\section{Neurodegeneration and the role of neurotoxic metabolites of the tryptophan pathway}

The depletion of tryptophan from the diet results in a reduction in serotonin in the brain that correlates with the onset of a depressed mood state (109). Tryptophan is metabolised by two main pathways, by tryptophan hydroxylase leading to the synthesis of serotonin in the brain and by indoleamine 2,3-dioxygenase (IDO) and tryptophan 2,3dioxygnase (TDO) resulting in the formation of kynurenine $(110,111)$. It has been hypothesized that, in depression the metabolism of tryptophan by IDO and TDO is increased thereby reducing the availability of the amino acid to synthesise serotonin (101). TDO is located in the liver and the brain while IDO is found in the lungs, placenta, blood and brain $(112,113)$. The activity of TDO is increased by tryptophan and by cortisol. As hypercortisolaemia frequently occurs in both depression and dementia, it would be anticipated that TDO is overactive in patients with these disorders. By contrast, IDO activity is increased by pro-inflammatory cytokines such as IL6 and IFN $\gamma$ and inhibited by anti-inflammatory cytokines such as IL4 $(114,115)$. Thus the activities of both TDO and IDO are likely to be increased in depression and dementia as a consequence of the rise in circulating cortisol and the pro-inflammatory cytokines. There are two main stages in the metabolism of tryptophan following the actions of the dioxygenases (116). Following the conversion of tryptophan to kynurenine by IDO or TDO, kynurenine is metabolised by kynurenine hydroxylase to the neurotoxic metabolites 3hydroxykynurenine, 3-hydroxy- anthranilic acid and quinolinic acid. An alternative pathway involves the conversion of kynurenine to 3-hydroxyanthranilic acid by kynureninase. These form the neurodegenerative arm of the tryptophan-kynurenine pathway.

Alternatively, kynurenine may be metabolised by kynurenine aminotransferase to the neuroprotective end product kynurenic acid (117). The mechanisms whereby quinolinic and kynurenic acids act as neurotoxic and neuroprotective agents respectively is related to their activation or inhibition of the N-methyl-D-aspartate (NMDA) receptor, quinolinic acid and 3-hydroxyanthranilic acids being agonists of the NMDA receptor while kynurenic acid is an antagonist $(118,119)$. It has also been hypothesized that the imbalance between those NMDA receptor antagonist and agonist pathophysiology of chronic or treatment resistant depression (101).

In the brain, the metabolism of tryptophan by the enzymes of the kynurenine pathway occurs in both astrocytes and microglia $(120,121)$ the former producing mainly kynurenic acid while the latter produces the neurotoxic end products 3-hydroxykynurenine, 3-hydroxyanthranilic acid and quinolinic acid (122). Astrocytes have been shown to metabolise quinolinic acid and thereby reduce the neurotoxic impact that may arise following microglia activation. From the foregoing evidence, it can be hypothe- 
sised that inflammatory changes in both depression and dementia involve the activation of microglia and an increase in the inflammatory challenge to the brain. Such changes also occur in patients with hepatitis who have been treated with the pro-inflammatory cytokine IFN $\alpha$ and who developed depressive symptoms as a side-effect of the treatment. In these patients, it has been shown that the plasma kynurenic acid concentration was reduced thereby suggesting that the neurodegenerative metabolites were increased (123). More recently we have shown that similar changes occur in the blood of patients with major depression (124). The result of this study also showed that therapeutically effective antidepressant treatment increased the neuroprotective kynurenic acid in the blood in those patients suffering from an acute episode of depression but not in those with chronic depression. These changes occurred irrespective of the clinical improvement in the symptoms of the patients. This suggests that the progress to dementia may increase as the depression becomes more chronic.

In patients with major depression, shrinkage of the hippocampus $(125,126)$, a decrease in the number of astrocytes and a neuronal loss from the pre-frontal cortex (38, $127,128)$ and the striatum (129) have been reported. Such findings support the view that neurodegenerative changes occur in several discrete regions of the brain in patients suffering from chronic depression. Furthermore, as the astrocytes are a major source of kynurenic acid, apoptosis of these cells would result in a reduction in the neuroprotective effect of kynurenic acid. There is evidence that in the astrocytes the kynurenine pathway is limited due to the absence of kynurenine hydroxylase. As a consequence, astrocytes only produce a very low concentration of the neurotoxin quinolinic acid and a relatively high concentration of the neuroprotective agent kynurenic acid (111). Furthermore, in astrocytes IDO is preferentially induced by IFN $\gamma$, a cytokine that also induces the catabolism of quinolinic acid (111). However, it is also apparent that the increase in the synthesis of kynurenine by the astrocytes can indirectly contribute to the formation of quinolinic acid by the microglia. This situation would be compounded by the increased activation of the microglia by the pro-inflammatory cytokines with the consequent rise in the concentration of the inflammatory mediators PGE2 and NO. Figure 3 summarises the pathways involved in the metabolism of tryptophan by the kynurenine pathway and the relationship with inflammatory cytokines in depression.

The inhibition of neuronal repair mechanisms resulting from the reduction in neurotrophic factors that follow the rise in blood and tissue cortisol (130), apoptosis of astrocytes which are the sources of several neurotrophic factors (131), and the possible disruption of the phospholipase D pathway that has anti-apoptotic properties and is involved in neurite formation and repair (132), further contribute to the neuronal loss. Another association between depression and dementia is through this IDO initiated kynurenine pathway related neurotoxicity. An immunohistochemical study has proven that the immunoreactivity of IDO and quinolinic acid are high in the hippocampus of Alzheimer's disease patients (133).

So far, emphasis has been placed on the role of inflammatory mediators and neurotoxins produced by the kynurenine pathway on the possible causes of the neurodegener- 


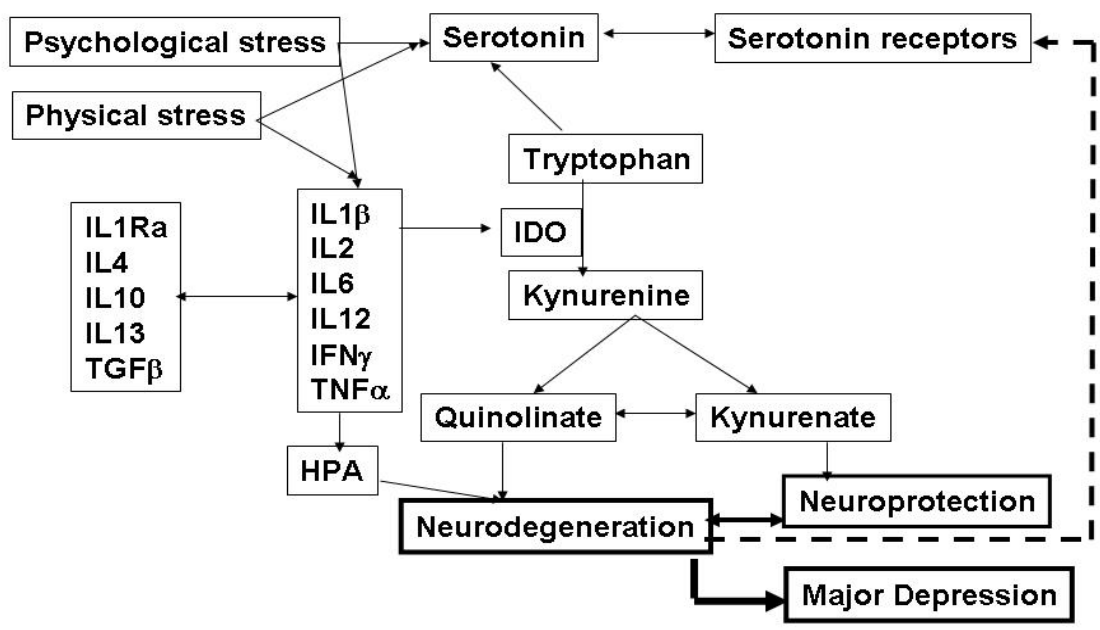

Figure 3-Outline of the kynurenine pathway and its induction by proinflammatory cytokines, that results in the accumulation of major neurotoxic metabolite. IL, interleukin; TGF, transforming growth factor; IFN, interferon; IDO, indoleamine 2,3-dioxygenase; HPA, hypothalamic pituitary adrenal.

ative changes in the brain that eventually develops into dementia. Recently, experimental evidence has shown that transgenic mice that over-express human tau protein (a prominent feature of different types of dementia) show depressive-like behaviour in the Forced Swim Test. This test is widely used to predict antidepressant activity and is based on the observation that when rodents are placed in a container of warm water from which they cannot escape, they soon adopt an immobile posture. This is assumed to reflect a state of "learned helplessness" that reflects a depressive-like state (134). This behavioural state was reversed by the administration of the selective serotonin re-uptake inhibitor antidepressant fluvoxamine. In vivo microdialysis studies showed that the release of serotonin from the pre-frontal cortex was reduced in the transgenic mice, an effect that was reversed by the fluvoxamine treatment. The results of this study suggest that transgenic mice over-expressing human tau protein show symptoms of depressivelike behaviour that are associated with a reduction in serotonergic function. As the behavioural and neurotransmitter changes are reversed by a SSRI antidepressant, it would appear that serotonin may provide a link between the pathological effects of tau protein and the subsequent depressive-like state. It would be incautious to extrapolate from this sub-chronic study in a transgenic mouse to the complex clinical situation in 


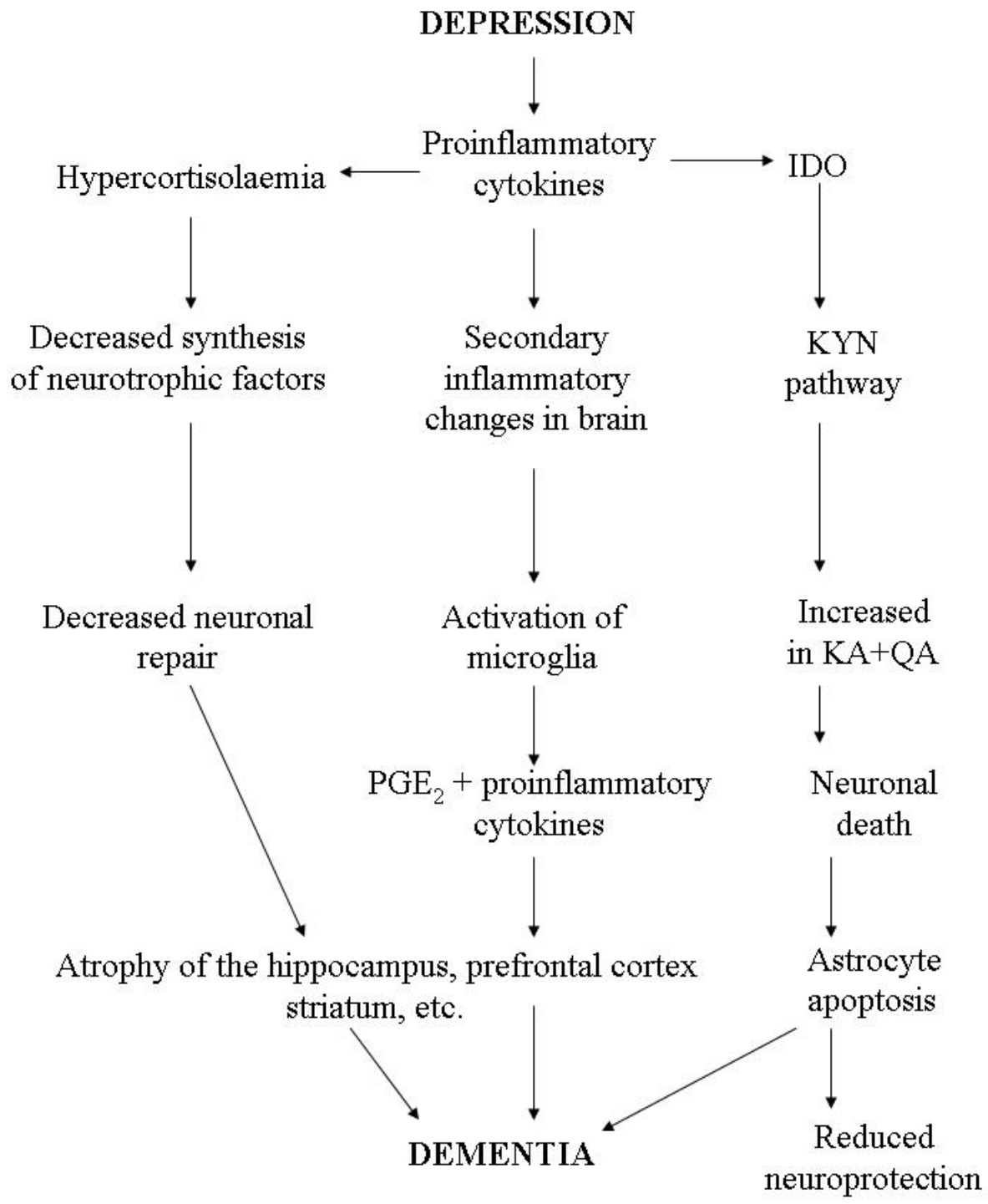

Figure 4-Theoretical pathway linking chronic depression to dementia. PGE2, prostaglandin E2; IDO, indoleamine 2,3-dioxygenase; KYN, kynurenine; KA, kynurenic acid; QA, quinolinic acid.

which multiple pathological changes contribute to the onset of dementia. Nevertheless, the experimental studies do provide evidence in support of the hypothesis that the longterm outcome of chronic depression is often dementia. Further evidence for this hy- 
pothesis comes from the study by Steffens et al (4) who demonstrated a link between late-onset depression and the rise in plasma apolipoprotein E4 which is widely considered to be a risk factor for late-onset Alzheimer's disease. Figure 4 summarises the possible pathways leading from depression to dementia.

\section{Conclusion}

Neuronal loss is a common feature of major depression and dementia. The progress of major depression to dementia could result from the chronic inflammatory changes that are linked to the activation of the microglia. The activation of inducible COX2 and NOS by the pro-inflammatory cytokines further increases the inflammatory challenge to the brain. As there is evidence that the kynurenine pathway is also activated by proinflammatory cytokines, it seems likely that the concentrations of the neurotoxins 3hydroxykynurenine, 3-hydroxyanthranillic acids and quinolinic acid will also increase as a result of the activation of the microglia. The increased apoptosis of the astrocytes, with a reduction in the availability of the neuroprotective agent kynurenic acid, further adds to the impact of the neurodegenerative changes. Hypercortisolaemia, a common feature of both dementia and major depression, and apoptosis of astrocytes decreases the synthesis of neurotrophic factors thereby reducing neuronal repair. This process may be further enhanced by the disruption of the phospholipase D pathway that normally plays an important role in neurite formation and neuronal repair. This hypothesis may assist in explaining the degenerative changes in the hippocampus and other brain regions that are the features of chronic major depression. It may also explain why chronic depression is frequently a prelude to dementia in the elderly patient.

\section{Acknowledgement}

AM Myint thanks the Universities of Maastricht and Antwerp for their financial support that enabled her to undertake the research that forms part of this presentation.

\section{References}

1. Geerlings MI, Schoevers RA, Beekman AT, Jonker C, Deeg DJ, Schmand B, et al. Depression and risk of cognitive decline and Alzheimer's disease. Results of two prospective community-based studies in The Netherlands. Br J Psychiatry 2000;176:568-75.

2. Visser PJ, Verhey FR, Ponds RW, Kester A, Jolles J. Distinction between preclinical Alzheimer's disease and depression. J Am Geriatr Soc 2000;48(5):479-84.

3. Modrego PJ, Ferrandez J. Depression in patients with mild cognitive impairment increases the risk of developing dementia of Alzheimer type: a prospective cohort study. Arch Neurol 2004;61(8):1290-3.

4. Steffens DC, Plassman BL, Helms MJ, Welsh-Bohmer KA, Saunders AM, Breitner JC. A twin study of late-onset depression and apolipoprotein E epsilon 4 as risk factors for Alzheimer's disease. Biol Psychiatry 1997;41(8):851-6.

5. Campbell IK, Roberts LJ, Wicks IP. Molecular targets in immune-mediated diseases: the case of tumour necrosis factor and rheumatoid arthritis. Immunol Cell Biol 2003;81(5):354-66.

6. Licinio J, Kling MA, Hauser P. Cytokines and brain function: relevance to interferon-alpha-induced mood and cognitive changes. Semin Oncol 1998;25(1 Suppl 1):30-8.

7. O’Mahony SM, Myint AM, Steinbusch H, Leonard BE. Efavirenz induces depressive-like behaviour, increased stress response and changes in the immune response in rats. Neuroimmunomodulation 2005;12(5):293-8.

8. Maes M, Bosmans E, De Jongh R, Kenis G, Vandoolaeghe E, Neels H. Increased serum IL6 and IL1 receptor antagonist concentrations in major depression and treatment resistant depression. Cytokine 1997;9(11):853-8. 
9. Smith RS. The macrophage theory of depression. Med Hypotheses 1991;35(4):298-306.

10. Mayne TJ, Vittinghoff E, Chesney MA, Barrett DC, Coates TJ. Depressive affect and survival among gay and bisexual men infected with HIV. Arch Intern Med 1996;156(19):2233-8.

11. Stern Y, McDermott MP, Albert S, Palumbo D, Selnes OA, McArthur J, et al. Factors associated with incident human immunodeficiency virus-dementia. Arch Neurol 2001;58(3):473-9.

12. Gilbertson MW, Shenton ME, Ciszewski A, Kasai K, Lasko NB, Orr SP, et al. Smaller hippocampal volume predicts pathologic vulnerability to psychological trauma. Nat Neurosci 2002;5(11):1242-7.

13. Sapolsky RM. The possibility of neurotoxicity in the hippocampus in major depression: a primer on neuron death. Biol Psychiatry 2000;48(8):755-65.

14. McEwen BS. Possible mechanisms for atrophy of the human hippocampus. Mol Psychiatry 1997;2(3):255-62.

15. Gold PW, Chrousos G, Kellner C, Post R, Roy A, Augerinos P, et al. Psychiatric implications of basic and clinical studies with corticotropin-releasing factor. Am J Psychiatry 1984;141(5):619-27.

16. Board F, Wadeson R, Persky H. Depressive affect and endocrine functions; blood levels of adrenal cortex and thyroid hormones in patients suffering from depressive reactions. AMA Arch Neurol Psychiatry 1957;78(6):612-20.

17. Sachar EJ, Hellman L, Fukushima DK, Gallagher TF. Cortisol production in depressive illness. A clinical and biochemical clarification. Arch Gen Psychiatry 1970;23(4):289-98.

18. Carroll BJ, Martin FI, Davies B. Pituitary-adrenal function in depression. Lancet 1968;1(7556):1373-4.

19. Arana GW, Mossman D. The dexamethasone suppression test and depression. Approaches to the use of a laboratory test in psychiatry. Neurol Clin 1988;6(1):21-39.

20. Trapp T, Holsboer F. Heterodimerization between mineralocorticoid and glucocorticoid receptors increases the functional diversity of corticosteroid action. Trends Pharmacol Sci 1996;17(4):145-9.

21. Evans DL, Nemeroff CB. Use of the dexamethasone suppression test using DSM-III criteria on an inpatient psychiatric unit. Biol Psychiatry 1983;18(4):505-11.

22. Hartmann A, Veldhuis JD, Deuschle M, Standhardt H, Heuser I. Twenty-four hour cortisol release profiles in patients with Alzheimer's and Parkinson's disease compared to normal controls: ultradian secretory pulsatility and diurnal variation. Neurobiol Aging 1997;18(3):285-9.

23. Davis KL, Mohs RC, Marin DB, Purohit DP, Perl DP, Lantz M, et al. Neuropeptide abnormalities in patients with early Alzheimer disease. Arch Gen Psychiatry 1999;56(11):981-7.

24. Scott LV, Dinan TG. Vasopressin and the regulation of hypothalamic-pituitary-adrenal axis function: implications for the pathophysiology of depression. Life Sci 1998;62(22):1985-98.

25. Bartanusz V, Jezova D, Bertini LT, Tilders FJ, Aubry JM, Kiss JZ. Stress-induced increase in vasopressin and corticotropin-releasing factor expression in hypophysiotrophic paraventricular neurons. Endocrinology 1993;132(2):895-902.

26. Raadsheer FC, van Heerikhuize JJ, Lucassen PJ, Hoogendijk WJ, Tilders FJ, Swaab DF. Corticotropinreleasing hormone mRNA levels in the paraventricular nucleus of patients with Alzheimer's disease and depression. Am J Psychiatry 1995;152(9):1372-6.

27. Amsterdam JD, Marinelli DL, Arger P, Winokur A. Assessment of adrenal gland volume by computed tomography in depressed patients and healthy volunteers: a pilot study. Psychiatry Res 1987;21(3):18997.

28. Krishnan KR, McDonald WM, Escalona PR, Doraiswamy PM, Na C, Husain MM, et al. Magnetic resonance imaging of the caudate nuclei in depression. Preliminary observations. Arch Gen Psychiatry 1992;49(7):553-7.

29. Nemeroff CB, Widerlov E, Bissette G, Walleus H, Karlsson I, Eklund K, et al. Elevated concentrations of CSF corticotropin-releasing factor-like immunoreactivity in depressed patients. Science 1984;226(4680):1342-4.

30. Hucks D, Lowther S, Crompton MR, Katona CL, Horton RW. Corticotropin-releasing factor binding sites in cortex of depressed suicides. Psychopharmacology (Berl) 1997;134(2):174-8.

31. Nemeroff CB, Owens MJ, Bissette G, Andorn AC, Stanley M. Reduced corticotropin releasing factor binding sites in the frontal cortex of suicide victims. Arch Gen Psychiatry 1988;45(6):577-9.

32. Newport D, Nemeroff, C. HPA axis: normal physiology and disturbances in depression. In: Thakore J, editor. Physical Consequences of Depression. Petersfield, UK: Washington Biomed Publishing; 2001. p. $1-22$.

33. Irwin M. Stress-induced immune suppression: role of brain corticotropin releasing hormone and autonomic nervous system mechanisms. Adv Neuroimmunol 1994;4(1):29-47.

34. Karten YJ, Nair SM, van Essen L, Sibug R, Joels M. Long-term exposure to high corticosterone levels attenuates serotonin responses in rat hippocampal CA1 neurons. Proc Natl Acad Sci U S A 1999;96(23):13456-61. 
35. Linthorst AC, Flachskamm C, Hopkins SJ, Hoadley ME, Labeur MS, Holsboer F, et al. Long-term intracerebroventricular infusion of corticotropin-releasing hormone alters neuroendocrine, neurochemical, autonomic, behavioral, and cytokine responses to a systemic inflammatory challenge. J Neurosci 1997;17(11):4448-60.

36. Duman RS, Heninger GR, Nestler EJ. A molecular and cellular theory of depression. Arch Gen Psychiatry 1997;54(7):597-606.

37. Sapolsky RM. Glucocorticoids and hippocampal atrophy in neuropsychiatric disorders. Arch Gen Psychiatry 2000;57(10):925-35.

38. Bremner JD, Narayan M, Anderson ER, Staib LH, Miller HL, Charney DS. Hippocampal volume reduction in major depression. Am J Psychiatry 2000;157(1):115-8.

39. Ongur D, Drevets WC, Price JL. Glial reduction in the subgenual prefrontal cortex in mood disorders. Proc Natl Acad Sci U S A 1998;95(22):13290-5.

40. Hayley S, Poulter MO, Merali Z, Anisman H. The pathogenesis of clinical depression: stressor- and cytokine-induced alterations of neuroplasticity. Neuroscience 2005;135(3):659-78.

41. Belanoff JK, Rothschild AJ, Cassidy F, DeBattista C, Baulieu EE, Schold C, et al. An open label trial of C-1073 (mifepristone) for psychotic major depression. Biol Psychiatry 2002;52(5):386-92.

42. Dringenberg HC. Alzheimer's disease: more than a 'cholinergic disorder'-evidence that cholinergicmonoaminergic interactions contribute to EEG slowing and dementia. Behav Brain Res 2000;115(2):235-49.

43. McGeer PL, McGeer EG. The inflammatory response system of brain: implications for therapy of Alzheimer and other neurodegenerative diseases. Brain Res Brain Res Rev 1995;21(2):195-218.

44. Eikelenboom P, Veerhuis R. The role of complement and activated microglia in the pathogenesis of Alzheimer's disease. Neurobiol Aging 1996;17(5):673-80.

45. Raitano $\mathrm{AB}$, Korc $\mathrm{M}$. Tumor necrosis factor up-regulates gamma-interferon binding in a human carcinoma cell line. J Biol Chem 1990;265(18):10466-72.

46. Suo Z, Tan J, Placzek A, Crawford F, Fang C, Mullan M. Alzheimer's beta-amyloid peptides induce inflammatory cascade in human vascular cells: the roles of cytokines and CD40. Brain Res 1998;807(12):110-7.

47. Kendler KS, Karkowski LM, Prescott CA. Causal relationship between stressful life events and the onset of major depression. Am J Psychiatry 1999;156(6):837-41.

48. McGeer PL, Rogers J, McGeer EG. Neuroimmune mechanisms in Alzheimer disease pathogenesis. Alzheimer Dis Assoc Disord 1994;8(3):149-58.

49. Eckert A, Cotman CW, Zerfass R, Hennerici M, Muller WE. Lymphocytes as cell model to study apoptosis in Alzheimer's disease: vulnerability to programmed cell death appears to be altered. J Neural Transm Suppl 1998;54:259-67.

50. Sulger J, Dumais-Huber C, Zerfass R, Henn FA, Aldenhoff JB. The calcium response of human T lymphocytes is decreased in aging but increased in Alzheimer's dementia. Biol Psychiatry 1999;45(6):737-42.

51. Nishimura T, Akiyama H, Yonehara S, Kondo H, Ikeda K, Kato M, et al. Fas antigen expression in brains of patients with Alzheimer-type dementia. Brain Res 1995;695(2):137-45.

52. Marz P, Heese K, Hock C, Golombowski S, Muller-Spahn F, Rose-John S, et al. Interleukin-6 (IL6) and soluble forms of IL6 receptors are not altered in cerebrospinal fluid of Alzheimer's disease patients. Neurosci Lett 1997;239(1):29-32.

53. Schott K. RE, Noda S. et al. Immunological alterations in Alzheimer's disease. In: Sperner-Unterweger B. FW, Kaschka UP., editor. Psychoneuroimmunology: Hypothesis and Current Research. Basel: Karger; 2001. p. 120-126.

54. Yamada M, Itoh Y, Shintaku M, Kawamura J, Jensson O, Thorsteinsson L, et al. Immune reactions associated with cerebral amyloid angiopathy. Stroke 1996;27(7):1155-62.

55. Blum-Degen D, Muller T, Kuhn W, Gerlach M, Przuntek H, Riederer P. Interleukin-1 beta and interleukin- 6 are elevated in the cerebrospinal fluid of Alzheimer's and de novo Parkinson's disease patients. Neurosci Lett 1995;202(1-2):17-20.

56. Kalman J, Juhasz A, Laird G, Dickens P, Jardanhazy T, Rimanoczy A, et al. Serum interleukin-6 levels correlate with the severity of dementia in Down syndrome and in Alzheimer's disease. Acta Neurol Scand 1997;96(4):236-40.

57. Hu J, Akama KT, Krafft GA, Chromy BA, Van Eldik LJ. Amyloid-beta peptide activates cultured astrocytes: morphological alterations, cytokine induction and nitric oxide release. Brain Res 1998;785(2):195-206.

58. Luterman JD, Haroutunian V, Yemul S, Ho L, Purohit D, Aisen PS, et al. Cytokine gene expression as a function of the clinical progression of Alzheimer disease dementia. Arch Neurol 2000;57(8):1153-60. 
59. Ho L, Purohit D, Haroutunian V, Luterman JD, Willis F, Naslund J, et al. Neuronal cyclooxygenase 2 expression in the hippocampal formation as a function of the clinical progression of Alzheimer disease. Arch Neurol 2001;58(3):487-92.

60. Rada P, Mark GP, Vitek MP, Mangano RM, Blume AJ, Beer B, et al. Interleukin-1 beta decreases acetylcholine measured by microdialysis in the hippocampus of freely moving rats. Brain Res 1991;550(2):287-90.

61. Roberts GW, Gentleman SM, Lynch A, Graham DI. beta A4 amyloid protein deposition in brain after head trauma. Lancet 1991;338(8780):1422-3.

62. Solomon GF MJ. Psychoneuroimmunology and aging. In: Ader R FD, Cohen N, editor. Psychoneuroimmunology. Third Edition ed. New York: Academic Press; 2001. p. 701-717.

63. Evans DL, Leserman J, Perkins DO, Stern RA, Murphy C, Zheng B, et al. Severe life stress as a predictor of early disease progression in HIV infection. Am J Psychiatry 1997;154(5):630-4.

64. Gallant JE. Initial therapy of HIV infection. J Clin Virol 2002;25(3):317-33.

65. Lyketsos CG, Hoover DR, Guccione M. Depression and survival among HIV-infected persons. Jama 1996;275(1):35-6.

66. Rabkin JG, Williams JB, Remien RH, Goetz R, Kertzner R, Gorman JM. Depression, distress, lymphocyte subsets, and human immunodeficiency virus symptoms on two occasions in HIV-positive homosexual men. Arch Gen Psychiatry 1991;48(2):111-9.

67. Meyers CA VA. Neurologic and psychiatric adverse effects of immunological therapy. CNS Drugs 1995;3:56-68.

68. Hansen MK, Taishi P, Chen Z, Krueger JM. Vagotomy blocks the induction of interleukin-1beta (IL1beta) mRNA in the brain of rats in response to systemic IL1beta. J Neurosci 1998;18(6):2247-53.

69. Banks WA, Kastin AJ, Ehrensing CA. Blood-borne interleukin-1 alpha is transported across the endothelial blood-spinal cord barrier of mice. J Physiol 1994;479 (Pt 2):257-64.

70. Minden SL, Schiffer RB. Affective disorders in multiple sclerosis. Review and recommendations for clinical research. Arch Neurol 1990;47(1):98-104.

71. Marshall PS. Allergy and depression: a neurochemical threshold model of the relation between the illnesses. Psychol Bull 1993;113(1):23-43.

72. Katon W, Sullivan MD. Depression and chronic medical illness. J Clin Psychiatry 1990;51 Suppl:3-11; discussion 12-4.

73. Schrott LM, Crnic LS. Anxiety behavior, exploratory behavior, and activity in NZB x NZW F1 hybrid mice: role of genotype and autoimmune disease progression. Brain Behav Immun 1996;10(3):260-74.

74. O’Neill B LB. Is there an abnormality in neutrophil phagocytosis in depression? IRCS Med Sci 1986; $14: 802-803$.

75. Kronfol Z HJ. Depression, HPA activity and lymphocyte function. Acta Psychiat Scand 1987;80:142147.

76. Irwin M, Smith TL, Gillin JC. Low natural killer cytotoxicity in major depression. Life Sci 1987;41(18):2127-33.

77. Song C, Dinan T, Leonard BE. Changes in immunoglobulin, complement and acute phase protein levels in the depressed patients and normal controls. J Affect Disord 1994;30(4):283-8.

78. Sluzewska A, Rybakowski J, Bosmans E, Sobieska M, Berghmans R, Maes M, et al. Indicators of immune activation in major depression. Psychiatry Res 1996;64(3):161-7.

79. Xia Z, DePierre JW, Nassberger L. Tricyclic antidepressants inhibit IL6, IL1 beta and TNF-alpha release in human blood monocytes and IL2 and interferon-gamma in T cells. Immunopharmacology 1996;34(1):27-37.

80. Neveu PJ CN. Is there evidence for an effect of antidepressant drugs on immune function? In: Dantzer R WE, Yirmiya R, editor. Cytokines, stress and depression. New York: Kluwer Academic/Plenum Press; 1999. p. 267-281.

81. Connor TJ, Harkin A, Kelly JP, Leonard BE. Olfactory bulbectomy provokes a suppression of interleukin-1beta and tumour necrosis factor-alpha production in response to an in vivo challenge with lipopolysaccharide: effect of chronic desipramine treatment. Neuroimmunomodulation 2000;7(1):27-35.

82. Myint AM, Leonard BE, Steinbusch HW, Kim YK. Th1, Th2, and Th3 cytokine alterations in major depression. J Affect Disord 2005.

83. Weiner HL. Oral tolerance: immune mechanisms and the generation of Th3-type TGF-beta-secreting regulatory cells. Microbes Infect 2001;3(11):947-54.

84. Aisen PS. Inflammation and Alzheimer disease. Mol Chem Neuropathol 1996;28(1-3):83-8.

85. McGeer PL, Itagaki S, Boyes BE, McGeer EG. Reactive microglia are positive for HLA-DR in the substantia nigra of Parkinson's and Alzheimer's disease brains. Neurology 1988;38(8):1285-91.

86. Liu B, Hong JS. Role of microglia in inflammation-mediated neurodegenerative diseases: mechanisms and strategies for therapeutic intervention. J Pharmacol Exp Ther 2003;304(1):1-7. 
87. Song C, Lin A, Bonaccorso S, Heide C, Verkerk R, Kenis G, et al. The inflammatory response system and the availability of plasma tryptophan in patients with primary sleep disorders and major depression. J Affect Disord 1998;49(3):211-9.

88. Ohishi K, Ueno R, Nishino S, Sakai T, Hayaishi O. Increased level of salivary prostaglandins in patients with major depression. Biol Psychiatry 1988;23(4):326-34.

89. Linnoila M, Whorton AR, Rubinow DR, Cowdry RW, Ninan PT, Waters RN. CSF prostaglandin levels in depressed and schizophrenic patients. Arch Gen Psychiatry 1983;40(4):405-6.

90. Schmidlin F, Loeffler S, Bertrand C, Landry Y, Gies JP. PLA2 phosphorylation and cyclooxygenase-2 induction, through p38 MAP kinase pathway, is involved in the IL1beta-induced bradykinin B2 receptor gene transcription. Naunyn Schmiedebergs Arch Pharmacol 2000;361(3):247-54.

91. Leonard BE, Song, C. Stress, depression and the role of cytokines. In: Dantzer R WE, Yirmiya R, editor. Cytokines, stress and depression. New York: Kluwer Academic/Plenum Press; 1999. p. 251-265.

92. Mtabaji JP, Manku MS, Horrobin DF. Actions of the tricyclic antidepressant clomipramine on responses to pressor agents. Interactions with prostaglandin E2. Prostaglandins 1977;14(1):125-32.

93. Glen A, and Ross, BM. Prostaglandins and eicosanoids in mental illness. In: Curtis-Prior P, editor. The Eicosanoids. Chichester, UK: John Wiley and Sons; 2004. p. 493-498.

94. Leonard BE. Brain cytokines and psychopathology of depression. In: Leonard BE, editor. Antidepressants. Basel: Birkhauser; 2001. p. 109-120.

95. Collantes-Esreres E, and Fernandez-Perrez, C. Impaired self control of osteoarthritis pain and self reported health states in non-responders to celecoxib switched to rofecoxib: results of PAVIA, an open label post marketing surgery in Spain. Curr Med Res Opinion 2003;19:402-410.

96. Muller N, Riedel M, Schwarz MJ, Engel RR. Clinical effects of COX-2 inhibitors on cognition in schizophrenia. Eur Arch Psychiatry Clin Neurosci 2005;255(2):149-51.

97. Muller N, Strassnig M, Schwarz MJ, Ulmschneider M, Riedel M. COX-2 inhibitors as adjunctive therapy in schizophrenia. Expert Opin Investig Drugs 2004;13(8):1033-44.

98. Sandrini M, Vitale G, Pini LA. Effect of rofecoxib on nociception and the serotonin system in the rat brain. Inflamm Res 2002;51(3):154-9.

99. Griffin DE, Wesselingh SL, McArthur JC. Elevated central nervous system prostaglandins in human immunodeficiency virus-associated dementia. Ann Neurol 1994;35(5):592-7.

100. Calabrese JR, Skwerer RG, Barna B, Gulledge AD, Valenzuela R, Butkus A, et al. Depression, immunocompetence, and prostaglandins of the E series. Psychiatry Res 1986;17(1):41-7.

101. Myint AM, Kim YK. Cytokine-serotonin interaction through IDO: a neurodegeneration hypothesis of depression. Med Hypotheses 2003;61(5-6):519-25.

102. Ikeda-Matsuo Y, Ikegaya Y, Matsuki N, Uematsu S, Akira S, Sasaki Y. Microglia-specific expression of microsomal prostaglandin E2 synthase-1 contributes to lipopolysaccharide-induced prostaglandin E2 production. J Neurochem 2005;94(6):1546-58.

103. Dawson VL, Dawson TM. Nitric oxide neurotoxicity. J Chem Neuroanat 1996;10(3-4):179-90.

104. Suzuki E, Yagi G, Nakaki T, Kanba S, Asai M. Elevated plasma nitrate levels in depressive states. J Affect Disord 2001;63(1-3):221-4.

105. Harvey B. Affective disorders and nitric oxide: a role in pathway to relapse and refractoriness? Hum Psychopharmacol 1996;11:309-319.

106. Moncada S, Higgs A, Furchgott R. International Union of Pharmacology Nomenclature in Nitric Oxide Research. Pharmacol Rev 1997;49(2):137-42.

107. Nathan C. Nitric oxide as a secretory product of mammalian cells. Faseb J 1992;6(12):3051-64.

108. Cuzzocrea S, Riley DP, Caputi AP, Salvemini D. Antioxidant therapy: a new pharmacological approach in shock, inflammation, and ischemia/reperfusion injury. Pharmacol Rev 2001;53(1):135-59.

109. Young SN, Smith SE, Pihl RO, Ervin FR. Tryptophan depletion causes a rapid lowering of mood in normal males. Psychopharmacology (Berl) 1985;87(2):173-7.

110. Guillemin GJ, Kerr SJ, Smythe GA, Smith DG, Kapoor V, Armati PJ, et al. Kynurenine pathway metabolism in human astrocytes: a paradox for neuronal protection. J Neurochem 2001;78(4):842-53.

111. Hayaishi O. Biochemical and Medical Aspects of Tryptophan Metabolism. Amsterdam: Elsevier/NorthHolland Biomedical Press; 1980.

112. Heyes MP, Saito K, Major EO, Milstien S, Markey SP, Vickers JH. A mechanism of quinolinic acid formation by brain in inflammatory neurological disease. Attenuation of synthesis from L-tryptophan by 6-chlorotryptophan and 4-chloro-3-hydroxyanthranilate. Brain 1993;116 (Pt 6):1425-50.

113. Mellor AL, Munn DH. Tryptophan catabolism and T-cell tolerance: immunosuppression by starvation? Immunol Today 1999;20(10):469-73.

114. Musso T, Gusella GL, Brooks A, Longo DL, Varesio L. Interleukin-4 inhibits indoleamine 2,3dioxygenase expression in human monocytes. Blood 1994;83(5):1408-11. 
115. Carlin JM, Borden EC, Sondel PM, Byrne GI. Biologic-response-modifier-induced indoleamine 2,3dioxygenase activity in human peripheral blood mononuclear cell cultures. $\mathrm{J}$ Immunol 1987;139(7):2414-8.

116. Chiarugi A, Calvani M, Meli E, Traggiai E, Moroni F. Synthesis and release of neurotoxic kynurenine metabolites by human monocyte-derived macrophages. J Neuroimmunol 2001;120(1-2):190-8.

117. Perkins MN, Stone TW. An iontophoretic investigation of the actions of convulsant kynurenines and their interaction with the endogenous excitant quinolinic acid. Brain Res 1982;247(1):184-7.

118. Kim JP, Choi DW. Quinolinate neurotoxicity in cortical cell culture. Neuroscience 1987;23(2):423-32.

119. Stone TW, Darlington LG. Endogenous kynurenines as targets for drug discovery and development. Nat Rev Drug Discov 2002;1(8):609-20.

120. Grant RS, Kapoor V. Murine glial cells regenerate NAD, after peroxide-induced depletion, using either nicotinic acid, nicotinamide, or quinolinic acid as substrates. J Neurochem 1998;70(4):1759-63.

121. Heyes MP, Achim CL, Wiley CA, Major EO, Saito K, Markey SP. Human microglia convert 1tryptophan into the neurotoxin quinolinic acid. Biochem J 1996;320 (Pt 2):595-7.

122. Guillemin GJ, Smythe G, Takikawa O, Brew BJ. Expression of indoleamine 2,3-dioxygenase and production of quinolinic acid by human microglia, astrocytes, and neurons. Glia 2005;49(1):15-23.

123. Wichers MC, Koek GH, Robaeys G, Verkerk R, Scharpe S, Maes M. IDO and interferon-alpha-induced depressive symptoms: a shift in hypothesis from tryptophan depletion to neurotoxicity. Mol Psychiatry 2005;10(6):538-44.

124. Myint AM, Leonard BE, Steinbusch HW, Kim YK. Th1, Th2, and Th3 cytokine alterations in major depression. J Affect Disord 2005;88(2):167-73.

125. Bremner JD. Does stress damage the brain? Biol Psychiatry 1999;45(7):797-805.

126. Sheline YI, Sanghavi M, Mintun MA, Gado MH. Depression duration but not age predicts hippocampal volume loss in medically healthy women with recurrent major depression. J Neurosci 1999;19(12):503443.

127. Cotter DR, Pariante CM, Everall IP. Glial cell abnormalities in major psychiatric disorders: the evidence and implications. Brain Res Bull 2001;55(5):585-95.

128. Rajkowska G, Miguel-Hidalgo JJ, Wei J, Dilley G, Pittman SD, Meltzer HY, et al. Morphometric evidence for neuronal and glial prefrontal cell pathology in major depression. Biol Psychiatry 1999;45(9):1085-98.

129. Krishnan KR, Doraiswamy PM, Lurie SN, Figiel GS, Husain MM, Boyko OB, et al. Pituitary size in depression. J Clin Endocrinol Metab 1991;72(2):256-9.

130. Nibuya M, Takahashi M, Russell DS, Duman RS. Repeated stress increases catalytic TrkB mRNA in rat hippocampus. Neurosci Lett 1999;267(2):81-4.

131. Wu H, Friedman WJ, Dreyfus CF. Differential regulation of neurotrophin expression in basal forebrain astrocytes by neuronal signals. J Neurosci Res 2004;76(1):76-85.

132. Klein J. Functions and pathophysiological roles of phospholipase D in the brain. J Neurochem 2005;94(6):1473-87.

133. Guillemin GJ, Brew BJ, Noonan CE, Takikawa O, Cullen KM. Indoleamine 2,3-dioxygenase and quinolinic acid immunoreactivity in Alzheimer's disease hippocampus. Neuropathol Appl Neurobiol 2005;31(4):395-404.

134. Egashira N, Iwasaki K, Takashima A, Watanabe T, Kawabe H, Matsuda T, et al. Altered depressionrelated behavior and neurochemical changes in serotonergic neurons in mutant R406W human tau transgenic mice. Brain Res 2005;1059(1):7-12. 


\section{Chapter 8}

\section{General Discussion and Future Perspective}




\section{Immune changes in major depression: cause or coexistence or consequence?}

A meta-analysis of over 180 studies, in which more than 40 immune parameters were determined, concluded that there is substantial evidence for a link between a dysfunctional immune system and depression (1). Both psychological stress and depression can induce immune dysfunction. In addition, the HPA and HPT axes are known to be involved in the immune changes induced by stress (2). Depressed patients frequently exhibit hypercortisolaemia associated with an elevation of CRF (3), the key neuropeptide that is involved in the integration of the immune, endocrine and neurotransmitter systems in response to stress. Thus CRF has been shown to alter both innate and cellular immunity and antibody formation $(4,5)$. Such effects also involve the activation of the sympathetic nervous system, an event that has been shown to suppress both natural killer cell (NKC) activity and T-lymphocytes $(6,7)$.

One of the earliest immune changes that relate to depression concern an increase in the number of white blood cells, specifically involving a change in the proportion of neutrophils and lymphocytes and a reduction in NKC's (8-17). It is of interest to note that the changes in the proportion of NKC's depend on the gender of the depressed patient. Thus the reduction in the NKC's is greater in male than in female patients (18) although it must be emphasised that this finding is controversial (19).

In regard to the cytokine changes in depression, several studies have reported that there is an increase in pro-inflammatory Th1 cytokines in patients with major depression (20-22) but not all studies can confirm this $(23,24)$. In some studies, the increase in pro-inflammatory cytokines has been linked to suicide attempts (25) rather than with major depression as such (26). Furthermore, differences in the changes in proinflammatory cytokines have been reported in melancholic verses non-melancholic depression (27) and between dysthymia and major depression (28). The variability in results may reflect the differences in study design, for example, whether drug naïve or medicated patients are studied, the sub-types of depression included and whether basal or stimulated cytokine concentrations are measured. Nevertheless, despite these limitations, it would appear that there is reasonable evidence to support the view that proinflammatory cytokines are increased in major depression.

In the present studies, the balance between representative Th1, Th2 and Th3 cytokines were determined in plasma before and following antidepressant treatment. The results clearly demonstrate that there is an increase in Th1 cytokines and a decrease in Th2 cytokines; Th3 cytokines increase in patients that recover from depression. It was of interest to find that the female patients showed an increase in Th1 cytokines following effective treatment whereas male patients, and post-menopausal patients, showed a reduction in the Th1 cytokines following antidepressant treatment. Other studies have shown somewhat similar changes (29-31). However, it is still uncertain whether the immune changes are the cause or the effect of depression. If the cytokine changes are related to the psychopathology of depression, as proposed by the neurodegeneration hypothesis, then the cytokine changes would be expected to be reflected in changes in the brain. To investigate this possibility, the effects of IFN alpha were studied in rats.

IFN has been shown to induce depressive-like states in patients being treated for certain malignancies and hepatitis B and C (32-34); IFN also induces depressive-like behaviour in rats (35). The results of study of the effects of IFN on the behaviour and on 
changes in microglia and astrocytes (36) clearly demonstrate that this cytokine induces an increase in the pro-inflammatory cytokines in the hypothalamus and hippocampus that are associated with depressive-like behaviour. These changes are reversed by chronic paroxetine treatment. IFN was also shown to reduce the density of astrocytes in the dendate gyrus and CA3 region of the hippocampus; chronic fluoxetine treatment failed to prevent such changes (37). Other investigators have shown that, in rats, stress can cause a reduction in astrocyte number and in astrocyte volume; events that are also not reversed by antidepressant treatment (38).

Taken together, these results suggest that the imbalance between Th1,Th2 and Th3 cytokines in the peripheral blood of depressed patients might contribute to the structural and functional changes induced by IFN treatment and that are also associated with major depression. Antidepressants may reduce the inflammatory changes but would appear to be much less effective in reversing the changes in the astrocytes that are associated with inflammation. As the astrocytes play an important role in neuroprotection it seems probable that such irreversible changes could be a prelude to neurodegeneration. This clearly requires further investigation.

To further confirm that immune changes can be the causative factor in pathophysiology of major depression, an experimental study was undertaken in which olfactory bulbectomised (OBX) rats were treated with the cyclooxygenase (COX) 2 inhibitor celecoxib. If the immune or inflammatory changes are causal factors, when those changes are reversed by inhibition of inflammatory cascade, the behavioural and central cytokine changes should also be reversed. It was shown that OBX rats treated with celecoxib did not show central pro-inflammatory cytokine changes or the behavioural changes that occurred in the untreated OBX rats. This lends further support to the hypothesis that inflammatory changes in the brain are important contributing factors to the behavioural abnormalities associated with the behaviour of the OBX rats.

The recent study on changes in tryptophan and kynurenine pathway metabolites in patients with major depression (39) demonstrated indirectly that impaired neuroprotection occurred in depressed patients. An imbalance in the neuroprotectionneurodegeneration kynurenine pathway was indicated by low plasma neuroprotective metabolite, kynurenic acid in depressed patients compared to their healthy controls. Moreover, antidepressant treatment did not reverse this impairment in neuroprotection in those patients with repeated episodes of depression despite the improvement in the clinical symptoms. This finding supports the hypothesis that explains how the cytokine imbalance is related to tryptophan and kynurenine metabolism and how that could lead to impaired neuroprotection in chronic major depression. However, to validate this further, it is necessary to measure the neurotoxic metabolites, such as 3hydroxykynurenine and quinolinic acid, to obtain direct evidence of imbalance neuroprotection-degeneration in terms of kynurenine pathway metabolites. Since there is epidemiological evidence to indicate the relationship between depression and dementia, the metabolic changes that lead to impaired neuroprotection in combination with other associated central inflammatory changes also require evaluation in order to verify the pathophysiological link between depression and dementia.

In conclusion, it would appear that immune changes in depression are both cause and consequence of depressive disorders. The immune changes induced by physical or psychological stress may trigger depressive illness and the depressive illness may induce further immune changes and impaired neuroprotection in the brain. This vicious cycle (figure 1) may explain the role of immune changes in depression. 


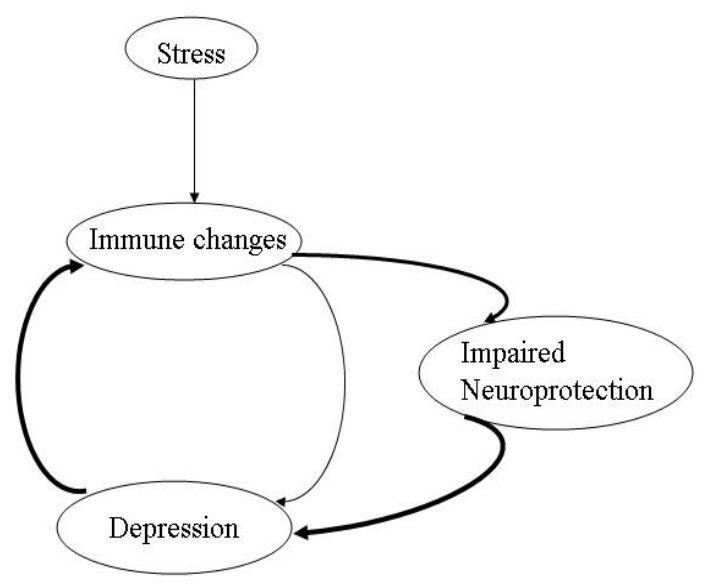

Figure 1-Stress-immune changes-depression interaction

\section{Future perspectives}

Though our studies support to a considerable extent the proposed hypothesis, it is still necessary to prove the certain critical points such as impaired neuronal network and evidence of neurodegeneration in major depression through systematic morphological or imaging studies. Moreover, it is necessary to investigate whether low kynurenic acid concentrations in plasma persist by performing long-term follow-up studies. The effects of different types of antidepressant and non-pharmacological treatments and changes in the kynurenine pathway in other types of psychiatric disorder and in the dementias also need to be explored. In addition, as the kynurenine pathway is widely distributed in the body, the reduction in kynurenic acid may be influenced by many different biological factors such as genetic, environmental or gene-environment interactions. These factors also require further investigation. Lastly, detailed experimental studies leading to a possible diagnostic tool, or a novel antidepressant treatment, by manipulating the neuroprotection-neurodegeneration balance in the kynurenine pathway are also necessary to extend the scope of the present studies. 


\section{References}

1. Zorrilla EP, Luborsky L, McKay JR, Rosenthal R, Houldin A, Tax A, et al. The relationship of depression and stressors to immunological assays: a meta-analytic review. Brain Behav Immun 2001;15(3):199-226.

2. Dhabhar FS, Miller AH, McEwen BS, Spencer RL. Stress-induced changes in blood leukocyte distribution. Role of adrenal steroid hormones. J Immunol 1996;157(4):1638-44.

3. Owens MJ, Nemeroff CB. Physiology and pharmacology of corticotropin-releasing factor. Pharmacol Rev 1991;43(4):425-73.

4. Friedman EM, Irwin MR. A role for $\mathrm{CRH}$ and the sympathetic nervous system in stress-induced immunosuppression. Ann N Y Acad Sci 1995;771:396-418.

5. Friedman EM, Irwin MR. Modulation of immune cell function by the autonomic nervous system. Pharmacol Ther 1997;74(1):27-38.

6. Irwin M, Brown M, Patterson T, Hauger R, Mascovich A, Grant I. Neuropeptide Y and natural killer cell activity: findings in depression and Alzheimer caregiver stress. Faseb J 1991;5(15):3100-7.

7. Madden KS, Sanders VM, Felten DL. Catecholamine influences and sympathetic neural modulation of immune responsiveness. Annu Rev Pharmacol Toxicol 1995;35:417-48.

8. Irwin M, Caldwell C, Smith TL, Brown S, Schuckit MA, Gillin JC. Major depressive disorder, alcoholism, and reduced natural killer cell cytotoxicity. Role of severity of depressive symptoms and alcohol consumption. Arch Gen Psychiatry 1990;47(8):713-9.

9. Irwin M, Patterson T, Smith TL, Caldwell C, Brown SA, Gillin JC, et al. Reduction of immune function in life stress and depression. Biol Psychiatry 1990;27(1):22-30.

10. Irwin M, Smith TL, Gillin JC. Low natural killer cytotoxicity in major depression. Life Sci 1987;41(18):2127-33.

11. Irwin M, Daniels $M$, Weiner H. Immune and neuroendocrine changes during bereavement. Psychiatr Clin North Am 1987;10(3):449-65.

12. Irwin M, Daniels M, Bloom ET, Smith TL, Weiner H. Life events, depressive symptoms, and immune function. Am J Psychiatry 1987;144(4):437-41.

13. Irwin MR, Vale W, Britton KT. Central corticotropin-releasing factor suppresses natural killer cytotoxicity. Brain Behav Immun 1987;1(1):81-7.

14. Irwin $\mathrm{M}$, Daniels $\mathrm{M}$, Smith TL, Bloom E, Weiner $\mathrm{H}$. Impaired natural killer cell activity during bereavement. Brain Behav Immun 1987;1(1):98-104.

15. Irwin M, Gillin JC. Impaired natural killer cell activity among depressed patients. Psychiatry Res 1987;20(2):181-2.

16. Kronfol Z, Turner R, Nasrallah H, Winokur G. Leukocyte regulation in depression and schizophrenia. Psychiatry Res 1984;13(1):13-8.

17. Kronfol Z, House JD. Depression, cortisol, and immune function. Lancet 1984;1(8384):1026-7.

18. Evans DL, Folds JD, Petitto JM, Golden RN, Pedersen CA, Corrigan M, et al. Circulating natural killer cell phenotypes in men and women with major depression. Relation to cytotoxic activity and severity of depression. Arch Gen Psychiatry 1992;49(5):388-95.

19. Schleifer SJ, Keller SE, Bond RN, Cohen J, Stein M. Major depressive disorder and immunity. Role of age, sex, severity, and hospitalization. Arch Gen Psychiatry 1989;46(1):81-7.

20. Connor TJ, Leonard BE. Depression, stress and immunological activation: the role of cytokines in depressive disorders. Life Sci 1998;62(7):583-606.

21. Anisman H, Ravindran AV, Griffiths J, Merali Z. Endocrine and cytokine correlates of major depression and dysthymia with typical or atypical features. Mol Psychiatry 1999;4(2):182-8.

22. Mikova O, Yakimova R, Bosmans E, Kenis G, Maes M. Increased serum tumor necrosis factor alpha concentrations in major depression and multiple sclerosis. Eur Neuropsychopharmacol 2001;11(3):203-8.

23. Weizman R, Laor N, Podliszewski E, Notti I, Djaldetti M, Bessler H. Cytokine production in major depressed patients before and after clomipramine treatment. Biol Psychiatry 1994;35(1):42-7.

24. Bauer J, Hohagen F, Gimmel E, Bruns F, Lis S, Krieger S, et al. Induction of cytokine synthesis and fever suppresses REM sleep and improves mood in patients with major depression. Biol Psychiatry 1995;38(9):611-21.

25. Haack M, Hinze-Selch D, Fenzel T, Kraus T, Kuhn M, Schuld A, et al. Plasma levels of cytokines and soluble cytokine receptors in psychiatric patients upon hospital admission: effects of confounding factors and diagnosis. J Psychiatr Res 1999;33(5):407-18.

26. Mendlovic S, Mozes E, Eilat E, Doron A, Lereya J, Zakuth V, et al. Immune activation in non-treated suicidal major depression. Immunol Lett 1999;67(2):105-8. 
27. Rothermundt M, Arolt V, Fenker J, Gutbrodt H, Peters M, Kirchner H. Different immune patterns in melancholic and non-melancholic major depression. Eur Arch Psychiatry Clin Neurosci 2001;251(2):907.

28. Schlatter J, Ortuno F, Cervera-Enguix S. Differences in interleukins' patterns between dysthymia and major depression. Eur Psychiatry 2001;16(5):317-9.

29. Kenis G, Maes M. Effects of antidepressants on the production of cytokines. Int J Neuropsychopharmacol 2002;5(4):401-12.

30. Kubera M, Lin AH, Kenis G, Bosmans E, van Bockstaele D, Maes M. Anti-Inflammatory effects of antidepressants through suppression of the interferon-gamma/interleukin-10 production ratio. J Clin Psychopharmacol 2001;21(2):199-206.

31. Mohr DC, Goodkin DE, Islar J, Hauser SL, Genain CP. Treatment of depression is associated with suppression of nonspecific and antigen-specific $\mathrm{T}(\mathrm{H}) 1$ responses in multiple sclerosis. Arch Neurol 2001;58(7):1081-6.

32. Zdilar D, Franco-Bronson K, Buchler N, Locala JA, Younossi ZM. Hepatitis C, interferon alfa, and depression. Hepatology 2000;31(6):1207-11.

33. Scalori A, Apale P, Panizzuti F, Mascoli N, Pioltelli P, Pozzi M, et al. Depression during interferon therapy for chronic viral hepatitis: early identification of patients at risk by means of a computerized test. Eur J Gastroenterol Hepatol 2000;12(5):505-9.

34. Cassidy EM, O’Keane V. Depression and interferon-alpha therapy. Br J Psychiatry 2000;176:494.

35. Makino M, Kitano Y, Komiyama C, Takasuna K. Human interferon-alpha increases immobility in the forced swimming test in rats. Psychopharmacology (Berl) 2000;148(1):106-10.

36. Myint AM, O’Mahony, S., Kubera, M, Ki⿱ $\underset{\sim}{ }$, YK., Kenny, C., Kaim-Basta, A., Steinbusch, HWM., Leonard, BE. Role of paroxetine in interferon induced immune and behavioural changes in male Wistar rats. Psychopharmachology 2006.

37. Myint AM SC, Steinbusch HP, Vossius S, Luchtman D, Van den Waarenburg M, Leonard BE, Steinbusch HWM. Effect of peripheral interferon-alfa injection on astrocytes and microglial changes in hippocampus of male Wistar rats. Exp. Neurol (submitted) 2006.

38. Czeh B, Simon M, Schmelting B, Hiemke C, Fuchs E. Astroglial Plasticity in the Hippocampus is Affected by Chronic Psychosocial Stress and Concomitant Fluoxetine Treatment. Neuropsychopharmacology 2006;31(8):1616-26.

39. Myint A, Kim, YK., Verkerk, R., Scharpe, S., Steinbusch, HWM., Leonard, BE. Kynurenine pathway in major depression: Evidence of impaired neuroprotection. J Affect Disord 2006. 
Summary 


\section{Summary}

Depression is a psychiatric disorder in which all neurotransmitters, endocrine and immune systems are involved. Moreover, these changes can lead to structural changes in the brain. There are different antidepressants developed since mid $20^{\text {th }}$ Century and those improved the clinical symptoms though there are still deficiencies. Recently, immune system changes become of interest in pathophysiology of depression and development of new antidepressant. This thesis addressed the role of neuro-immune balance in clinical and experimental depression, and the role of certain current antidepressants and immunomodulation in this context.

Chapter 1.1, the general discussion is the introduction in which the scientific background in brief related to the reason why the hypothesis was formulated.

Chapter 1.2 is the hypothesis formulated upon which this whole thesis was based and the research studies were designed and carried out. This hypothesis explained the integrated role of neuro-immune-endocrine-metabolism interaction in pathophysiology of depression and the possible coping mechanisms.

Chapter 2 addressed the importance of the balance between representative Th1, Th2 and Th3 cytokines in drug naïve or drug free depressed patients and the effect of antidepressant treatment. The results clearly demonstrate that there is an increase in Th1 cytokines and a decrease in Th2 cytokines in depressed and Th3 cytokine increases in patients that recovered from depression.

Chapter 3 addressed the issue that the proinflammatory cytokine IFN $\alpha$ induced depressive-like behaviour in rats and both peripheral and central cytokine changes. The central cytokine changes occurred in the area like hypothalamus and hippocampus, which are involved in depression. Moreover this chapter addressed the preventive role of SSRI paroxetine in IFN $\alpha$-induced depression.

Chapter 4 addressed the observation that the proinflammatory cytokine, IFN $\alpha$, induced not only the cytokine changes in the brain, but also reduction in astrocyte density in hippocampus area of the brain in the rats. In addition, this chapter explained that the SSRI antidepressant, fluoxetine could not fully prevent the changes. As the astrocytes play an important role in neuroprotection it seems probable that such irreversible changes could be a prelude to neurodegeneration.

Chapter 5 addressed the fact that immunomodulation could improve the symptoms of depression through an experimental study undertaken in olfactory bulbectomised (OBX) rats which were treated with the cyclooxygenase (COX) 2 inhibitor celecoxib. It was shown that OBX rats treated with celecoxib did not show central pro-inflammatory cytokine changes or the behavioural changes that occurred in the untreated OBX rats.

Chapter 6 addressed the changes in tryptophan and kynurenine pathway metabolites in patients with major depression which demonstrated indirectly that impaired neuroprotection occurred in depressed patients. An imbalance in the neuroprotection- 
neurodegeneration kynurenine pathway was indicated by low plasma neuroprotective metabolite, kynurenic acid in depressed patients compared to their healthy controls. Moreover, antidepressant treatment did not reverse this impairment in neuroprotection in those patients with repeated episodes of depression despite the improvement in the clinical symptoms. This finding supports the hypothesis that explains how the cytokine imbalance is related to tryptophan and kynurenine metabolism and how that could lead to impaired neuroprotection in chronic major depression.

In the chapter 7 reviewed the possible relationship between depression and dementia through the metabolic changes that lead to impaired neuroprotection in combination with other associated central inflammatory changes also require evaluation in order to verify the pathophysiological link between depression and dementia.

The last chapter, Chapter 8 discussed on the overall finding through the work in this thesis and the future perspectives. 
Acknowledgement 


\section{Acknowledgement}

The work that contributes to this thesis took almost four years. Within these years, in Europe, so far away from my homeland, Burma, passing through so many hard times, extreme circumstances and challenges, there were many people whom I met or worked with or spoke with or discussed with. All of them meant something in my life and I have gratitude on all of them though I could not mention all the names in these few pages.

First of all, I would like to express my heartfelt thanks to my promoters Prof. Dr. Brian E Leonard and Prof. Dr. Harry Steinbusch and my co-promoter Prof. Dr. Simon Scharpe. I would like to express my gratitude to Prof. Leonard for giving me inspiration, guidance and protection throughout the period. Prof. Leonard is my mentor as well as my father in this land so far away from my homeland and my family. I also would like to express my thanks to Prof. Steinbusch for all his support since the beginning up to now. His support gives me strength to face those circumstances and he trains me to be tough enough. I would also like to thank Prof. Scharpe, for his invaluable help that brought me to stand as an independent entity.

My gratitude is also due to my comrades (paranimfen) Marjanne Markerink and Hellen Steinbusch. I have chosen both of them as my companions for all their invaluable technical and psychological supports as comrades fighting together against this battle of this part of my life.

I would also like to express my heartfelt thanks to Robert Verkerk for his pains taking contribution in tedious sample analyses and all colleagues from University of Antwerp, Department of Medical Biochemistry, for all their help during my research period in Antwerp University.

I would like to acknowledge my gratitude also to Mr. Paul Verstappen, Mrs. Agnes Quest, Mrs. Chantal Huysman, Mr. Danny Mondelaers and all my colleagues from DiaMed Eurogen and DiaMed Benelux and Dr. Manfred Schawaller from DiaMed Switzerland for all their helps and supports in many ways. I would like to thank Paul for being my leader and a father figure who takes care of me in many ways during these difficult years. I would like to thank Agnes and Chantal also for all their helps and for being my 'Belgian sisters'. Without the help of all of them this work would not be finished in this way.

My gratitude is also due to Prof. Yong $\mathrm{Ku} \mathrm{Kim}$ for his invaluable support and collaboration throughout the study period. I would also like to thank Dr. Willem Berfelo, Dr. Marian Majoe, Dr. Hulsman and Kempenhaeghe group for all their collaborations. I would also like to thank all my colleagues from (Psychoimmunology) PNI working group (Leuven, Muenster, Munich and Innsbruck) for giving me strength to continue research in this area.

I would also like to thank my colleagues from University of Maastricht, Department of Psychiatry and Neuropsychology, Dr. Nicole Senden, Mrs. Akke Spauwen, Mrs. Mirèse Willems, Dr. Ronald Deumens, Dr. Mario Losen, Dr. Pilar Martinez, Dr. Daniel van de Hove, Dr. Gunter Kenis, Dr. Jos Prickaerts, Dr. Christoph Schmitz and everyone, for all of them have made me stronger and stronger in many different ways. I would also like to thank Frijnts RGL (Richard), Tinnemans RLP (Rik) and Zeegers HHM (Harry) from Animal Experimentation Department for all the help in animal experiments. I would also thank Shobhain O'Mahony, Lieve Desbonnent, Lillian Garret, Christina Kenny, Dirk Luchtman and Sofie Vossius for their participations. 
I would also like to express my gratitude to Fr. Vincent McMahon L.C., Fr. Carl Kuss L.C., Matteo Bruschettini, Abraham Garcia, Luca Allaria, Anne Gabriel, Cally-lou Noen and all those from our prayer group who give me spiritual strength during those days.

My heartfelt thanks are also due to Drs. Johan Jocken for being a nice little brother to me through these years since his support gave me strength to withstand the stress and difficulties. I would also thank Drs. Mandy Claessens for being a good friend to me.

I would like to express my heartfelt thanks also to Dr. med. Markus Schwarz for being a business partner, a collaborator, and most of all, a good friend who always gives me strength and always be available to talk about all my problems and give mental support.

My gratitude is also due to my Mum (Daw Aye Myint) and Dad (U Ohn Myint) who brought me up to be very decisive, stubborn, obsessive and tough to face all the difficulties and hardships in life.

Last but not least, I would like to express my heartfelt thanks to all the patients and normal subjects who participated in the clinical studies and all the animals which gave their lives in my experimental studies. Without them, there'll be no such a study and I wish that all these contributions would be of some value for helping those patients who are suffering from depression, the pain in mind that makes an individual lose both body and mind.

\section{A wish from a scientist}

A scientist in a laboratory, An animal experiment for a study.

The arenas, squares and objects, We've done behavioural tests.

Time comes to take blood and brain, Make a wish in my heart, with great pain, In the expense of these little creatures, I could help the sufferings in near future.

(C) Aye Mu Myint, 2006, International Library of Poetry 


\section{Curriculum vitae}

Aye Mu Myint was born on $29^{\text {th }}$ of November, 1961 in Hpar-Kant (Jade Land), Myanmar. After the secondary education, she studied Medicine at Institute of Medicine (2), Yangon and got the degree of "Bachelor of Medicine and Bachelor of Surgery (M.B.,B.S.)". After that, she was appointed at the Clinical Research Unit under the Department of Medical Research as a medical officer and Institute of Medicine (Mandalay) as a demonstrator and did clinical practice, research and medical education. Afterwards, she did her Master degree at Institute of Medicine (1), Yangon and got the degree of "Master of Medical Science (M.Med.Sc.), and served as Research Scientist and Head of Nuclear Medicine Research Division at the Department of Medical Research. She was involved in research projects related to endocrinology and neonatal screening for prevention of mental retardation funded by International Atomic Energy Agency. In 2002, she started her Ph.D. project at the Department Psychiatry and Neuropsychology, Faculty of Medicine, University of Maastricht, also part of the Institute of Brian and Behaviour, University of Maastricht and European Graduate School of Neuroscience (EURON) in collaboration with Department of Clinical Biochemistry, Institute of Pharmaceutical Sciences, University of Antwerp, Belgium. She has proposed the "Neurodegeneration Hypothesis of Depression" in 2002 and her work contributed in this thesis based on this hypothesis regarding the relationship between inflammatory changes and neuroactive metabolic changes that can lead to depression. The finding from her research was patented in collaboration with DiaMed, and universities of Maastricht, Antwerp and Munich. 


\section{List of Publications}

\section{Scientific papers}

Myint AM, Kim YK. Cytokine-serotonin interaction through IDO: a neurodegeneration hypothesis of depression. Med Hypotheses. 2003 Nov-Dec;61(5-6):519-25.

Kim YK, Myint AM. Clinical application of low serum cholesterol as an indicator for suicide risk in major depression. J Affect Disord. 2004 Aug;81(2):161-6.

Kim YK, Myint AM, Lee BH, Han CS, Lee HJ, Kim DJ, Leonard BE. Th1, Th2 and Th3 cytokine alteration in schizophrenia. Prog Neuropsychopharmacol Biol Psychiatry. 2004 Nov;28(7):1129-34.

Kim YK, Myint AM, Lee BH, Han CS, Lee SW, Leonard BE, Steinbusch HW. Thelper types 1, 2, and 3 cytokine interactions in symptomatic manic patients. Psychiatry Res. 2004 Dec 30;129(3):267-72.

Tetich M, Dziedzicka-Wasylewska M, Kusmider M, Kutner A, Leskiewicz M, Jaworska-Feil L, Budziszewska B, Kubera M, Myint AM, Basta-Kaim A, Skowronski M, Lason W. Effects of PRI-2191 - a low-calcemic analog of 1,25-dihydroxyvitamin D3 on the seizure-induced changes in brain gene expression and immune system activity in the rat. Brain Res. 2005 Mar 28;1039(1-2):1-13.

Myint AM, Leonard BE, Steinbusch HW, Kim YK. Th1, Th2, and Th3 cytokine alterations in major depression. J Affect Disord. 2005 Oct;88(2):167-73.

O’Mahony SM, Myint AM, Steinbusch H, Leonard BE. Efavirenz induces depressivelike behaviour, increased stress response and changes in the immune response in rats. Neuroimmunomodulation. 2005;12(5):293-8.

Leonard BE, Myint AM. Changes in the immune system in depression and dementia: causal or co-incidental effects? Dialogues Clin. Neurosci. 2006;8 (2):164-174.

Myint AM, Kim YK, Verkerk R, Scharpé S, Steinbusch HWM, Leonard BE Kynurenine pathway in Major Depression: Evidence of impaired neuroprotection. $J$ Aff. Dis, 2006 Sept1; [Epub ahead of print]

O’Mahony SM, Myint AM, van den Hove D, Desbonnent L, Steinbusch H, Leonard BE. Gestational Stress Leads to Depressive-Like Behavioural and Immunological Changes in the Rat. Neuroimmunomodulation. 2006 Oct 10;13(2):82-88 [Epub ahead of print]

Myint AM, S O’Mahony, M Kubera, YK Kim, C Kenny, A Kaim-Basta, HWM Steinbusch, and BE Leonard. Role of paroxetine in Interferon- $\alpha$-induced immune and behavioural changes in male Wister rats. J. Psychopharm, 2006. (in press)

Leonard BE, Myint AM. Inflammation and Depression: Is there a causal connection with dementia? Neurotoxicity Research, 2006. (in press)

Myint AM, Steinbusch H, Schmidt C, Vossius S, Luchtman D, Van den Waarenburg M, Leonard BE, Steinbusch HWM. Effect of peripheral Interferon- $\alpha$ injection 
on inflammatory related morphological changes in hippocampus of male Wister rats. ? J. Chem. Neuroanat., 2006.(submitted)

Myint AM, Steinbusch HWM, Luchtman D, Kenny C, Leonard BE. Effect of COX2 inhibitor celecoxib on behaviour and immune changes in Olfactory-bulbectomised rat model of depression. Neuroimmunomodulation. 2006.(submitted)

Myint AM, Kim YK, Verkerk R, Scharpé S, Steinbusch HWM, Leonard BE. Tryptophan and Kynurenine pathway in bipolar mania. J. Aff. Dis., 2006. (submitted)

\section{Patent}

Neurodegenerative markers for psychiatric conditions, Patent application at: Fa. Diamed Eurogen, Belgium, Inventors: Myint AM, Schawaller M, Verkerk R, Schwarz MJ, Hampel H, Müller N. October 12, 2006: Patent publication No: WO2006105907. 